\title{
STEFAN WEISS
}

\section{ONKEL UND NEFFE}

\section{Die Beziehungen zwischen Deutschland und Frankreich unter Kaiser Karl IV. und König Karl V. und der Ausbruch des Großen Abendländischen Schismas. Eine Studie über mittelalterliche Außenpolitik}

\author{
1. Teil: Vom Reichstag zu Metz \\ bis zum Ausbruch des Großen Schismas
}

\section{Einleitung}

$\mathrm{Zu}$ den umstrittenen Seiten Kaiser Karls IV. zählt seine Politik gegenüber Frankreich, insbesondere soweit das alte Königreich Burgund, das Arelat, betroffen war $^{2}$. Einerseits hat Karl IV. durch seine Krönung in Arles 1365 die kaiserliche Oberherrschaft über jenes Teilreich noch einmal eindrucksvoll unterstrichen. Andererseits hat er, indem er diverse Herrschaftsrechte sowohl des französischen Königs als auch solche von dessen Verwandten nicht nur tole-

\footnotetext{
${ }^{1}$ Wertvolle Anregungen verdanke ich den Teilnehmern eines an der Universităt des Saarlandes (Saarbrücken) abgehaltenen Hauptseminars, den stud. phil. Klaus Becker, Oliver Emanuel, Thomas Maldener und Patrick Trautmann. Für weitere Hinweise und fördernde Kritik danke ich Armand Jamme, Philippe Genequand, Georg Kreuzer, Michael Lindner, Sarah Noethlichs, Werner Paravicini, Karsten Plöger, Heinz Thomas und Andreas Willershausen. Der zweite Teil dieser Studie wird unter dem Titel »Prag - Paris - Rom: Der Ausbruch des Großen Abendländischen Schismas im Kontext der deutsch-französisch-päpstlichen Politik«, in: Hans-Joachim SCHMIDT, Gisela DROSSBACH (Hg.), Vom Zentrum zum Netzwerk. Raumüberwindung in der hoch- und spätmittelalterlichen Kirche, erscheinen.

${ }^{2}$ „Ganz besonderes Rätselraten hat die Politik des Kaisers in dem zum Römischen Reich gehörenden Arelat ausgelöst«, so faßt Heinz Thomas, dem wir eingehende Studien über das Thema verdanken, den Forschungsstand zusammen. Heinz THOMAS, Frankreich, Karl IV. und das Große Schisma, in: Peter MORAw (Hg.), »Bündnissysteme« und »Außenpolitik» im späteren Mittelalter, Berlin 1988 (Zeitschrift für Historische Forschung, Beiheft 5), S. 69104, hier S. 84. Ganz ähnlich äußern sich Ferdinand SEIBT, Karl IV. Ein Kaiser in Europa, München 1978, S. $351 \mathrm{ff.,} \mathrm{und} \mathrm{jüngst} \mathrm{Martin} \mathrm{KINTZINGER,} \mathrm{Kaiser} \mathrm{und} \mathrm{König.} \mathrm{Das} \mathrm{römisch-}$ deutsche Reich und Frankreich im Spätmittelalter, in: Dieter BERG, DERS., Pierre MONNET (Hg.), Auswärtige Politik und internationale Beziehungen im Mittelalter (13. bis 16. Jahrhundert), Bochum 2002 (Europa in der Geschichte, 6), S. 113-136, hier S. 128.
} 
riert, sondern sogar ausgeweitet hat, die französische Ausdehnung auf das rechte Rhôneufer aktiv gefördert. Ihren Höhepunkt erreichte diese Begünstigung Frankreichs, als Karl IV. am 7. Januar 1378 - kurz vor seinem Tod dem französischen Kronprinzen Karl (VI.) auf Lebenszeit das Recht seiner des Kaisers - Stellvertretung im gesamten Arelat verlieh.

Bei der Untersuchung dieses Problems will ich nicht allein seit langem bekannte Quellen und Ereignisse neu deuten, sondern auch einige grundsätzliche Probleme der politischen Geschichte des Mittelalters erörtern. Zunächst einige Worte zu den Quellen. Generell ist die Quellenlage für unser Thema nicht schlecht: Aus erzählenden Quellen, aus Urkunden und Briefen und nicht zuletzt auch aus Rechnungsbüchern läßt sich eine Vielzahl von relevanten Informationen zusammentragen. Gleichwohl handelt es sich dabei um eine sehr fragmentarische, zufällige Überlieferung, von durchgehenden Aktenreihen wie in der Neuzeit kann hier noch keine Rede sein. Vor allem fehlt es - gerade in bezug auf die Außenpolitik - an Quellen, welche uns über die Intentionen der handelnden Fürsten und Monarchen informieren würden. Das gilt in doppelter Hinsicht: Nicht genug damit, daß es an Quellen für die geheimen, lediglich in vertrauten Beraterkreisen geäußerten Absichten fehlt, wir wissen fast ebensowenig über die offiziellen, nach außen hin vertretenen und propagierten Ziele - beide müssen ja keineswegs identisch gewesen sein.

Eine Geschichtsschreibung, die sich nicht mit einer rein annalistischen Aneinanderreihung von Daten und Ereignissen zufrieden geben will, benötigt in einem solchen Fall ein übergreifendes Muster, ein Paradigma, in das sich die ermittelten Fakten einigermaßen widerspruchsfrei einfügen lassen. Für das französisch-deutsche Verhältnis im Mittelalter steht denn auch ein solches $\mathrm{Pa}$ radigma zur Verfügung; es weist bereits ein ehrwürdiges Alter auf: Ich meine das Paradigma vom französisch-deutschen Gegensatz bzw. von den französischen Ausdehnungsbestrebungen nach Osten und den entsprechenden deutschen Abwehrbestrebungen ${ }^{3}$.

Ich bin auf den Vorwurf gefaßt, daß ich hier offene Türen einrenne, daß dieses - früher zweifellos nachweisbare - Erklärungsmodell mittlerweile doch gründlich diskreditiert und außer Gebrauch gekommen $\operatorname{sei}^{4}$. Indes, eine nähere Beschäftigung mit dem hier gewählten Thema hat mich - zu meiner eigenen Überraschung - das Gegenteil gelehrt; im folgenden wird Gelegenheit sein, dies auch am konkreten Detail aufzuzeigen.

${ }^{3}$ Auf französischer Seite entsprach dem spiegelbildlich das Paradigma von der Wiedervereinigung (réunion) der östlichen Landesteile mit Zentralfrankreich. Dieses Erklärungsmodell ist jedoch mittlerweile völlig verschwunden, nicht, weil es grundsätzlich widerlegt oder durch ein besseres ersetzt worden wäre, sondern vielmehr deshalb, weil generell die politische Geschichte in Frankreich stark ins Hintertreffen geraten ist.

${ }^{4}$ Ansätze für eine historiographiegeschichtliche Aufarbeitung finden sich bei Carlrichard BRÜHL, Deutschland - Frankreich. Die Geburt zweier Völker, Köln 1990, S. 342ff. 
Zudem sind die Nachwirkungen dieses Paradigmas nicht allein bei der Interpretation der französisch-deutschen Beziehungen feststellbar, sondern auch in bezug auf die Kirchengeschichte und den Ausbruch des Großen Schismas. Bis in die Gegenwart hinein kann man in einschlägigen Darstellungen lesen, das Avignoneser Papsttum sei von Frankreich abhängig gewesen, eine Behauptung, deren Richtigkeit anscheinend so offensichtlich ist, daß bis heute niemand versucht hat, sie einmal aus den Quellen nachzuweisen ${ }^{6}$. Für den Ausbruch des Großen Schismas schließlich wird ebenfalls bis heute König Karl V. von Frankreich verantwortlich gemacht; er habe nicht ertragen können, daß die Päpste sich aus der Abhängigkeit von Frankreich hätten lösen wollen. Dabei handelt es sich nicht etwa um eine gut belegte Tatsache, sondern bestenfalls um eine fragwürdige Hypothese ${ }^{7}$.

${ }^{5}$ Ohne Anspruch auf Vollständigkeit seien genannt: Herbert GRUNDMANN, Frühneuzeit und Mittelalter, Stuttgart ${ }^{9} 1970$ (Gebhardt. Handbuch der deutschen Geschichte, 1), S. 502; Joachim LEUSCHNER, Deutschland im späten Mittelalter, Göttingen 1975 (Deutsche Geschichte, 3), S. 134f.; Howard KAMINSKY, Simon de Cramaud and the Great Schism, New Brunswick 1983, S. $17 \mathrm{ff}$; ähnlich Kaminky in seiner Überblicksdarstellung: DERS., The Great Schism, in: The New Cambridge Medieval History, Bd. 6, Cambridge 2000, S. 674-696; Dieter BERG, Deutschland und seine Nachbarn 1200-1500, München 1997 (Enzyklopädie Deutscher Geschichte, 40), S. 14; Horst FuhrmanN, Die Päpste. Von Petrus zu Johannes Paul II., München 1998, S. 150. Partielle Kritik an dieser Lehrmeinung übt Franz J. FELTEN, Johann der Blinde und das Papsttum, in: Michael PAULY (Hg.), Johann der Blinde. Graf von Luxemburg, König von Böhmen 1296-1346, Luxemburg 1997 (Publications de la section historique de l'Institut grand-ducal de Luxembourg, 115), S. 383-417, hier S. 392ff. Es wirrde sich lohnen, diese Problematik einmal historiographiegeschichtlich aufzuarbeiten. Der gleiche Johannes Haller etwa, der in seinem bahnbrechenden Werk: Johannes HALLER, Papsttum und Kirchenreform, Bd. 1 (mehr nicht erschienen) Berlin 1903 (ND Berlin 1966), S. 24f., die Abhängigkeit von Frankreich noch als eine veraltete, längst überholte These behandelt hatte, hat knapp vier Jahrzehnte später exakt in das gleiche Horn gestoßen, vgl. Anm 6. Über Hallers Verhältnis zu Frankreich vgl. auch Heribert MÜLLER, Der bewunderte Erbfeind. Johannes Haller, Frankreich und das französische Mittelalter, in: Historische Zeitschrift 252 (1991), S. 265-317.

${ }^{6}$ Am ehesten findet man einen solchen Versuch in zwei Büchern, die wohl nicht ganz zufällig in den Jahren 1943 und 1944 publiziert worden sind: Friedrich Bock, Reichsidee und Nationalstaaten. Vom Untergang des Alten Reiches bis zur Kündigung des deutsch-englischen Bündnisses im Jahre 1341, München 1943; Johannes HALLER, Das Papsttum, Bd. 3,1, Berlin 1945 = DeRS., Das Papsttum, hg. von Heinrich DanNEnBauer, Bde. 4 und 5, Basel ${ }^{2} 1953$. Hallers Darstellung bricht jedoch mit der Wahl Johannes' XXII. unvollendet ab. Bei Bock ist sehr deutlich, daß er das, was er nachweisen will, immer schon als selbstverständlich voraussetzt. Ähnliche Tendenzen gewahrt man auch in der zeitgenössischen italienischen Forschung. Vgl. etwa Eugenio DUPRÉ-THEISEIDER, I Papi di Avignone et la questione romana, Florenz 1939.

7 Auch in neueren Überblicksdarstellungen ist dieses Paradigma durchaus noch lebendig. Vgl. etwa Jörg K. HOENSCH, Die Luxemburger. Eine spätmittelalterliche Dynastie gesamteuropäischer Bedeutung 1308-1437, Stuttgart 2000, S. 173: "Seine [Urbans VI.] vom französischen König Karl V. ermutigten Gegner im Kardinalskollegium erklärten fast gleichzeitig die Wahl Urbans für ungültig«; dagegen bereits Karl A. FINK, Das große Schisma bis 
Daß dieses Erklärungsmodell bis heute nachwirkt, dürfte zwei Gründe haben. Zunächst sind die grundlegenden Studien, welche die Quellen erschließen und die somit aus gutem Grund immer noch herangezogen werden, im späten 19. und frühen 20. Jahrhundert entstanden ${ }^{8}$, in einem Zeitraum also, in dem aus naheliegenden Gründen besagtes Paradigma besonders aktuell war. Da man nach wie vor auf diese Arbeiten zurückgreifen muß, ist die Gefahr groß, nicht nur die dort angehäuften Informationen, sondern auch die dort vorgenommenen Interpretationen zu übernehmen, zumal beides im Einzelfall gar nicht leicht $\mathrm{zu}$ trennen ist.

Nach dem Zweiten Weltkrieg aber war eine Geschichtsschreibung, die sich der mittelalterlichen Außenpolitik widmet, lange Zeit in Mißkredit geraten'; neue Studien müssen daher notgedrungen an einen Forschungsstand anknüpfen, der sich über mehrere Jahrzehnte hinweg nur wenig verändert hat ${ }^{10}$. Der schlechte Ruf einer speziell der Außenpolitik gewidmeten Historiographie hat freilich gute Gründe gehabt. Nicht nur diente sie oftmals zur Rechtfertigung einer knuden Machtpolitik, man hat auch in Frage gestellt, ob sie überhaupt den mittelalterlichen Realitäten gerecht werden kann. "Außenpolitik« ist ein

zum Konzil von Pisa, in: Hubert JEDIN (Hg.), Handbuch der Kirchengeschichte, Bd. 3,2, Freiburg i.Br. 1968, S. 490-516, hier S. 496.

${ }^{8}$ Der beste Führer durch die deutschen Quellen ist immer noch Johann Friedrich BöHMER (Hg.), Regesta imperii, Bd. VIII: Die Regesten des Kaiserreichs unter Kaiser Karl IV. 1346-1378, hg. und ergänzt von Alfons HUBER, Innsbruck 1877 (ND 1968), und Ergänzungsheft Innsbruck 1889 (im folgenden: B-H mit Angabe der Nummer); im Internet unter www.regesta-imperii.de. Nachträge verzeichnet Winfried DOTZAUER, Quellenkunde zur deutschen Geschichte im Spätmittelalter (1350-1500), Darmstadt 1996, S. 78ff. Viel Material enthalten bis zum Jahre 1357 die Bände der MGH Constitutiones et acta publica imperatorum et regum, hg. von Karl ZEUMER u.a., Bde. VIII-XI, Hannover u.a. 1910-1992 (im folgenden: Const.). Die ausführlichste Biographie über Karl IV., die in der Fülle der verarbeiteten Quellen unübertroffen ist, stammt von Emil WERUNSKY, Geschichte Kaiser Karls IV. und seiner Zeit, 3 Bde., Innsbruck 1880-1892. Sie ist unvollendet geblieben und reicht nur bis 1368. Für die französischen Quellen und zur politischen Geschichte Frankreichs jener Zeit ist nach wie vor grundlegend Roland DELACHENAL, Histoire de Charles V, 5 Bde., Paris 1909-1931.

${ }^{9}$ Das gilt für Frankreich noch mehr als für Deutschland. Vgl. etwa Bruno GaLlaND, Les papes d'Avignon et la maison de Savoie (1309-1409), Paris 1998 (Collection de l'École française de Rome, 247), S. 11f., der sich förmlich rechtfertigt, ein derartiges Thema gewählt zu haben.

${ }^{10}$ In letzter Zeit scheint sich die Renaissance einer speziell der Außenpolitik gewidmeten Geschichtsschreibung anzubahnen. Vgl. die Sammelbände von BERG, KINTZINGER, MONNET (Hg.), Auswärtige Politik (wie Anm. 2), und Joachim EHLERs (Hg.), Deutschland und der Westen Europas im Mittelalter, Stuttgart 2002 (Vorträge und Forschungen, 56); Forschungsüberblick von Dieter BERG, in: EHLERS (Hg.), Deutschland, S. 47ff.; DERS., Einleitung, in: DERS., KINTZINGER, MONNET (Hg.), Auswärtige Politik (wie Anm. 2), S. 11-14. Vgl. auch Arnd REITEMEIER, Außenpolitik im Spätmittelalter. Die diplomatischen Beziehungen zwischen dem Reich und England 1377-1422, Paderborn 1999 (Veröffentlichungen des Deutschen Historischen Instituts London, 45), S. $15 \mathrm{ff}$. 
neuzeitliches Konzept; es setzt die Existenz souveräner Staaten voraus; die mittelalterlichen Reiche kann man bekanntlich nur mit großen Einschränkungen als solche bezeichnen. Offenbar liegt der Hauptunterschied zwischen mittelalterlicher und neuzeitlicher Außenpolitik darin, daß jenes Gewaltmonopol im Inneren, welches den neuzeitlichen Staat charakterisiert, im Mittelalter noch nicht bestanden hat, weshalb die diversen Monarchen mit den mächtigsten ihrer Untertanen nicht in herrschaftlicher Weise, sondern auf dem Wege der Diplomatie verkehren mußten. Es bestand somit kein grundsätzlicher, sondern lediglich ein gradueller Unterschied in der Art und Weise, wie beispielsweise Kaiser Karl IV. mit König Karl V. - einem auswärtigen Herrscher - und mit Herzog Albrecht III. von Österreich - einem Reichsfürsten - verkehrte. Noch komplizierter wird der Sachverhalt speziell für die deutsche Geschichte durch die eigenartige Verschränkung von Kaiser- und Königtum. Das Kaiserreich bestand bekanntlich aus den drei Königreichen Deutschland, (Nord-)Italien und Burgund. Soll man die Italienpolitik der deutschen Könige und Kaiser nun unter Innen- oder Außenpolitik subsumieren? ${ }^{11}$

Man hat aus dem skizzierten Sachverhalt geschlossen, es habe im Mittelalter keine Außenpolitik gegeben ${ }^{12}$. Das ist jedoch fragwürdig. Zunächst einmal ist zu bedenken, daß das genannte Begriffspaar "Außenpolitik « und "Innenpolitik « eine rein begriffliche Entgegensetzung ist ${ }^{13}$ und keineswegs eine Beschreibung (früh)neuzeitlicher Realität. Noch das bismarcksche Kaiserreich etwa ist teilweise mit außenpolitischen Methoden regiert worden ${ }^{14}$. Man wird gut daran tun, Außen- und Innenpolitik nicht als Gegensatz, sondern vielmehr als zwei Pole anzusehen, zwischen denen sich Politik generell bewegt.

Versucht man, die mittelalterliche Politik zwischen diesen Polen zu verorten, bemerkt man, daß - ganz im Gegensatz zu der referierten Ansicht - das Feld der Außenpolitik im Mittelalter weit größer als heute war, gerade weil nicht nur die außerstaatlichen, sondern auch die innerstaatlichen Beziehungen mit außenpolitischen Methoden aufrechterhalten werden mußten. Eher könnte man die Existenz von mittelalterlicher Innenpolitik bestreiten.

${ }^{11}$ Ähnliche Probleme bietet die französische Geschichte. Vgl. Françoise AUTRAND, Jean de Berry. L'art et le pouvoir, Paris 2000, S. $393 \mathrm{ff}$.

${ }^{12}$ Dazu kritisch bereits THOMAS, Frankreich (wie Anm. 2), S. 69f. Für Frankreich vgl. etwa Françoise AUTRAND, Y a-t-il des »affaires étrangères « dans la France des $\mathrm{XIV}^{*}$ et $\mathrm{XV}^{*}$ siècles?, in: Berg, KINTZINGer, MonNet (Hg.), Auswärtige Politik (wie Anm. 2), S. 23-29.

${ }_{13}$ Ähnlich äußert sich Wolfgang GEORGI, intra und extra. Überlegungen zu den Grundlagen auswärtiger Beziehungen im früheren Mittelalter: Wahrnehmung, Kommunikation und Handeln, in: BERG, KINTzINGER, MONNET (Hg.), Auswärtige Politik (wie Anm. 2), S. 47-86, hier S. 48f.: "Desgleichen erweist sich die Vorstellung von gleichberechtigten Staaten nur als theoretisches Konstruktu.

${ }^{14}$ Dies zeigt John RÖHL, Kaiser, Hof und Staat. Wilhelm II. und die deutsche Politik, München 1987 , S. $122 \mathrm{ff}$. 
Indes will ich mich nicht in Paradoxien verlieren. Vielmehr sollen diese Ausführungen lediglich dazu dienen, auf die grundsätzliche Andersartigkeit mittelalterlicher Außenpolitik aufmerksam zu machen. Diese besteht vor allem darin - womit ich ein Ergebnis der folgenden Untersuchung vorwegnehme -, daß es sich im wesentlichen um dynastische Politik handelte. Der eigenartige Sachverhalt, da $\beta$ ein bestimmter Mensch von Geburt an einen legitimen, allgemein anerkannten Anspruch darauf hatte, als Herrscher in einem bestimmten Staatswesen zu amtieren, ist uns heute schwer verständlich, es handelte sich aber - mindestens bis zur Französischen Revolution, im Grunde aber bis zum Jahre 1918 - um das in Europa absolut vorherrschende politische System. Im späten Mittelalter speiste sich dynastische Politik zunächst aus der prinzipiellen Vererbbarkeit von Herrschaftsansprüchen; sie gingen in der Regel vom Vater auf den ältesten Sohn über. Sie speisten sich aber ebenfalls aus der Akkumulierbarkeit von Herrschaftsansprüchen, d.h. im Idealfall war es möglich, dem eigenen Staatswesen durch geschickte Heiratspolitik noch weitere hinzuzufügen. Ein solcher Fall trat dann ein, wenn die übliche Abfolge vom Vater auf den Sohn nicht möglich war, sei es, daß ein solcher nicht vorhanden war, sei es, daß er nicht aus einer legitimen Ehe stammte. In solchen Fällen konnten auch Töchter oder andere Verwandte nachfolgen. Gelang es einem Herrscher, den eigenen, vorzugsweise den ältesten Sohn mit einer solchen Erbtochter zu verheiraten, so konnte - wohlgemerkt im Idealfall - dieser dem eigenen ein zweites Staatswesen in Personalunion hinzufügen. Freilich waren solche Ansprüche in der Regel alles andere als eindeutig, auch gab es häufig konkurrierende Ansprüche und diese führten nicht selten zu blutigen Kriegen.

Wir wissen seit langem, daß derartige Eheschließungen langfristig geplant wurden: kaum geboren, wurden Königs- und Fürstenkinder von ihren Eltern anderen versprochen. Was sich jedoch nicht planen ließ, waren Todesfälle und Geburten, beide konnten geknüpfte Verbindungen jäh entwerten oder abreißen lassen, mit der Folge, daß die besagten Königs- und Fürstenkinder im Verlauf ihrer Kindheit und Jugend nicht selten mehrmals ver- und wieder entlobt wurden, bis sie endlich alt genug waren, eine gültige Ehe zu schließen ${ }^{15}$. Soviel zur Skizzierung der Rahmenbedingungen; verfolgen wir nun den Ablauf der Ereignisse.

${ }^{15} \mathrm{Zu}$ den kirchenrechtlichen Fragen vgl. Dieter VELDTRUP, Zwischen Eherecht und Familienpolitik. Studien zu den dynastischen Heiratsprojekten Karls IV., Warendorf 1988 (Studien zu den Luxemburgern und ihrer Zeit, 2), S. 76ff.; Ders., Ehen aus Staatsraison. Die Familien- und Heiratspolitik Johanns von Böhmen, in: PAULY ( $\mathrm{Hg}$.), Johann der Blinde (wie Anm. 5), S. 483-543, hier S. 486ff.; allgemein auch Karl-Heinz SPIESS, Familie und Verwandtschaft im deutschen Hochadel des Spätmittelalters. 13. bis Anfang des 16. Jahrhunderts, Stuttgart 1993 (Vierteljahrschrift für Sozial- und Wirtschaftsgeschichte, Beiheft 111), bes. S. $113 \mathrm{ff}$. 


\section{Luxemburg und Valois - zwei Dynastien}

Karl IV. ${ }^{16}$ war wohl derjenige deutsche König des Mittelalters, der die engsten Bindungen an Frankreich hatte. Im Gefolge seines Vaters, Johanns des Blinden, des Königs von Böhmen (1296-1346), hatte Karl den größten Teil seiner Jugend in Frankreich, und zwar meist am königlichen Hof, verbracht. Selbst seinen Namen verdankte der ursprünglich Wenzel getaufte Karl seinem Onkel, dem französischen König Karl IV., dem Schönen (1322-1328). Seine Schwester Bonne (Guta) war die Gattin des französischen Königs Johann II. (13501364), womit Karl zu dessen Schwager und zum Onkel von dessen Nachfolger Karl V. ${ }^{17}(1364-1380)$ wurde. Schließlich war Karls erste Gattin, Blanche von Valois, eine Schwester König Philipps VI. von Frankreich $(1328-1350)^{18}$. Seit der späten Karolingerzeit waren die verwandtschaftlichen Beziehungen zwischen der östlichen und westlichen Herrscherdynastie nicht mehr so eng gewesen.

Nun können verwandtschaftliche Beziehungen sicher dazu beitragen, ein vertrauensvolles Zusammenwirken zweier Herrscherhäuser zu sichern, sie müssen es jedoch nicht. In der Forschung herrscht denn auch die Meinung vor, das deutsch-französische Verhältnis in dieser Zeit sei ganz im Gegenteil von gegenseitigem Mißtrauen und immer neuen Spannungen geprägt gewesen ${ }^{19}$.

Hier ist freilich zu differenzieren. Man hat schon länger gesehen, daß sich Karls IV. Verhältnis zu den französischen Monarchen und Verwandten durchaus nicht einheitlich gestaltet hat. Am schlechtesten - darüber ist man sich

${ }^{16}$ Neuere Biographien bieten SEIBT, Karl IV. (wie Anm. 2); Jiri SPEVÁCEK, Karl IV. Sein Leben und seine staatsmännische Leistung, Wien 1978; Heinz STOOB, Kaiser Karl IV. und seine Zeit, Graz, Wien, Köln 1990 (leider ohne Anmerkungen). Den neuesten Überblick gibt Martin KINTZINGER, Karl IV. (1346-1378), in: Bernd SCHNEIDMÜlLER, Stefan WEINFURTER (Hg.), Die deutschen Herrscher des Mittelalters, München 2003, S. 408-432, 593f. Eine neue Biographie bereitet Heinz Thomas vor.

${ }^{17}$ Über Karl V. ist grundlegend DELACHENAL, Histoire (wie Anm. 8), Bd. 1-5; eine neue Biographie: Françoise AUTRAND, Charles V: le Sage, Paris 1994; einen kurzen Überblick gibt Heinz THOMAS, Karl V. 1364-1380, in: Joachim EHLERS, Heribert MÜLLER, Bernd SCHNEIDMÜLLER (Hg.), Die französischen Könige des Mittelalters, München 1996, S. 285 $302,404$.

${ }^{18}$ Vgl. vor allem DERS., Die Beziehungen Karls IV. zu Frankreich von der Rhenser Wahl im Jahre 1346 bis zum großen Metzer Hoftag, in: Blätter für Deutsche Landesgeschichte 113 $(1978)=$ Hans PATZE (Hg.), Kaiser Karl IV. 1316-1378. Forschungen über Kaiser und Reich, Neustadt a.d. Aisch 1978, S. 165-201, hier S. 165f., 196ff.; einen kurzen Überblick gibt DERS., Deutsche Geschichte des Spätmittelalters 1250-1500, Stuttgart 1983, S. $283 \mathrm{ff}$. Über die persönlichen Beziehungen Karls IV. zu Karl V. vgl. Raymond CAZELLES, La société politique, noblesse et couronne sous Jean le Bon et Charles V, Genf, Paris 1982 (Mémoires et documents, 28), S. 556f;; AUTRAND, Charles V (wie Anm. 17), S. 14ff., $23 \mathrm{ff}$.

${ }^{19} \mathrm{Vgl}$. THOMAS, Frankreich (wie Anm. 2), S. $82 \mathrm{ff}$. 
einig - stand er mit Philipp VI. ${ }^{20}:$ Nur gegen dessen Widerstand war es ihm gelungen, die römisch-deutsche Königswürde zu erringen. Nicht frei von Konflikten war sein Verhältnis zu dessen Nachfolger und seinem Schwager Johann II. Hier scheinen auch persönliche Gründe eine Rolle gespielt zu haben, denn die Ehe von Johanns Gemahlin - Karls Schwester - war keineswegs glücklich ${ }^{21}$. Dieser nur mühsam verdeckte Konflikt zwischen den Eheleuten hatte auch Auswirkungen auf die nächste Generation. Zwischen König Johann II. und dem Kronprinzen, dem jungen Karl (V.), brachen zeitweise schwere Gegensätze auf, während sich zwischen dem Kronprinzen und seinem Onkel ein enges Vertrauensverhältnis herausbildete. Bekannt ist, daß Karl V. ernsthaft geplant hat, an den Hof Karls IV. zu fliehen ${ }^{22}$.

Mit diesen eher persönlichen Beziehungen verschränkten sich die politischen. Betrachtet man die beiden herrschenden Dynastien - die Valois und die Luxemburger - , ist das politische Gewicht beider erheblichen Schwankungen unterworfen. Konnte Frankreich zunächst als mächtigstes Staatswesen, sein König als bedeutendster Fürst Europas gelten, änderte sich das mit der katastrophalen Niederlage bei Poitiers (1356) und der Gefangennahme König Johanns II. grundlegend. Der Tiefpunkt war hier der Frieden von Brétigny (1361), in dem die Valois das südwestliche Viertel Frankreichs an den englischen Gegner abtreten mußten. Als Johann II. 1364 verstarb, hinterließ er seinem Sohn ein verarmtes, verwüstetes und zerrissenes Staatswesen. Ganz anders sah die Bilanz im östlichen Nachbarland aus. War Karl IV. zunächst gleichsam der »arme Verwandte« gewesen, der froh sein mußte, wenn er am französischen Hof Aufnahme fand, gelang es ihm nicht nur, durch geschickte Politik die Königs- und dann die Kaiserkrone zu erlangen, sondern auch seine Herrschaft auf eine feste Basis im Osten des Reiches zu stellen. Seit langem hatte kein deutscher König eine solche Machtstellung innegehabt. Damit hatten sich binnen weniger Jahre die Gewichte zwischen beiden Herrscherhäusern erheblich verschoben.

${ }^{20}$ Hierfür ist seine Autobiographie aufschlußreich: Vita Caroli quarti. Die Autobiographie Karls IV., hg. von Eugen HilleNBRAND, Stuttgart 1979, S. 85; neue Ausgabe: Vita ab eo ipso conscripta, et Hystoria nova de Sancto Wenceslao Martyre. Autobiography of Emperor Charles IV and his Legend of St Wenceslas, hg. von Balázs NAGY, Frank SCHAER, Budapest 2001 (Central European Medieval Texts) (freundlicher Hinweis von Karsten Plöger); vgl. vor allem THOMAS, Beziehungen (wie Anm. 18), S. $166 \mathrm{ff}$.

${ }^{21} \mathrm{Vgl}$. Autrand, Charles V (wie Anm. 17), S. 16.

${ }^{22}$ Vgl. Delachenal, Histoire (wie Anm. 8), Bd. 1, S. 116ff.; AUTRAnd, Charles V (wie Anm. 17), S. 164ff. Ähnlich konfliktreich war auch das Verhältnis zwischen Johann dem Blinden und Karl IV. Vgl. Vita Caroli quarti (wie Anm. 20), cap. VIII, S. 120ff.; SEIBT, Karl IV. (wie Anm. 2), S. 115 ff.; Heinz THOMAS, Vater und Sohn - König Johann und Karl IV., in: PAULY (Hg.), Johann der Blinde (wie Anm. 5), S. 445-482. 
Als Karl (V.) im Jahre 1356 zunächst als Regent für seinen gefangenen Vater die Regierung übernahm ${ }^{23}$, war sein größtes Problem der Krieg mit England; hierfür suchte er auf dem im selben Jahr stattfindenden Hoftag zu Metz die Unterstützung seines Onkels zu erlangen. Diese Hoffnung hat Karl IV. jedoch nur teilweise erfüllt. Zwar hat er während des Hoftages das bereits mit Johann II. vorbereitete Bündnis zwischen Frankreich und dem Imperium ${ }^{24}$ mit Karl V. abgeschlossen, und er hat auch - vielleicht als Beitrag zum Lösegeld für den in England gefangenen Johann II. - Karl V. 50000 Gulden geliehen ${ }^{25}$. Indes hat sich der römisch-deutsche König trotz dieses Bündnisses nicht zu einem aktiven Vorgehen gegen England bewegen lassen; mehr als eine freundschaftliche Neutralität wollte er seinem Neffen nicht zubilligen. Hierfür gab es gute Gründe: Abgesehen davon, daß schwer nachzuvollziehen wäre, daß Karl IV. sich ohne Notwendigkeit an einem Krieg beteiligt hätte, hatte er genug eigene Probleme. Nicht nur gab es immer wieder neue Schwierigkeiten mit den deutschen Fürsten, deren divergierende Interessen auch die geschickte Diplomatie des Kaisers nicht immer ausgleichen konnte, sondern er verfolgte auch eigene außenpolitische Interessen. Das zentrale Thema war hier - abgesehen von der immer aktuellen Italienpolitik und der Kaiserkrönung - das Verhältnis zu den osteuropäischen Reichen, wo Karl IV. seiner Dynastie neue Länder zu erwerben hoffte.

Immerhin sollte man nicht übersehen, daß selbst diese Neutralität von hohem Wert für Frankreich war, zumal wenn man bedenkt, daß unter Ludwig dem Bayern der englische König Eduard III. (1327-1377) in seiner Eigen-

${ }^{23}$ Seine Krönung erfolgte 1364; bei ihr war anwesend - wie die offizösen »Grandes Chroniques« beifällig bemerken - der frere de l'Empereur et oncle du dit roy de France, nämlich Graf Wenzel von Luxemburg, der Halbbruder Karls IV. Les Grandes Chroniques de France. Chronique des règnes de Jean II et Charles V (1350-1380), hg. von Roland DELACHENAL, 4 Bde., Paris 1910-1920, Bd. 2, S. 3.

${ }^{24}$ Vgl. B-H 2233, ed. in: Const. XI, S. 295, n. 518 von 1355 Aug. 26; B-H Reichssachen 234 irrig zu 1355 Mai = Const. XI, S. 425, n. 755 von 1356 Mai (nur Reg.). Vgl. B-H Reichssachen $240=$ Const. XI, S. 380 , n. 675 zu (1355 Okt.-Nov.), aus dem hervorgeht, daß Johann II. den Vertrag nicht ratifiziert hat. Vgl. Fritz TRAUTz, Die Könige von England und das Reich 1272-1377, Heidelberg 1961, S. 368ff. Zur Rolle Karls V. auf dem Metzer Hoftag vgl. Delachenal, Histoire (wie Anm. 8), Bd. 1, S. 268ff.; Heinrich Neureither, Das Bild Kaiser Karls IV. in der zeitgenössischen französischen Geschichtsschreibung, Diss. Heidelberg 1964, S. 102ff.; THOMAS, Beziehungen (wie Anm. 18), S. 194ff.; AuTrand, Charles V (wie Anm. 17), S. 258ff.; Marie-Luise HECKMANN, Das Reichsvikariat des Dauphins im Arelat 1378. Vier Diplome zur Westpolitik Kaiser Karls IV., in: Ellen WIDDER, Mark MERSIOWSKY, Maria-Theresia LEUKER (Hg.), Manipulus Florum. Aus Mittelalter, Landesgeschichte, Literatur und Historiographie. Festschrift für Peter Johannek zum 60. Geburtstag, Münster 2000, S. $73 \mathrm{ff}$.

${ }^{25} \mathrm{~B}-\mathrm{H}$ Reichssachen 278 (irreführend formuliert, daher wohl die Fehlinterpretation von DELACHENAL, Histoire [wie Anm. 8], Bd. 1, S. 280, mit Anm. 6), ed. in: Const. XI, S. 513, n. 910 von 1356 Dez. 28. 
schaft als Reichsvikar ${ }^{26}$ beträchtliche Truppenkontingente in Niederlothringen hatte anwerben können. Dagegen hat Karl IV. Bestrebungen seines Neffen unterstïtzt, der nun seinerseits deutsche Truppen anzuwerben versuchte ${ }^{27}$. Auch ist durch das Abkommen von Metz das von Karl IV. geschlossene Bündnis mit England ${ }^{28}$ aus dem Jahre 1348 endgültig aufgebrochen worden.

Ist somit die Frage des antienglischen Bündnisses ein Punkt gewesen, der möglicherweise zu Verstimmungen Anlaß gegeben hat $^{29}$, so gab es jedoch zumindest einen Bereich, in dem beide Dynastien zusammenwirkten, nämlich im Arelat ${ }^{30}$. Seit Konrad II. in den Jahren 1032-1034 die Vereinigung der burgundischen mit der deutschen Krone erreicht hatte, war das Arelat - ganz anders als Italien - immer ein königsfernes Gebiet gewesen. Für die kaiserliche Politik spielte lediglich der nördliche Teil eine Rolle, weil hier wichtige Alpenpässe verliefen, die für den Weg nach Italien von Bedeutung waren, der Süden dagegen blieb außerhalb des Itinerars der deutschen Könige und Kaiser. Lediglich Friedrich Barbarossa, der durch seine Ehe mit Beatrix von Burgund engere Beziehungen zu diesem Teilreich hatte, ist dorthin gezogen und hat sich in Arles krönen lassen ${ }^{31}$, aber selbst während seiner Regierungszeit spielte das Arelat hinter Deutschland und Italien doch nur eine Nebenrolle in der kaiserlichen Politik. In noch größerem Maße gilt das für Barbarossas Nachfolgern; erst Karl IV. sollte dann abermals diese Region aufsuchen und sich als zweiter und letzter der römisch-deutschen Kaiser des Mittelalters in Arles krönen lassen. Auch die Verhältnisse im Arelat sind Gegenstand der Gespräche zwischen Karl IV. und Karl V. in Metz gewesen, sie seien kurz skizziert.

${ }^{26}$ Vgl. zuletzt Marie-Luise HECKMANN, Das Reichsvikariat Eduards III. von England per Alemanniam et Galliam (1338-1341) - Eine Neuinterpretation, in: Peter THORAU, Sabine PENTH, Rüdiger FUCHS (Hg.), Regionen Europas - Europa der Regionen. Festschrift für Kurt-Ulrich Jäschke zum 65. Geburtstag, Köln 2003, S. 167-188.

${ }^{27} \mathrm{Vgl}$. DELACHENAL, Histoire (wie Anm. 8), Bd. 1, S. 281.

${ }^{28}$ B-H 701, ed. in: Const. VIII, S. 625, n. 613 von 1348 Juni 24. In der Urkunde wird ausdrücklich vorbehalten, daß Karl IV. gegen den König von Frankreich nicht Beistand leisten müsse.

${ }^{29}$ Vgl. DELACHENAL, Histoire (wie Anm. 8), Bd. 1, S. 29, $268 \mathrm{ff}$.

${ }^{30} \mathrm{Vgl}$. Paul FOURNIER, Le royaume d'Arles et de Vienne (1138-1378). Étude sur la formation territoriale de la France dans l'est et le sud-est, Paris 1891; allgemein DELACHENAL, Histoire (wie Anm. 8), Bd. 1, S. 270ff.

${ }^{31}$ Vgl. Johannes FrIED, Friedrich Barbarossas Krönung in Arles, in: Historisches Jahrbuch 103 (1983) S. 347-371 (freundlicher Hinweis von Georg Kreuzer). 
Im Norden des Arelats ist zunächst die Grafschaft Savoyen zu nennen. Hier regierte Graf Amadeus VI. (1343-1383), bekannt als der "grüne Graf « ${ }^{32}$; ihm hatte Karl IV. bereits während seines ersten Italienzuges dessen alte Privilegien bestätigt ${ }^{33}$. Einige Jahre später ging Karl IV. noch weiter. Mit einer goldbullierten Urkunde löste er im Jahre 1361 Savoyen aus dem Verband des Arelats und inkorporierte es dem Reich direkt $\mathrm{t}^{34}$. Uberhaupt ist in den folgenden Jahren der nördliche, überwiegend deutschsprachige Teil des Arelats in das Reich eingegliedert worden, ohne daß dafür die Quellen in jedem Fall erhalten $\operatorname{sind}^{35}$. Zu Karls Entschluß mag beigetragen haben, daß von Savoyen die erwähnten Alpenpässe ausgingen ${ }^{36}$, hier also ein besonderes Interesse des Reichs vorlag. Es wird sich für die Folgezeit noch als wichtig erweisen, daß seither kaiserliche Rechtsakte fur das Arelat die Grafschaft Savoyen und die sich daran nördlich anschließenden Territorien nicht mehr betrafen. Vielleicht als Gegenleistung verpflichtete sich Amadeus dem Kaiser zur Heeresfolge ${ }^{37}$.

Im Süden schloß sich an Savoyen die Dauphiné an. Letzter einheimischer "Dauphin« - so der traditionelle Herrschertitel in jenem Territorium - war Humbert II. (1333-1349) gewesen. Er hatte 1349 seine Herrschaftsrechte an den französischen Thronfolger verkauft ${ }^{38}$, neuer Dauphin wurde der Kronprinz

${ }^{32} \mathrm{Vgl}$. Eugene Cox, The Green Count of Savoy. Amadeus VI and Transalpine Savoy in the Fourteenth Century, Princeton 1967 (freundlicher Hinweis von Werner Paravicini); jetzt vor allem GALLAND, Les papes (wie Anm. 9).

${ }^{33}$ B-H 1973 zu 1355 Jan. 13 = Const. XI, S. 182, n. 333 von 1355 Jan. 9 (nur Reg.). Hier und öfters haben die »Constitutiones« die Edition von Dino Muratore übersehen: Dino $\mathrm{MU}$ RATORE, L'imperatore Carlo IV nelle terre sabaude nel 1365 e il vicariato imperiale del conte Verde, 2. Teil, in: Memorie della Reale Accademia delle Scienze di Torino. Classe di Scienze morali, storiche et filologiche, 2. Serie, 56 (1906), S. 159-215, hier S. 202, n. 4; B-H $2166=$ Const. XI, S. 252, n. 446 von 1355 Juni 18 (nur Reg.). Vgl. generell MURATORE, L'imperatore, S. $163 \mathrm{ff}$.

${ }^{34}$ B-H 3695 = 7056 von 1361 Mai 17. Vgl. zu dieser Urkunde Edmund E. STENGEL, Regnum und Imperium. Engeres und weiteres Staatsgebiet im Alten Reich (zuerst 1930), überarbeitete Fassung in: DERS., Abhandlungen und Untersuchungen zu Geschichte des Kaisergedankens im Mittelalter, Köln, Graz 1965, S. 171-205, hier S. 196ff. Vgl. allgemein auch Hedwig SANMANN-VON BŪLOW, Die Inkorporationen Karls IV. Ein Beitrag zur Geschichte des Staatseinheitsgedankens im späteren Mittelalter, Marburg 1942 (Marburger Studien zur älteren deutschen Geschichte, II. Reihe, 5), bes. S. $47 \mathrm{ff}$.

${ }^{35}$ Vgl. Rudolf HOKE, Die Freigrafschaft Burgund, Savoyen und die Reichsstadt Besançon im Verbande des mittelalterlichen deutschen Reiches, in: Zeitschrift der Savigny-Stiftung für Rechtsgeschichte. Germanistische Abteilung 79 (1962), S. 106-194, hier S. 123ff., und STENGEL, Regnum (wie Anm. 34).

${ }^{36}$ Über diese vgl. GallaND, Les papes (wie Anm. 9), S. 23 f.

${ }^{37}$ B-H Reichssachen 377 von 1362 Juni 21.

${ }^{38}$ Vgl. AUTRAND, Charles V (wie Anm. 17), S. 51ff.; Stefan WeIss, Die Versorgung des päpstlichen Hofes in Avignon mit Lebensmitteln, Berlin 2002, S. 254; zuletzt HECKMANN, 
und spätere König Karl V. ${ }^{39}$ In historischen Atlanten und Darstellungen wird nicht selten das Jahr 1349 als das des Überganges der Dauphiné an Frankreich bezeichnet. Jedoch ist Karl V. mit diesem Rechtsakt lediglich in die Rechte Humberts II. eingetreten, die Reichsrechte an diesem Territorium wurden dadurch nicht berührt ${ }^{40}$. Wir haben es hier mit einem der aus heutiger Sicht so verwirrenden Fälle geteilter Souveränität zu tun, wie sie im Mittelalter nicht selten vorkamen. Gerade für Frankreich trifft das zu, wo bekanntlich der Herzog von Aquitanien gleichzeitig König von England war. Der skizzierte Sachverhalt ist von Karl V. durchaus anerkannt worden: Auf dem erwähnten Hoftag zu Metz im Dezember 1356 hat er - damals noch Thronfolger und Regent für seinen gefangenen Vater Johann II. - für die Dauphiné Karl IV. die Lehnshuldigung geleistet und seine Herrschaftsrechte in diesem Gebiet bestätigt bekommen. Aber nicht genug damit, daß Karl IV. die Rechte seines Neffen auf die Dauphiné anerkannte ${ }^{41}$, er hat sie darüber hinaus noch erweitert, indem er Karl V. zum Reichsvikar in der Dauphiné ernannte und ihm die Appelationsgerichtsbarkeit in diesem Land einräumte ${ }^{42}$. Die höchste Instanz in Rechtsstreitigkeiten für die Dauphiné war somit nicht mehr in Prag, sondern in Paris zu finden. Kurze Zeit zuvor hatte Karl IV. in ähnlicher Weise die Appellationsgerichtsbarkeit in Savoyen dem Grafen Amadeus VI. verliehen ${ }^{43}$. Hier wird ein Muster deutlich, das wir in der Folgezeit noch öfter beobachten können: In Savoyen wie in der Dauphiné hat Karl den herrschenden Dynasten immer weitergehende Rechte eingeräumt, somit auf die Reichsrechte verzichtet. Welche Gegenleistung er dafür erwartete, wird noch genauer erörtert wer-

Reichsvikariat (wie Anm. 24), S. 67ff. Die neue Arbeit von Anne LEMONDE, Le temps des libertés en Dauphiné. L'intégration d'une principauté à la Couronne de France (1349-1408), Grenoble 2002, geht auf die hier interessierenden Fragen leider kaum ein.

${ }^{39}$ Seither hat sich der Titel »Dauphin« für den französischen Thronfolger eingebürgert.

${ }^{40} \mathrm{Daß}$ Karl IV. zu diesem Zeitpunkt noch gewillt war, die Reichsrechte in der Dauphiné zu wahren, ergibt sich aus B-H 258, ed. in: Const. VIII, S. 172, n. 105, 106. Vgl. THOMAS, Beziehungen (wie Anm. 18), S. 191.

${ }^{41}$ Vgl. B-H 2553a = Const. XI, S. 495, n. 885 von 1356 Dez. 25; B-H $6909=6375$ $=$ Const. XI, S. 497, n. 889 (nur Reg.), ed. bei Ulysse CHEVALIER (Hg.), Choix de documents historiques inédits sur le Dauphiné, Lyon 1874 (Collection des cartulaires Dauphinois, 7; Bulletin de la Société Statistique du département de l'Isère, 3. Serie, 6), S. 150, n. 51 von 1356 Dez. 26; B-H $2582=6910=$ Const. XI, S. 520, n. 923 (nur Reg.), ed. bei CHEVALIER, Choix, S. 151, n. 52 von 1357 Jan. 1. Zum Hoftag zu Metz vgl. generell THOMAS, Beziehungen (wie Anm. 18), S. 194ff.; AUTRAND, Charles V (wie Anm. 17), S. $161 \mathrm{ff}$.

${ }^{42}$ B-H $2581=6374=6911$ zu 1356 Dez. 26, ed. bei Chevalier (Hg.), Choix (wie Anm. 41), S. 153, n. 53; Const. XI, S. 518, n. 921 von 1356 Dez. 31.

${ }^{43}$ B-H 2471 = Const. XI, S. 439, n. 777 (nur Reg), ed. bei Muratore, L'imperatore (wie Anm. 33), S. 203, n. 5 von 1356 Juli 17; B-H $2481=$ Const. XI, S. 442, n. 784, ed. bei Danielle ANEX-CABANIS, Jean-François POUDRET (Hg.), Les sources du droit du canton de Vaud. Moyen Âge $\left(\mathrm{X}^{\mathrm{e}}-\mathrm{XVI}^{\mathrm{e}}\right.$ siècles), B. Droits seigneuriaux et franchises municipales, I. Lausanne et les terres épiscopales, Aarau 1977, S. 108, n. 90 von 1356 Juli 21. Vgl. auch B-H 2482 von 1356 Juli 24. 
den, hier sei lediglich angemerkt, daß dem Kaiser der Gedanke, auf diese Weise ein gewisses Gleichgewicht zwischen Savoyen und der Dauphiné aufrechtzuerhalten, wohl nicht ferngelegen hat ${ }^{44}$.

Vernachlässigen können wir die geistlichen Territorien - die Erzbistümer Aix und Arles und ihre Suffragane - wie auch die kleine Grafschaft Valentinois. Ihre Grafen waren den Dauphins für einige Gebiete lehnsabhängig; sie konnten kaum eine selbständige Position einnehmen ${ }^{45}$. Graf Aymar VI. (der Dicke) von Valence und Die hat zeitweise das Reichsvikariat im Arelat innegehabt $^{46}$, scheint aber keine größeren Aktivitäten entfaltet zu haben. Immerhin ist er auch vom Prinzen Johann, dem späteren König Johann II. - also dem Schwager Karls IV. -, fast gleichzeitig auch zum lieutenant in der Dauphiné ernannt worden ${ }^{47}$; er war somit Amtsträger sowohl des »burgundischen«, d.h. deutschen Königs, als auch des französischen Kronprinzen, ein Verhältnis, das in vieler Hinsicht auf kommende Entwicklungen vorausweist.

Ähnliche Verhältnisse wie in der Dauphiné finden wir im Süden des Arelats, in der Grafschaft Provence ${ }^{48}$. Seit Karl von Anjou, der Graf der Provence, das regnum Siciliae - also Süditalien - erobert hatte, war dessen König identisch mit dem Grafen der Provence. Während unseres Untersuchungszeitraums regierte in Neapel die Königin Johanna (1343-1382 ${ }^{49}$, die Enkelin König Roberts des Weisen. Der Schwerpunkt der neuen Dynastie lag eindeutig in Italien, die Provenzalen bekamen ihren Grafen bzw. ihre Gräfin nur selten zu sehen. Die Verwaltung des Landes hatte ihren Sitz in Aix, dort regierte im Namen des Grafen ein Seneschall, dort befand sich die Rechenkammer der Provence, welche die Abgaben einzog und die Überschüsse nach Neapel weiterleitete $^{50}$. Auch hier ist $\mathrm{zu}$ berücksichtigen, daß die Zugehörigkeit der Provence zum Arelat und damit die Oberhoheit des römischen Königs bzw. Kaisers außer Frage standen. Der König von Neapel hatte lediglich die gräflichen Rechte in diesem Territorium inne und schuldete dem Kaiser die Lehnshuldi-

${ }^{44}$ So auch HeckmanN, Reichsvikariat (wie Anm. 24), S. 80f. Schon vor dem Verkauf der Dauphiné an Frankreich hatte es häufige Konflikte zwischen Savoyen und der Dauphiné gegeben. Vgl. dazu GALLAND, Les papes (wie Anm. 9), S. 90ff.

${ }^{45}$ Vgl. ibid., S. 88, 171.

${ }^{46}$ B-H 888, ed. in: Const. IX, S. 165, n. 219 von 1349 März 16.

${ }^{47}$ HeCkMANN, Reichsvikariat (wie Anm. 24), S. 69, mit Anm. 30 von 1349 Dez. 22. Sie korrigiert hier die ältere Forschung - darunter ihre eigene: DIES., Stellvertreter, Mit- und Ersatzherrscher: Regenten, Generalstatthalter, Kurfursten und Reichsvikare in Regnum und Imperium vom 13. bis zum frühen 15. Jahrhundert, 2 Bde., Warendorf 2002 (Studien zu den Luxemburgern und ihrer Zeit, 9), Bd. 1, S. 120, Bd. 2, S. 554 -, welche den Beginn von Aymars Amtszeit als lieutenant erst zu 1354 ansetzt.

${ }^{48}$ Streng genommen handelte es sich um die drei Grafschaften Provence, Forcalquier und Piemont. Die beiden letzteren sind im folgenden immer mit inbegriffen.

${ }^{49}$ Über Johanna und das Königreich Neapel vgl. vor allem Émile G. LÉONARD, Les Angevins de Naples, Paris 1954.

${ }^{50}$ Vgl. WEISS, Versorgung (wie Anm. 38), S. 52ff. 
gung. Diese hat Johanna von Neapel 1355 Karl IV. durch ihre Gesandten auch leisten lassen ${ }^{51}$. Da Johannas Königreich Neapel ein päpstliches Lehen war, liegt hier der nicht alltägliche Fall vor, daß die gleiche Person zugleich Lehnsträger des Papstes wie des Kaisers war.

Schließlich ist unter den Territorialherren des Arelats auch das Papsttum zu nennen. Seit dem Frieden von Paris (1229) verfügte das Papsttum im Arelat über eine Exklave des Kirchenstaates, die Grafschaft Venaissin; ihr Territorium grenzte unmittelbar an das Gebiet der Stadt Avignon an. 1316 verlegte Johannes XXII. den Sitz der Kurie dauerhaft nach Avignon; er residierte somit auf dem Boden des Imperiums. Avignon selbst gehörte damals noch zur Grafschaft Provence, erst 1348 hat Papst Clemens VI. der Königin Johanna von Neapel die Stadt Avignon abgekauft und ist somit in die Rechte der Gräfin eingetreten ${ }^{52}$. Clemens VI. hat nicht gezögert, die Zustimmung des römischen Königs zu diesem Rechtsakt einzuholen; Karl IV. schenkte denn auch am ersten und zweiten November 1348 dem Papst alle kaiserlichen und königlichen Herrschafts- und Eigentumsrechte über Avignon ${ }^{53}$. Auf seine Rechte in der Grafschaft Venaissin hatte Karl bereits 1346 verzichtet $^{54}$. Ähnlich wie Savoyen waren seither also auch Avignon und das Venaissin aus dem Verband des Arelats herausgelöst, kaiserliche Rechtsakte fuir das Arelat in diesen Territorien nicht mehr gültig ${ }^{55}$.

Clemens VI. war es auch, der nicht nur den päpstlichen Palast in Avignon ausbauen, sondern auch in Villeneuve - gegenüber von Avignon am anderen Ufer der Rhône gelegen - eine weitere Residenz errichten ließ. In ihr pflegte er die Sommermonate zu verbringen; seine Nachfolger folgten überwiegend diesem Beispiel ${ }^{56}$. Da die Rhône die Grenze zwischen Frankreich und dem Imperium bildete, wechselte der Papst jedes Mal, wenn er über die berühmte

51 Vgl. B-H Reichssachen 198 = Const. XI, S. 118, n. 119 von 1354 Juni 15 (nur Reg.), und B-H Reichssachen 225, ed. in: Const. XI, S. 188, n. 351 von 1355 Febr. 1; B-H 6798, ed. in: Const. XI, S. 188, n. 351 von 1355 Febr. 1; außerdem die ergänzenden Urkunden B-H 6795$6799=$ Const. XI, S. 186, n. 344, 345. Vgl. auch B-H 6132, ed. in: Const. XI, S. 184, n. 339 von 1355 Jan. 24. Wohl als Gegenleistung hat Karl IV. der Königin 30000 Goldgulden auszahlen lassen. Vgl. B-H 2077 = Const. XI, S. 230, n. 405 (nur Reg.), ed. bei Franz ZIMMERMANN (Hg.), Acta Karoli IV Imperatoris inedita. Ein Beitrag zu den Urkunden Kaiser Karls IV., Innsbruck 1891, S. 39, n. 16 von 1355 Apr. 22. Auch die gleichzeitig erfolgte Verleihung der Reichsrechte im Arelat an Erzbischof Stephan von Arles gehört in diesen Zusammenhang. Vgl. B-H 6808, ed. in: Const. XI, S. 229, n. 404 von 1355 Apr. 22.

${ }^{52}$ Vgl. Joseph AlBANĖs, Gallia christiana novissima, Bd. 7: Avignon, Valence 1920, S. 354, n. 1306 von 1348 Juni 9, S. 355, n. 1308 von 1348 Juni 21.

${ }^{53}$ B-H $774=6542$, ed. in: Const. VIII, S. 679, n. 676 von 1348 Nov. 1; B-H 775 von 1348 Nov. 2 (vgl. aber zu dieser Urkunde Const. VIII, S. 680, Anm. 1).

${ }^{54}$ Vgl. B-H 228, ed. in: Const. VIII, S. 12, n. 9 von 1346 Apr. 22.

${ }^{55}$ Das hat den Bischof von Avignon und Bruder Urbans V., Anglicus Grimoardi, nicht daran gehindert, sich die alten, von Friedrich Barbarossa herrührenden Privilegien seiner Kirche von Karl IV. erneuern zu lassen, als dieser nach Avignon kam. Vgl. Anm. 82.

${ }^{56} \mathrm{Vgl}$. WEISs, Versorgung (wie Anm. 38), S. $120 \mathrm{ff}$. 
Brücke von Avignon zwischen seinen Residenzen hin- und herzog, auch das Staatswesen, welches ihm Gastfreundschaft bot.

Für das Verhältnis Karls IV. zum Papsttum gilt Ähnliches wie für das zu Frankreich. Kein deutscher König und Kaiser des Mittelalters unterhielt so enge Beziehungen zum Stellvertreter Petri wie Karl IV. In seiner Jugend hatte er die Predigten des Abtes von Fécamp, Pierre Roger, gehört, ihn traf der junge Markgraf von Mähren wenige Jahre (1340) später in Avignon wieder, wo Pierre Roger inzwischen zum Kardinal avanciert war ${ }^{57}$. Als Clemens VI. sollte dieser Kardinal dann den Papstthron besteigen, mit seiner Hilfe erlangte Karl IV. die Königswürde ${ }^{58}$, mit Hilfe von dessen Nachfolger Innozenz VI. die Kaiserwürde. Auch mit dessen Nachfolgern, Urban V. und Gregor XI., hat Karl IV. gute Beziehungen aufrechterhalten. Ihm ist es gelungen, den Dauerkonflikt zwischen Papst- und Kaisertum zu beenden, wenn nicht ein Mit-, so doch wenigstens ein friedliches Nebeneinander der beiden Universalgewalten herbeizuführen.

Nur bedingt zum Arelat, eher schon zum deutschen Reich, gehörte die nördlich an Savoyen sich anschließende Freigrafschaft Burgund ${ }^{59}$; ihr lag auf der anderen Seite der Saône das französische Herzogtum Burgund gegenüber. Ähnlich wie Karl V. für die Dauphiné hat auch Philipp de Rouvre, der Herzog von Burgund, auf dem Hoftag zu Metz durch seine Gesandten Karl IV. die Lehnshuldigung für die Freigrafschaft geleistet ${ }^{60}$. Auch später förderte hier Karl IV. seine französischen Verwandten. Offenbar um habsburgischen Ansprüchen auf die Freigrafschaft entgegenzuwirken, begünstigte er seinen Neffen, Philipp den Kühnen (1342-1404), den jüngsten Bruder König Karls V. ${ }^{61}$. Philipp seinerseits hatte durch Bevollmächtigte Karl IV. den Treueid und

${ }^{57}$ Vgl. B-H 81c von 1340, vor allem aber Karls Autobiographie: Vita Caroli quarti (wie Anm. 20), cap. III, S. 84, cap. XIV, S. $172 \mathrm{ff}$.

${ }^{58} \mathrm{Vgl}$. zuletzt Heinz ThOMAS, Clemens VI. und Ludwig der Bayer, in: Hermann NEHLSEN, Hans-Georg HERMANN (Hg.), Kaiser Ludwig der Bayer. Konflikte, Weichenstellungen und Wahrnehmung seiner Herrschaft, Paderborn 2002 (Quellen und Forschungen aus dem Gebiet der Geschichte. Neue Folge, 22), S. 75-117.

${ }^{59}$ Ähnlich wie die deutschsprachigen Teile des Arelats hatte auch die Freigrafschaft seit dem 12. Jahrhundert begonnen, sich aus dem Arelat zu lösen; sie wurde im 13. und 14. Jahrhundert allmählich in das deutsche Reich eingefügt. Vgl. HOKE, Freigrafschaft (wie Anm. 35), bes. $123 \mathrm{ff}$; veraltet, aber in den Einzelheiten immer noch wertvoll ist STENGEL, Regnum (wie Anm. 34), S. $171 \mathrm{ff}$.

${ }^{60}$ Vgl. B-H Reichssachen 234 = Const. XI, S. 425, n. 755 von 1356 Mai. Vgl. Jean SCHOOS, Der Machtkampf zwischen Burgund und Orléans unter den Herzögen Philipp dem Kühnen, Johann ohne Furcht von Burgund und Ludwig von Orléans. Mit besonderer Berücksichtigung der Auseinandersetzung im deutsch-französischen Grenzraum, Luxemburg 1956 (Publications de la section historique de l'Institut grand-ducal de Luxembourg, 75), S. 24ff. THOMAS, Beziehungen (wie Anm. 18), S. 193ff., bes. S. 195, mit Anm. 164.

${ }^{61}$ Vgl. B-H 2224, ed. in: Const. XI, S. 285, n. 505 von 1355 Aug. 21; B-H Reichssachen 335 von 1360 Mai 21. 
Mannschaft für die Freigrafschaft leisten lassen ${ }^{62}$. Philipp war seit $1364 \mathrm{zu}$ gleich auch Herzog von Burgund (d.h. des französischen Herzogtums Burgund) ${ }^{63}$. Ganz ähnlich wie in der Dauphiné hat Karl IV. auch hier die Ambitionen der Valois nach Burgund keineswegs zu hindern versucht, sondern im Gegenteil aktiv unterstützt.

Generell können wir festhalten, daß Karl IV. nur wenig Interesse am Arelat hatte. Das Königreich wurde sich selbst überlassen; die nur noch auf dem Papier bestehenden Reichsrechte waren willkommene Verhandlungsmasse, um andere Vorteile zu erlangen. Diese Politik ist leicht zu erklären: Karls Einflußmöglichkeiten im Arelat waren gering, er mußte froh sein, wenn seine Herrschaft wenigstens prinzipiell anerkannt wurde. Indem er Rechte, die er nicht behaupten konnte, für andere Vorteile eintauschte, zeigte er jene illusionslose Einsicht in die politische Lage, welche ihm in der Forschung schon seit längerer Zeit zugeschrieben wird.

\section{Karl V. und das Arelat}

Bevor wir uns nun der Arlesreise des Kaisers zuwenden, sollen die französischen Interessen im Arelat erörtert werden. Der schon erwähnte Verkauf der Dauphiné an den französischen Thronfolger hatte zur Folge gehabt, daß der französische Hof sehr direkt in die Politik des Arelats involviert war. Als Quelle für seine weitergehenden Ziele pflegt man drei Verhandlungsinstruktionen heranzuziehen ${ }^{64}$, welche die Aufgabe hatten, nals Grundlage für Berathungen durch den Dauphin und dessen Rath über die Forderungen, welche

${ }^{62} \mathrm{~B}-\mathrm{H} 3811$ = 7070 von 1362 Jan. 15. Bereits in dem Entwurf für einen Vertrag zwischen Johann II. und Karl IV. war vorgesehen, daß der Graf von Burgund seine Grafschaft vom Kaiser zum Lehen nehmen sollte. Vgl. die vorletzte Anm.

${ }^{63}$ Vgl. Delachenal, Histoire (wie Anm. 8), Bd. 3, S. $101 \mathrm{f}$.

${ }^{64}$ Es handelt sich um die folgenden drei Schriftstücke: 1. »Memoriale pro domino nostro Dalphino super requirendis ab Imperatore pro parte Dalphinalik, ed. bei CHEVALIER (Hg.), Choix (wie Anm. 41), S. 130, n. 44; danach B-H Reichssachen 762 zu (1350-1355, wahrscheinlich 1354); zit. bei FouRNIER, Royaume (wie Anm. 30), S. 449, mit Anm. 2 zu (nach 1355 Mai 22); HeCKMANN, Reichsvikariat (wie Anm. 24), S. 69, mit Anm. 31 zu (um 1350). 2. "Super infrascriptis videat dominus meus (Dalphinus) et ejus nobile consilium, si placet", ed. bei Chevalier (Hg.), Choix (wie Anm. 41), S. 140, n. 48; danach B-H Reichssachen 762 zu (1350-1355, wahrscheinlich 1354); zit. bei FOURNIER, Royaume (wie Anm. 30), S. 449, mit Anm. 2 zu (1352 Dez. 6 - 1355 Apr. 5), Fournier setzt es somit vor dem vorangegangenen Stück an; HECKMANN, Reichsvikariat (wie Anm. 24), S. 71-73 zu (1355 Frühsommer). 3. "Memoriale factum super peticionibus faciendis domino Karolo Quarto, imperatori Romanorum, quando venit Gracionopolim [= Grenoble]«, ed. bei CHEVALIER (Hg.), Choix (wie Anm. 41), S. 161, n. 59; danach B-H Reichssachen 719 zu 1365 Mai; vgl. zur Überlieferung FourNIER, Royaume (wie Anm. 30), S. 475, mit Anm. 2. 
derselbe im Interesse Frankreichs an den Kaiser stellen solk zu dienen $^{65}$. Ihre gemeinsame Überlieferung und die inhaltlichen Übereinstimmungen deuten darauf hin, daß man bei der Abfassung des jeweils späteren Stückes auf das vorangegangene zurückgegriffen hat. Der Verdacht, die Arelatpolitik des französischen Hofes sei einfach nach den aktuellen politischen Tageskonstellationen erfolgt, erweist sich damit als unzutreffend. Vielmehr beweisen sie ein hohes $\mathrm{Maß}$ an Kontinuität. Fassen wir also die drei Schriftstücke etwas genauer ins Auge.

Vor allem die beiden ersten Stücke hängen eng zusammen; umstritten ist, welches der beiden dem anderen vorangegangen ist. Einigkeit besteht indes darüber, daß die beiden Texte in den Kontext von Verhandlungen gehören, die zwischen Johann II. und Karl IV. über ein französisch-deutsches Bündnis geführt wurden. Als französischer Thronfolger und zugleich als Dauphin - also Herrscher der Dauphiné - war Karl V. zugleich auch Reichsfürst, sein Verhältnis zum römisch-deutschen König bedurfte der Klärung. Die in den beiden Texten aufgelisteten französischen Interessen gingen weit über die Dauphiné hinaus: Als Maximalforderung wird die Überlassung des gesamten Arelats als erbliches Lehen an den Thronfolger genannt; als Minimalforderung wird der kaiserliche Vikariat über das gesamte Arelat angestrebt ${ }^{66}$. Hier ist zu bedenken, daß diese Instruktionen noch vor der Niederlage Johanns II. bei Poitiers abgefaßt worden waren; durch diese haben sich die Gewichte zwischen regnum und imperium erheblich verschoben. Den von Johann II. noch abgelehnten Vertragsentwurf über das französisch-deutsche Bündnis hat Karl V. auf dem Hoftag zu Metz ratifiziert; ebenso hat er dort - wie erwähnt - die Dauphiné als Reichslehen erhalten hat und ist zum Reichsvikar ernannt worden ${ }^{67}$.

Es fällt leicht, die genannten Texte im Kontext des deutsch-französischen Gegensatzes zu interpretieren, hier einen Nachweis expansiver französischer Außenpolitik zu erblicken. Genauere Lektüre nötigt jedoch zu einer vorsichtigeren Interpretation. Sowohl im Falle einer Belehnung als auch im Falle der Ernennung zum Reichsvikar hätte der Dauphin die kaiserliche Oberhoheit über dieses Territorium anerkannt. Seine Herrschaft im Arelat hätte auf einer kaiserlichen Privilegierung beruht, das Arelat weiterhin zum Imperium gehört. Für Karl IV. hätte sich mit dem Eingehen auf diese Forderungen faktisch kaum etwas geändert; seine Oberherrschaft im Arelat beruhte doch letztlich ausschließlich auf der freiwilligen Anerkenntnis durch die dortigen Landesherren; reale Befugnisse oder Besitztümer, auf die er sich hätte stützen können,

${ }^{65}$ B-H Reichssachen 762.

${ }^{66}$ Eingehend diskutiert bei HECKMANN, Reichsvikariat (wie Anm. 24), S. 71 ff. Zum Reichsvikariat generell vgl. Marie-Luise FAVREAU-LILIE, Reichsherrschaft im spätmittelalterlichen Italien. Zur Handhabung des Reichsvikariats im 14./15. Jahrhundert, in: QFIAB 80 (2000), S. 53-116; HeCKMANN, Stellvertreter (wie Anm. 47).

${ }^{67}$ Siehe oben mit Anm. 24. 
besaß er dort nicht. Sehr viel hätte sich dagegen für diese Landesherren geändert. Anders als Karl IV. wäre sein französischer Kollege durchaus in der Lage gewesen, seinen Willen im Arelat nötigenfalls auch gewaltsam durchzusetzen. Insofern wären die arelatensischen Landesherren die eigentlich Betroffenen eines solchen Abkommens gewesen. Es dürfte dem Kaiser durchaus bewußt gewesen sein, daß er auf diese Weise ihnen gegenüber ein nicht zu unterschätzendes Druckmittel in der Hand hatte. Daß Amadeus von Savoyen um die Ernennung zum Reichsvikar nachsuchte, daß Johanna von Neapel die Provence von Karl IV. zu Lehen nahm, dürfte seine Ursache auch darin gehabt haben, $\mathrm{da} ß$ sie sich als Untertanen des Kaisers einer weitaus größeren Unabhängigkeit denn als solche des französischen Königs erfreuten.

$\mathrm{Zu}$ solch weitgehenden Zugeständnissen hat Karl IV. sich in Metz nicht bereitgefunden; er hat sich - wie erwähnt - darauf beschränkt, Karl V. den Reichsvikariat und die Gerichtsbarkeit in der Dauphiné einzuräumen ${ }^{68}$, und, fast gleichzeitig, Amadeus VI. ein ähnliches Vorrecht in Savoyen verliehen ${ }^{69}$.

\section{Das Treffen in Avignon und Arles}

Fassen wir nun die Reise nach Arles ins Auge ${ }^{70}$. Karl IV. hatte seinen französischen Verwandten seine Ankunft bereits für das Osterfest angekündigt ${ }^{71}$; er verspätete sich jedoch und feierte es am 13. April 1365 in Nürnberg. Dann brach er in Richtung Elsaß auf. Am 24. April war er in Straßburg. Von dort aus nahm der den Weg nach Süden: Über Basel, Bern, Genf und Lausanne erreichte er Morat; dort - an der Grenze Savoyens - erwartete ihn Graf Amadeus VI. Dieser hatte sich in beträchtliche Unkosten gestürzt, um den Kaiser würdig zu empfangen ${ }^{72}$. Am 12. Mai leistete er dem Kaiser in Chambéry die Lehnshuldigung; bei dieser Gelegenheit erneuerte Karl IV. die alten Privilegien des Grafen ${ }^{73}$, investierte ihn ${ }^{74}$ und ernannte ihn zum kaiserlichen Vikar in

\footnotetext{
${ }^{68}$ Siehe oben mit Anm. 41.

${ }^{69}$ Siehe oben mit Anm. 43.

${ }^{70}$ Ein besseres Itinerar als B-H bieten für die Arlesreise Paul-Emile GIRAUD, Ulysse CHEVALIER (Hg.), Le mystère des trois doms, joué à Romans en MDIX, Lyon 1887 (Documents inéd. sur l'histoire du Dauphiné), S. CXXff.; vgl. auch DELACHENAL, Histoire (wie Anm. 8), Bd. 3, S. $211 \mathrm{ff}$.; GALLAND, Les papes (wie Anm. 9), S. $171 \mathrm{ff}$; Kenneth FowLER, Medieval Mercenaries, Bd. 1: The Great Companies, Oxford 2001, S. 121 ff. (freundlicher Hinweis von Werner Paravicini).

${ }^{71}$ Siehe unten mit Anm. 148.

${ }^{72} \mathrm{Vgl}$. die Auszüge aus seinen Rechnungsbüchern, ed. bei MURATORE, L'imperatore (wie Anm. 33), S. 199 ff. Vgl. auch DELACHENAL, Histoire (wie Anm. 8), Bd. 3, S. 216, Anm. 1.

${ }^{73} \mathrm{~B}-\mathrm{H}$ - ed. bei MURATORE, L'imperatore (wie Anm. 33), S. 205, n. 7 von 1365 Mai 12. Vgl. auch NEUREITHER, Bild (wie Anm. 27), S. 174ff., der die erzählenden Quellen auswer-
} 
Savoyen $^{75}$. Ebenfalls auf Amadeus' Bitten hin genehmigte Karl IV. im Verlauf der Reise die Gründung einer Universität in $\mathrm{Genf}^{76}$. Der Graf schloß sich dem Kaiser für die Weiterreise an; bei Karls feierlichem Einzug in Avignon sollte er ihm dann das Reichsschwert vorantragen ${ }^{77}$.

In Chambéry war am 12. Mai auch Raoul de Louppy, der Gouverneur Karls V. in der Dauphiné, mit großem Gefolge eingetroffen ${ }^{78}$. Für ihn war die dritte der genannten Instruktionen bestimmt gewesen ${ }^{79}$; sie dürfte ihm bei seinen Verhandlungen mit dem Kaiser als Arbeitsgrundlage gedient haben. Wie schon die beiden früheren Texte listet sie eine Reihe von französischen Forderungen das Arelat betreffend auf: Der Unterschied zu den früheren besteht lediglich darin, daß der zu übertragende Rechtstitel vager als früher umschrieben wird; die in den beiden älteren Stücken zu findende Unterscheidung von Lehnshoheit und Vikariat ist weggefallen, lediglich von einer allgemein gehaltenen Oberhoheit (feudum superioritatem et majus dominium) ist die $\operatorname{Rede}^{80}$. In welcher Rechtsform die Übertragung stattfinden sollte, hat man wahrscheinlich von den Verhandlungen selbst abhängig machen wollen. Abermals wird aber keineswegs die Loslösung des Arelats vom Imperium gefordert, zumindest implizit wird dessen Oberhoheit anerkannt. Abermals indes ist Karl IV. auf diese Forderung nicht eingegangen. Er hat vielmehr - fast gleich-

tet, jedoch der irrigen Ansicht ist, das Zusammentreffen in Chambéry habe auf Karls Rückreise und nicht auf der Hinreise stattgefunden; CoX, Green Count (wie Anm. 32), S. $189 \mathrm{ff}$.

${ }^{74} \mathrm{~B}-\mathrm{H}$ - ed. bei MURATORE, L'imperatore (wie Anm. 33), S. 206, n. 8 von 1365 Mai 12.

${ }^{75}$ B-H 4170, ed. bei MURATORE, L'imperatore (wie Anm. 33), S. 207, n. 9 von 1365 Mai 12. Vgl. auch B-H 7155, ed. bei MURATORE, L'imperatore (wie Anm. 33), S. 208, n. 10 von 1365 Mai 12; B-H - ed. bei MURATORE, L'imperatore (wie Anm. 33), S. 210, n. 11 von 1365 Mai 12; B-H 4364 von 1366 Sept. 14 = Joseph ALBANÈs, Gallia christiana novissima, Bd. 3: Arles, Montbéliard 1899, S. 705, n. 1624. Zur Sache vgl. auch MURATORE, L'imperatore (wie Anm. 33), S. 171 ff.; Delachenal, Histoire (wie Anm. 8), Bd. 3, S. 212f.; GaLLAND, Les papes (wie Anm. 9), S. 172f. Karl IV. erweiterte hier sein vorangegangenes Privileg von 1356 (vgl. Anm. 43), in dem er Amadeus die Appelationsgerichtsbarkeit in Savoyen eingeräumt hatte. Zur weiteren Entwicklung des savoyischen Vikariats vgl. künftig Comel ZWIERLEIN, Savoyen-Piemonts Verhältnis zum Reich 1536 bis 1618: zwischen ständischer Reichspolitik und absolutistischer Außenpolitik.

${ }^{76}$ Siehe unten mit Anm. 99.

77 Johannes Neplach, Chronicon, hg. von J. EMLER, in: Fontes rerum Bohemicarum, Bd. 3, Prag 1882, S. 481-484, hier S. 483; vgl. auch Achim Th. HACK, Das Empfangszeremoniell bei mittelalterlichen Papst-Kaiser-Treffen, Köln 1999 (Forschungen zur Kaiser- und Papstgeschichte des Mittelalters, 18), S. 555.

${ }_{78}$ Über Raoul vgl. Heinz THOMAS, Zwischen Regnum und Imperium. Die Fürstentümer Bar und Lothringen zur Zeit Kaiser Karls IV., Bonn 1973, S. 223ff.; CAZElles, Société (wie Anm. 18), S. 420ff.; Vital CHOMEL, in: Lexikon des Mittelalters, Bd. 5, München 1991, Sp. 2139; HeCKMANN, Stellvertreter (wie Anm. 47), Bd. 2, S. 544ff.; LEMONDE, Temps (wie Anm. 38), S. 77ff. und passim.

${ }^{79}$ Siehe oben Anm. 64.

${ }^{80}$ Wie Anm. 64, vgl. auch DELACHENAL, Histoire (wie Anm. 8), Bd. 3, S. 225, mit Anm. 3. 
zeitig und wahrscheinlich in Anwesenheit der französischen Gesandtschaft Amadeus VI. zum Reichsvikar in Savoyen ernannt ${ }^{81}$.

Wieder fällt es leicht, die französische Forderung als Beleg für Ausdehnungsbestrebungen und Karls Reaktion als deren Abwehr zu deuten. Die folgenden Ereignisse stützen diese Interpretation jedoch nicht. Die französische Gesandtschaft hat sich keineswegs brüskiert gefühlt, ganz im Gegenteil hat sie - wie noch gezeigt wird - alles getan, um die kaiserliche Reise zu einem Erfolg zu machen. Ich deute diesen Befund dahingehend, daß bei diesen Gesprächen eine vorläufige Einigung erzielt worden ist, eine definitive Regelung jedoch von einer bestimmten weiteren Entwicklung, die im Interesse beider Seiten - der deutschen wie der französischen - gelegen hätte, abhängig gemacht worden ist. Wie diese antizipierte Entwicklung ausgesehen hätte, welche Ziele die kaiserliche und die königliche Politik im Arelat verfolgten, wird im folgenden zu klären sein. Generell sollte man bedenken, daß die französische Diplomatie schwerlich eine solche Forderung gestellt hätte, wenn sie nicht der Ansicht gewesen wäre, daß diese entweder auch im Interesse des Kaisers gelegen oder sie entsprechende Gegenleistungen anzubieten gehabt hätte.

Zunächst jedoch sei der weitere Ablauf der Reise verfolgt. Über Grenoble und Romans ging es nach Valence, wo die Abgesandten Urbans V. dem kaiserlichen Zug entgegenkamen. Am 23. Mai hielt Karl IV. seinen feierlichen Einzug in Avignon ${ }^{82}$; dort empfing ihn Papst Urban V. Am 1. Juni feierten Papst und Kaiser zusammen das Pfingstfest ${ }^{83}$. Am 4. Juni 1365 fand dann in Arles die Krönung zum König von Burgund statt ${ }^{84}$.

Die deutsche wie die französische Forschung interpretieren Reise und Krönung - in an sich erfreulicher Übereinstimmung - als eine antifranzösische Demonstration. Karl IV. habe augenfällig machen wollen, daß die kaiserlichen Herrschaftsrechte im Arelat weiterhin aufrechterhalten werden sollten. Damit habe er französischen Ausdehnungsbestrebungen entgegentreten wollen ${ }^{85}$.

${ }^{81}$ So mit Recht Cox, Green Count (wie Anm. 32), S. 189ff.

${ }^{82} \mathrm{Vgl}$. B-H 4170a, 7155a von 1365 Mai 23; ALBANĖs, Gallia, Bd. 7 (wie Anm. 52), S. 391, n. 1412. Die Urkunden Karls IV. für den Bischof von Avignon und andere lokale Empfänger, die in B-H 7156ff. noch als ungedruckt registriert sind, sind ediert bei ALBANÈS, Gallia, Bd. 7 (wie Anm. 52), S. 391ff., n. $1413 \mathrm{ff}$.

${ }^{83} \mathrm{~B}-\mathrm{H} 4170 \mathrm{~b}$ von 1365 Juni 1.

${ }^{84}$ Die Quellen sind zusammengestellt bei B-H 4171a von 1365 Juni 4; ausführlicher bei ALBANĖs, Gallia, Bd. 3 (wie Anm. 75), S. 703, n. 1622, und Étienne BALUZE (Hg.), Vitae paparum Avenionensium, neu hg. von Guillaume Mollat, 4 Bde., Paris 1914-1927, Bd. 2, S. 502. Dazu kommt das in Anm. 111 genannte Schreiben Karls IV. an die Königin Johanna, aus dem auch das Datum der Krönung hervorgeht.

${ }^{85}$ Vgl. etwa Delachenal, Histoire (wie Anm. 8), Bd. 3, S. 209f., der seinerseits auf WERUNSKY, Geschichte (wie Anm. 8), Bd. 3, S. 319 rekuriert; einschränkend THOMAS, Frankreich (wie Anm. 2), S. 85: „Zwar hat sich Karl [...] in Arles zum burgundischen König krönen lassen und hat damit in sehr demonstrativer Weise sowohl dem Papst als auch dem durch 
Die Quellen indes wissen nichts von einer solchen Absicht. Den eingehendsten Bericht bietet Johannes Neplach, Abt im Benediktinerkloster Opatowitz bei $\operatorname{Prag}^{86}$. Er hat seine Informationen aller Wahrscheinlichkeit nach von einem Teilnehmer der Reise und Angehörigen des kaiserlichen Hofes erhalten; sein Bericht hat offiziösen Charakter. Ganz im Gegensatz zu der Ansicht der Forschung ist sein Text von der Tendenz durchzogen, die herzliche Übereinstimmung beider Herrscherhäuser zu betonen. Für die problemlose Reise des Kaisers nach Avignon hätten Gesandte des Königs von Frankreich gesorgt, ja sogar die Kosten getragen ${ }^{87}$. $\mathrm{Zu}$ der Einholungsgesandtschaft, welche Urban V. dem Kaiser entgegenschickte, habe kein geringerer als Ludwig von Anjou, ältester der drei Brüder Karls V., gehört, der ja ebenfalls ein Neffe des Kaisers war $^{88}$. Nicht nur bei dem festlichen Gastmahl, mit dem Urban V. seine Gäste bewirtete, sei Ludwig von Anjou anwesend gewesen, sondern auch bei der anschließenden Beratung zwischen Papst, Kaiser und Kardinälen ${ }^{89} . \mathrm{Daß}$ diese Angaben sachlich richtig sind, wird durch andere Quellen bestätigt ${ }^{90}$.

den Herrn von Louppy vertretenen König von Frankreich zu verstehen gegeben, daß das burgundische Reich auch weiterhin zum Imperium Romanum gehören solle [...]«; ähnlich HOENSCH, Die Luxemburger (wie Anm. 7), S. 160, und jüngst KINTZINGER, Karl IV. (wie Anm. 16), S. 429. Auch die tschechische Forschung ist (oder war) dieser Ansicht. Vgl. SPEVÁCEK, Karl IV. (wie Anm. 16), S. 105.

${ }^{86}$ Johannes Neplach, Chronicon (wie Anm. 77), S. 481-484. Es handelt sich um die Fortsetzung von dessen »Summula cronice tam Romane quam Boemice«, die er zwischen 1355 und 1362 verfaßt hat. Von dieser Fortsetzung ist infolge einer Beschädigung der einzigen Handschrift nur ein Fragment für das Jahr 1365 erhalten. Es enthält neben der Schilderung von Karls Reise nach Arles noch einen kurzen Überblick über die vorangegangenen Beziehungen Karls IV. und Johanns des Blinden mit dem französischen Königshaus. Vgl. Ottokar LoRENZ, Deutschlands Geschichtsquellen im Mittelalter seit der Mitte des 13. Jahrhunderts, 2 Bde., Berlin ${ }^{3} 1886-1887$, Bd. 1, S. 313ff.; Norbert KERSKEN, Geschichtsschreibung im Europa der nationes. Nationalgeschichtliche Gesamtdarstellungen im Mittelalter, Köln 1995 (Münstersche Historische Forschungen, 8), S. 595ff.; Repertorium fontium historiae medii aevi, Bd. 8, Rom 2001, S. 172.

${ }^{87}$ Post hoc per nuncios regis francie decentisssime et lautissime in expensis fuit procuratus [...]; Johannes Neplach, Chronicon (wie Anm. 77), S. 482.

${ }_{88}^{8}[. .$.$] nec non illustris nepos ipsius domini imperatoris Ludwicus, frater regis Francie, cum$ comitibus, baronibus et multitudine nobilium copiosa domino imperatori in occursum reverenter venerunt $[\ldots]$; ibid., S. 483.

${ }^{89}$ Et facto prandio sumptuoso et honorifico dominus papa, dominus imperator, cardinales et Ludowicus, nepos imperatoris prefatus, ceteris omnibus exclusis ad consilium iverunt et ibidem per aliquod spacium steterunt. Ibid.

${ }^{90}$ Den - abgesehen von Johannes Neplach - ausführlichsten Bericht bietet der englische Chronist Johannes von Reading: Chronica Johannis de Reading et Anonymi Cantuariensis 1346-1367, hg. von James TAIT, Manchester 1914 (Publications of the University of Manchester. Historical Series, 20), S. 164ff. Eine neue und auf breitem Quellenfundament ruhende Darstellung von Karls Zusammentreffen mit Urban V. in Avignon bietet HACK, Empfangszeremoniell (wie Anm. 77), S. 549ff., der aber DELACHENAL, Histoire (wie Anm. 8), Bd. 3, S. $211 \mathrm{ff}$, übersehen hat, wo man ergänzende Informationen findet. Vgl. auch WEISS, Versorgung (wie Anm. 38), S. 232f. und passim. 
Nun liegt hier der Einwand nahe, daß eine solch offiziöse Darstellung die wahren Absichten ihres Auftraggebers durchaus hätte verschweigen können. Generell ist das richtig, indes war ja die Arlesreise - so jedenfalls die Ansicht der Forschung - gerade als eine augenfällige Demonstration, nicht als Akt geheimer Diplomatie gedacht.

Die zeitgenössischen französischen Chronisten haben Karls Reise nach Arles völlig ignoriert ${ }^{91}$. Das gilt auch für die offiziösen "Grandes Chroniques«, die im Auftrage Karls V. verfaßt worden sind ${ }^{92}$. Nun ist das argumentum ex silentio immer mißlich, aber es fällt doch schwer zu glauben, daß eine gegen Frankreich gerichtete Machtdemonstration des Kaisers so völlig ignoriert worden wäre. Indes brauchen wir uns damit nicht weiter abgeben; es gibt andere Quellen, welche den Johannes Neplach auch in seiner Tendenz bestätigen.

Die wichtigste ist das Rechnungsbuch des Raoul de Louppy, des Gouverneurs Karls V. in der Dauphiné ${ }^{93}$. Nicht nur wird hier die Angabe bestätigt, daß Karl V. für die Durchreise Karls IV. durch die Dauphiné die Kosten getragen hat ${ }^{94}$, sie zeigt auch, daß Raoul vom König angewiesen war, den Kaiser mit allen Ehren zu empfangen. Das hat er auch getan: Mit einem Gefolge von 73 Reitern, anscheinend den hohen Adligen der Dauphiné, ist er dem Kaiser entgegengezogen und hat ihn dann nach Avignon und Arles begleitet, wo er auch bei der Krönung anwesend war ${ }^{95}$. Zudem ersieht man aus dem Rech-

${ }^{91}$ Zur französischen Geschichtsschreibung dieser Zeit ist immer noch heranzuziehen Auguste MOLINIER, Les sources de l'histoire de France, Bd. 4, Paris 1904, passim; vgl. auch den Überblick bei DELACHENAL, Histoire (wie Anm. 8), Bd. 1, S. XVIIIff.; ergänzend NEUREITHER, Bild (wie Anm. 27), S. 172ff. CAZELLES, Société (wie Anm. 18), S. 525ff., betont, daß die zeitgenössische französische Chronistik generell für Karl V. nicht sehr ergiebig ist. Vgl. jetzt auch Jean-Marie MOEGLIN, Die historiographische Konstruktion der Nation, in: EHLERS (Hg.), Deutschland (wie Anm. 10), S. 353-377, bes. S. 374ff.

${ }_{92}$ DelaChENAL (Hg.), Chronique (wie Anm. 23); vgl. Delachenals Einleitung in Bd. 3, S. IXLVI, bes. S. XXXIIIff.

${ }_{93}$ Ulysse Chevalier (Hg.), Compte de Raoul de Louppy, gouverneur du Dauphiné de 1361 à 1369, publ. d'après l'orig. des Archives de la Préfecture de l'Isère, Romans 1886 (Bulletin d'histoire ecclésiastique et d'archéologie religieuse des diocèses de Valence, Gap, Grenoble et Viviers, 40). Auf S. II-VIII findet man ein Itinerar des Raoul. Das Rechnungsbuch ist die Hauptquelle für DELACHENAL, Histoire (wie Anm. 8), Bd. 3, S. 215f. Einige Korrekturen zu Chevaliers Edition aufgrund einer anderen Handschrift bietet die Rezension von Maurice ProU, in: Bibliothèque de l'École des Chartes 47 (1886) S. 567-573.

${ }^{94}$ Eigens zu diesem Zweck hatte Raoul eine Sondersteuer ausgeschrieben. Vgl. die Quellen bei Giraud, Chevalier (Hg.), Mystère des trois doms (wie Anm. 70), S. 681-688, 713715. Vgl. auch DELACHENAL, Histoire (wie Anm. 8), Bd. 3, S. 216.

${ }^{95}$ Chevalier (Hg.), Compte (wie Anm. 93), S. 34f.: Pour autres despens [...] pour aler au devant de l'Empereur son oncle hors du Dalphiné et ycellui acompaigner bien et honorablement ou conté de Savoye, en Avignon et en Arle et parler à lui de certaines choses secretes [...]. Ähnlich auf S. 34: Adam Chanteprime, trésorier du Dalphiné, pour deniers par lui baillez au dit gouverneur pour les despens de lui et de ses gens en alant par le comandement du Roy en la compaignie de l'Empereur à Avignon, à Arle et ou comté de Savoye, en may $1365[\ldots]$. 
nungsbuch, daß bereits vorher Boten zwischen Karl V., Raoul, Ludwig von Anjou und Urban V. in bezug auf den kaiserlichen Zug unterwegs gewesen waren $^{96}$. Offensichtlich hatte also Karl IV. seinen königlichen Neffen im voraus von seinen Reiseplänen unterrichtet ${ }^{97}$.

Nicht nur in Avignon, sondern auch in Arles war eine hochrangige französische Gesandtschaft anwesend und hat das Einverständnis des französischen Königs mit dem Geschehen augenfällig unter Beweis gestellt. Am Tag seiner Krönung erhielten vom Kaiser die Städte Orange ${ }^{98}$ und Genf jeweils ein Privileg für die Gründung einer Universität ${ }^{99}$; unter den Zeugen, welche die beiden Stücke unterschrieben haben, finden wir die Herzöge Ludwig von Anjou und

${ }^{96}$ Vgl. ibid., S. 32f.

${ }^{97}$ Das konzediert auch Delachenal, Histoire (wie Anm. 8), Bd. 3, S. 214. Vgl. auch den in Anm. 148 genannten Brief Karls V. an Philipp den Kühnen.

${ }^{98} \mathrm{Vgl}$. auch das von Françoise GASPARRI, La principauté d'Orange au Moyen Âge (fin XII$\mathrm{I}^{\mathrm{e}}-\mathrm{XV}^{\mathrm{e}}$ siècle), Paris 1985, S. 223, edierte Protokoll der Beratungen des Stadtrats von Orange vom Mai 1365 über die Kosten, die der Stadt für den Empfang des Kaisers entstanden waren. Über die Gründung der Universität Orange vgl. ibid., S. 133, woraus sich ergibt, daß der Stadtrat auch die Unterstützung des Kardinals Guido von Boulogne für sein Anliegen gewonnen hatte. Vorangegangen war ein Privileg Urbans V., durch welches in Orange schon ein studium particulare genehmigt worden war (Marcel FoURNIER [Hg.], Les statuts et privilèges des universités françaises, Bd. 2, Paris 1891 , n. 1542 von 1365 Jan. 1). Überhaupt wird man die kaiserlichen Privilegierungen für Universitäten im Zusammenhang mit den gleichzeitigen Gründungen Urbans V. im Arelat und Südfrankreich zu sehen haben. Vgl. Ludwig VONES, Urban V. (1362-1370): Kirchenreform zwischen Kardinalkollegium, Kurie und Klientel, Stuttgart 1998 (Päpste und Papsttum, 28), S. 412ff. Angemerkt sei, daß Karl IV. seinerseits die Gelegenheit nutzte, um an der Kurie einen Supplikenrotulus zu Gunsten der Doktoren und Magister der Universität Prag vorzulegen. B-H - ed. in: Monumenta Vaticana res gestas Bohemicas illustrantia, Bd. 3: Acta Urbani V. (1362-1370), hg. vom Lande Böhmen durch das Böhmische Landesarchiv, Prag 1944, S. 353, n. 585 von 1365 Juni 20.

${ }^{99}$ B-H 4171 = Max MEYHÖFER, Die kaiserlichen Stiftungsprivilegien für Universitäten, in: Archiv für Urkundenforschung 4 (1912), S. 291-418, hier S. 297, n. 8 (mit Zeugenliste) zu 1365 Juni 2; ed. bei Charles BorgeaUd, Histoire de l'université de Genève, Genf 1900, S. 619-622; danach zit. bei Delachenal, Histoire (wie Anm. 8), Bd. 3, S. 212, Anm. 2, S. 218, Anm. 1 zu 1365 Juni 4; B-H 7161 = MEYHÖFER, Stiftungsprivilegien, S. 297, n. 9 (mit Zeugenliste), ed. bei FoURNIER (Hg.), Statuts, Bd. 2 (wie Anm. 98), n. 1543 von 1365 Juni 4, Regest und (kaum lesbares) Faksimile bei GASPARRI, La principauté (wie Anm. 98), S. 235f. und Tafel XXIV, Abb. 62. Über die Privilegien Karls IV. für diverse Universitäten vgl. MEYHŐFER, Stiftungsprivilegien (mit Regesten der kaiserlichen und päpstlichen Stiftungsurkunden auf S. 294ff., 395ff.); Roderich SCHMIDT, Begriundung und Bestätigung der Universität Prag durch Karl IV., in: Blätter für Deutsche Landesgeschichte $113(1978)=$ PATZE (Hg.), Kaiser Karl IV. (wie Anm. 18), S. 695-719, hier S. 710ff. Beide Urkunden datieren vom 4. Juni, als Ausstellungsort wird jedoch nicht Arles, sondern Avignon genannt. Wie bereits Heinrich DENIFLE, Die Entstehung der Universitäten des Mittelalters bis 1400 , Berlin 1885, S. 468, Anm. 1014, anmerkte, müssen wir entweder annehmen - was möglich, aber sehr unwahrscheinlich ist -, daß Karl IV. am frühen Morgen in Avignon geurkundet hat, dann im Eilmarsch nach Arles gehetzt und dort am späten Abend gekrönt worden ist, oder daß die Urkunden vorher in Avignon geschrieben und dann in Arles datiert und übergeben worden sind. Über derartige Abweichungen von Ort und Datum vgl. B-H, S. XLVIIIff. 
Johann von Berry ${ }^{100}$, Brüder des französischen Königs und Neffen des Kaisers. Ebenfalls anwesend war Ludwig II. von Bourbon, Schwager des französischen Königs, der zudem mit der Gattin des Grafen von Savoyen verwandt war $^{101}$. Wahrscheinlich waren noch drei weitere französische Gesandte in Arles: der Erzbischof von Sens, der Bischof von Nevers und der Kanzler der Dauphiné ${ }^{102}$. Auch mit einem entsprechenden Gefolge wird man zu rechnen haben.

$\mathrm{Da} ß$ der französische König eine gegen ihn selbst gerichtete Demonstration nicht nur toleriert, sondern sogar unterstützt und finanziert hätte, das wäre doch der Gipfel des Absurden, müßte zumindest schlüssig nachgewiesen werden. Ganz im Gegenteil gewinnt man den Eindruck, daß - in moderner Terminologie - in Avignon und Arles ein deutsch-französisch-arelatensisches Gipfeltreffen stattgefunden hat. Der französische König war zwar nicht persönlich anwesend $^{103}$, er hatte jedoch mit der erwähnten Gesandtschaft, welche von keinem geringerem als seinem eigenen Bruder Ludwig von Anjou geführt wurde, eine Vertretung entsandt, wie sie hochrangiger gar nicht sein konnte. Nicht nur wegen Ludwigs enger Verwandtschaft mit dem Kaiser wie mit dem König, er war darüber hinaus als königlicher lieutenant für die Languedoc ${ }^{104}$ auch institutionell derjenige, der für die unmittelbar an das Arelat angrenzende

${ }^{100}$ Über die Beteiligung des Herzogs Johann von Berry an der französischen Gesandtschaft vgl. Françoise LeHOUX, Jean de France, duc de Berry, sa vie, son action politique (13401416), Bd. 1: De la naissance de Jean de France à la mort de Charles V, Paris 1966, S. 188ff.; zuletzt HECKMANN, Stellvertreter (wie Anm. 47), Bd. 1, S. $165 \mathrm{ff}$.

${ }^{101}$ B-H 4171a von 1365 Juni 4; vgl. auch DELACHENAL, Histoire (wie Anm. 8), Bd. 3, S. 225; CoX, Green Count (wie Anm. 32), S. 198f.

${ }^{102}$ Sie werden genannt in dem Brief Karls V. an seinen Bruder Philipp den Kühnen von 1365 Mai 2 (wie Anm. 148).

${ }^{103}$ Es stellt sich die Frage, warum er nicht anwesend war, zumal er ja zwei Jahre zuvor damals noch Kronprinz - 1363 in Mouzon mit seinem Onkel zusammengetroffen war. Vgl. B-H 3896a von 1363 Jan. 6; dazu STOOB, Karl IV. (wie Anm. 16), S. 209; AUTRAND, Charles V (wie Anm. 17), S. 445f. Dafür mag es zahlreiche Gründe gegeben haben, denkbar ist aber, daß eine gewisse protokollarische Verlegenheit Karls V. die Ursache war. Wie erinnerlich, hatte er noch als Thronfolger seinem Onkel Karl IV. die Lehnshuldigung für die Dauphiné geleistet, sich also vor aller Augen als »Mann« des Kaisers zu erkennen gegeben. Mittlerweile war er selbst König, hatte aber noch keinen Sohn, der ihm als Dauphin hätte nachfolgen können; er hat somit die Würde des Dauphins zunächst selbst beibehalten (Carolus Dei gratia Francorum rex et Dalphinus Viennensis [...], lautet die Intitulatio der zeitgenössischen französischen Königsurkunden; vgl. DELACHENAL, Histoire [wie Anm. 8], Bd. 3, S. 14). Bei einem Zusammentreffen mit Karl IV., vielleicht gar auf dem Boden der Dauphiné, hätte er kaum vermeiden können, daß diese Statusminderung in irgendeiner Weise augenfällig geworden wäre. Daß Karl V. in diesem Punkt sehr empfindlich war, wissen wir von der späteren Reise des Kaisers nach Paris, wo Karl V. sehr bemüht war, alles zu vermeiden, was in irgendeiner Weise als protokollarischer Vorrang des Kaisers vor ihm selbst hätte gedeutet werden können. Siehe unten mit Anm. 213.

${ }^{104} \mathrm{Vgl}$. DELACHENAL, Histoire (wie Anm. 8), Bd. 3, S. 15. 
Region zuständig war ${ }^{105}$. Schließlich war er, da König Karl V. noch keine männlichen Nachkommen hatte ${ }^{106}$, zu diesem Zeitpunkt auch französischer Thronfolger. Daß schließlich der Papst selbst mit der Krönung vollauf einverstanden war, wird - abgesehen von dem schon erwähnten ehrenvollen Empfang des Kaisers - in der Person des Koronators deutlich: Der Erzbischof von Arles, Guillaume de la Garde, war früher als päpstlicher Notar, dann als päpstlicher Legat tätig gewesen ${ }^{107}$; er kann somit als Vertrauter des Papstes gelten.

$\mathrm{Da} ß$ es sich bei der Reise und der Krönung nicht um eine antifranzösische Demonstration gehandelt haben kann, dürfte klar geworden sein. Demonstriert worden ist vielmehr das deutsch-französisch-savoyardisch-päpstliche Einverständnis. Gegen wen aber richtete sich diese Demonstration? Die Antwort ist leicht zu finden, wenn man sich fragt, wer in Avignon und Arles eigentlich nicht vertreten war. Es fehlte die Person, in deren Stadt, auf deren Territorium die Krönung stattgefunden hat, die Königin Johanna von Neapel, die Stadtherrin von Arles, die Landesherrin der Provence ${ }^{108}$. Weder war sie selbst erschienen, noch hat sie Gesandte geschickt; es hat den Anschein, daß sie gar nicht rechtzeitig von Karls Reise erfahren hat oder daß umgekehrt Karl IV. sie vorher nicht hat informieren lassen. Lediglich ihr Statthalter, Raymond d'Agout, der Seneschall der Provence, war bei der Krönung anwesend ${ }^{109}$. Die Königin scheint damit keineswegs einverstanden gewesen zu sein: Kurz nach der Abreise des Kaisers erschien ein hochrangiger Funktionär des neapolitanischen Hofes in der Provence, welcher die Befugnisse des Seneschalls erheblich einschränkte ${ }^{110}$.

Erst Wochen nachdem Karl IV. von Arles wieder nach Norden aufgebrochen war, hat ihn eine Gesandtschaft Johannas erreicht; in Straßburg, am 30. Juni 1365, hat er eine Urkunde ausgestellt, in der er erklärt, er habe mit der Krönung in Arles die Rechte der Königin Johanna in der Provence nicht ein-

${ }^{105}$ Die Statthalterschaft für die Dauphiné hat Ludwig von Anjou erst 1370 erlangt. Vgl. ibid., Bd. 4, S. 261 f.; HECKMANN, Stellvertreter (wie Anm. 47), S. 163.

${ }^{106}$ Zwei Töchter Karls V. waren 1360 gestorben. Der spätere Thronerbe, Karl VI., wurde erst 1368 geboren. Vgl. Delachenal, Histoire (wie Anm. 8), Bd. 3, S. 13.

${ }^{107}$ Vgl. Albanès, Gallia, Bd. 3 (wie Anm. 75), S. 682ff.; Thibout DE MOREMBERT, in: Dictionnaire d'histoire et géographie ecclesiastique, Bd. 19, 1981, Sp. 1228f.; B. GUILLEMAIN, in: Lexikon des Mittelalters, Bd. 5, München 1991, Sp. 1613f.; Baluze, Mollat (Hg.), Vitae paparum (wie Anm. 84), Bd. 2, S. 390ff.

${ }^{108}$ Die Angabe in den »Chroniques de Savoye» (danach B-H 4170a), sie wäre in Avignon anwesend gewesen, ist längst als falsch widerlegt. Vgl. FOURNIER, Royaume (wie Anm. 30), S. 473.

${ }^{109}$ Vgl. B-H 4171 a nach Garoscus de Ulmoisca Veteri bei Baluze, Mollat (Hg.), Vitae paparum (wie Anm. 84), Bd. 2, S. 502; Franz EHRLE (Hg.), Die Chronik des Garoscus de Ulmoisca Veteri und Bertrand Boysset (1365-1415), in: Archiv für Litteratur- und Kirchengeschichte des Mittelalters 7 (1893), S. 318-333.

${ }^{110}$ Vgl. LÉONARD, Les Angevins (wie Anm. 49), S. 424. 
schränken wollen ${ }^{11} . \mathrm{Ob}$ nun der Kaiser die Königin nicht rechtzeitig informiert oder ob diese das Ereignis bewußt ignoriert hat, in dem einen wie dem anderen Fall läge eine schwere und gewollte Brüskierung vor. Noch deutlicher wird die antineapolitanische Stoßrichtung von Karls Krönung, wenn wir sie im Zusammenhang mit den französischen Forderungen nach dem Reichsvikariat im Arelat sehen. Nachdem sowohl Savoyen ${ }^{112}$ als auch das Venaissin aus dem Verband des Arelats herausgenommen worden waren ${ }^{113}$, in der Dauphiné der französische König sowieso schon regierte, blieben lediglich die Provence bzw. die Königin Johanna, welche von einer solchen Vikariatsverleihung an den französischen König unmittelbar betroffen gewesen wären ${ }^{114}$.

\section{Die Königin Johanna und Italien}

Alle in Avignon und Arles anwesenden Parteien hatten - wenn auch aus verschiedenen Gründen - Anlaß, mit Johanna unzufrieden zu sein; diese seien nunmehr skizziert:

Seit der Erhebung Herzog Rogers II. zum König von Sizilien durch Anaklet II. hatte das sizilianisch-neapolitanische Reich in einem besonders engen Verhältnis zur Kurie gestanden, hatten die Päpste immer wieder auf die Unterstützung dieser süditalienischen Monarchie zurückgreifen können. Umgekehrt war der Kampf um die Beherrschung Süditaliens einer der Hauptgründe für den Konflikt zwischen den Staufern und Päpsten gewesen. Auch zur Zeit des Avignoneser Papsttums hatte sich an diesem Sachverhalt zunächst nichts geändert. Bei seinen Versuchen den Kirchenstaat zurückzuerobern und in seinen Auseinandersetzungen mit Ludwig dem Bayern hatte Papst Johannes XXII. immer wieder die Hilfe König Roberts von Neapel in Anspruch genommen. Dies änderte sich seit dem Regierungsantritt der Königin Johanna. Das neapolitanische Reich wurde von immer größeren innen- wie außenpolitischen Problemen heimgesucht, für welche die Königin sicher nicht alleinverantwortlich, an denen sie aber dadurch, daß sie sich anscheinend an der folgenreichen Ermordung ihres ersten Gatten beteiligt hatte, auch nicht unschuldig war ${ }^{115}$.

Nachdem Innozenz VI. mit der Entsendung des Kardinals Albornoz nach Italien die Eroberung des Kirchenstaates wiederaufgenommen hatte, wurde

${ }^{111}$ B-H 7171 von 1365 Juni 30.

112 Siehe oben mit Anm. 34.

${ }^{113}$ Siehe oben mit Anm. 54.

${ }^{1 / 4}$ Die antineapolitanische Stoßrichtung der französischen Bestrebungen, den Reichvikariat im Arelat zu erhalten, hat bereits LÉONARD, Les Angevins (wie Anm. 49), S. 423f., erkannt. Ähnlich THOMAS, Deutsche Geschichte (wie Anm. 18), S. 298.

${ }^{115}$ Vgl. generell LÉONARD, Les Angevins (wie Anm. 49), passim. 
diese Problematik akut. In diesen langwierigen Kämpfen wäre dem Papsttum neapolitanische Hilfe hochwillkommen gewesen, Johanna indes vermochte weniger wohl aus Mangel an gutem Willen, als vielmehr wegen dieser inneren Schwierigkeiten - der Kurie die erwünschte Hilfe nicht zu leisten; sie war vielmehr selbst auf päpstliche Unterstützung angewiesen. Gerade Urban V. hatte sich zunächst sehr zuvorkommend der Königin gegenüber gezeigt: Die dritte Ehe Johannas mit Jakob IV., dem Titularkönig von Mallorca, war mit seiner Genehmigung geschlossen worden. In seinem Bewilligungsschreiben hatte der Papst den Wunsch ausgedrückt, sie möge einen Mann ehelichen, der fähig sei, "weise zu regieren und das Königreich männlich zu verteidigen «" ${ }^{116}$.

Der neue Prinzgemahl zeigte sich jedoch als unfähig, den päpstlichen Wünschen genüge zu tun. Abgesehen von den häufigen Zerwürfnissen mit seiner Gemahlin sollte er vielmehr das Verhältnis Johannas zu Frankreich noch zusätzlich belasten, insofern er 1367 an dem Feldzug des Schwarzen Prinzen nach Spanien teilnahm, wo dieser die französischen Truppen unter Bertrand du Guesclin besiegte ${ }^{117}$. Zudem blieb auch Johannas dritte Ehe kinderlos, womit die Nachfolgefrage weiterhin im Raume stand. Für Urban seinerseits, der die Rückkehr des Papsttums nach Rom vorbereitete, wurde, je mehr die Vorbereitungen voranschritten, auch die Frage der Zustände in Neapel immer drängender; vor die Aussicht gestellt, in den kaum unterworfenen Kirchenstaat zurückzukehren, wäre ihm neapolitanischer Rückhalt und entsprechende Unterstützung willkommen gewesen.

Unter diesen Umständen mag Urban V. der Gedanke nicht ganz fern gelegen haben, daß ein anderer Fürst - energischer und loyaler als Johanna - einen besseren Herrscher als die amtierende Königin in Neapel abgeben würde. Wohl nicht ganz zufällig war denn auch eine Person, die entsprechende Ambitionen hatte, in Arles und Avignon anwesend: der schon genannte Ludwig von Anjou $^{118}$. Als königlicher lieutenant für die Langue d'Oc war er derjenige Franzose, der - abgesehen vom französischen König selbst - von der kaiserlichen Arelatpolitik am stärksten betroffen war. Hätte Karl IV. dem französischen König tatsächlich das Reichsvikariat im Arelat eingeräumt, wäre Ludwig von Anjou sehr wahrscheinlich derjenige gewesen, der ihn ausgeübt hätte. Darauf, daß er dieses Ziel konkret angestrebt hat, deutet eine von Dietrich von Nieheim überlieferte Nachricht hin, die zwar längst als falsch widerlegt ist, die

${ }^{116}$ Ed. bei Maurice ProU, Étude sur les rélations politiques du pape Urban V avec les rois de France Jean II et Charles V (1362-1370), Paris 1888 (Bibliothèque de l'École des Hautes Études, 76), S. 82, n. 1 von 1362 Nov. 7; hier zit. nach LÉONARD, Les Angevins (wie Anm. 49), S. 403.

${ }^{117}$ Vgl. Philippe CONTAMINE, À l'ombre des fleurs de lis. Les rapports entre les rois de France Valois et les Angevins de Naples et de Provence (1320-1382), in: Noël-Yves ToNNERRE, Élisabeth VERRY (Hg.), Les princes angevins du XIII ${ }^{e}$ au XV siècle. Un destin européen, Rennes 2003, S. 117-130, hier S. 126.

${ }^{118}$ Über ihn vgl. zuletzt HFCKMANN, Stellvertreter (wie Anm. 47), Bd. 1, S. $160 \mathrm{ff}$. 
aber zeigt, wie das Treffen in Avignon von den Zeitgenossen aufgefaßt worden ist. Ihr zufolge hätte Ludwig von Anjou in Villeneuve ein Festmahl für Karl IV. ausgerichtet; bei dieser Gelegenheit hätte der Kaiser ihm das Arelat übertragen $^{119}$.

Ludwig von Anjou hat sein hier erstmals sichtbar werdendes Ziel in der Folgezeit konsequent weiterverfolgt. 1375, nach dem Tod Jakobs IV. von Mallorca, des Gatten der Königin Johanna, der seine Rechte seiner Schwester Isabella vererbt hatte, kaufte Ludwig ihr diese - mit Zustimmung seines Bruders Karl V. - $a b^{120}$, hatte nunmehr also auch ohne den Vikarstitel einen Rechtsanspruch, der einen Zugriff nicht nur auf das Königreich Mallorca einschließlich des Roussillons und Montpelliers, sondern eventuell auch auf die Provence und das Königreich Neapel legitimieren konnte. Entscheidend mußte hier jedoch die Zustimmung des Papstes sein, der als Lehnsherr des neapolitanischen Reichs ein gewichtiges Wort mitzusprechen hatte.

Stellt man sich schließlich auf den Standpunkt Karls IV., wird deutlich, daß auch dieser keinen Grund hatte, für Johanna einzutreten. Seit jeher waren die Anjous in Neapel Hauptstütze nicht nur des Papsttums, sondern auch der Guelfen in Reichsitalien gewesen ${ }^{121}$, hier einen befreundeten und verwandten Fürsten auf dem Thron zu wissen, hätte indirekt zu einer Stabilisierung der Reichsgewalt in Norditalien führen können.

Die in Avignon zweifellos erörterte Frage nach dem weiteren Schicksal des Arelats $^{122}$, der Provence und der Königin Johanna verquickte sich aufs engste mit einer weiteren, die dort ebenfalls besprochen worden sein dürfte, die nach der Rückkehr des Papsttums nach Rom - eine Frage, die in ganz ähnlicher Weise die päpstliche, die deutsche und die französische Politik tangierte. Diese Rückkehr nach Rom war offenbar von Anfang an das Ziel von Urbans Politik $^{123}$, an ihr hatte auch Karl IV. hohes Interesse. Daß in Avignon Karls zweiter Italienzug zusammen mit der Reise Urbans nach Rom besprochen und vorbereitet worden ist, ist unbestritten ${ }^{124}$.

119 Vgl. Delachenal, Histoire (wie Anm. 8), Bd. 3, S. 226; Beat Frey, Pater Bohemiae Vitricus Imperii, Böhmens Vater, Stiefvater des Reichs. Kaiser Karl IV. in der Geschichtsschreibung, Bern 1978 (Geist und Werk der Zeiten, 53), S. 35.

${ }^{120} \mathrm{Vgl}$. Delachenal, Histoire (wie Anm. 8), Bd. 5, S. $45 \mathrm{ff}$.

${ }^{121}$ In seiner Autobiographie erwähnt Karl IV. selbst, daß Johannas Vorgänger, Robert der Weise, sich an einer Verschwörung gegen ihn beteiligt habe. Vita Caroli quarti (wie Anm. 20), cap. IV, S. 93.

122 Über die dortigen Verhandlungen sehr eingehend DelaCHENAL, Histoire (wie Anm. 8), Bd. 3, S. $219 \mathrm{ff}$.

${ }^{123}$ Über Urban vgl. vor allem Vones, Urban V. (wie Anm. 98), passim.

124 Vgl. Roland PAULER, Die Auseinandersetzungen zwischen Kaiser Karl IV. und den Päpsten. Italien als Schachbrett der Diplomatie, Neuried 1996 (Politik im Mittelalter, 1), S. 182ff.; Ellen WIDDER, Itinerar und Politik. Studien zur Reiseherrschaft Karls IV. südlich der Alpen, Köln 1993 (Forschungen zur Kaiser- und Papstgeschichte des Mittelalters, 10), S. $270 f$. 
Nicht beachtet wird dagegen das französische Interesse an dieser Rückkehr, wenn es nicht gar völlig geleugnet wird. Daß die Rückkehr des Papsttums von Avignon nach Rom gegen den Widerstand des französischen Hofes geschah $^{125}$, ist ein ähnlicher Glaubenssatz der Forschung wie der immerwährende deutsch-französische Gegensatz ${ }^{126}$. Sieht man die Rückkehr nach Rom im Licht von Ludwigs italienischen Ambitionen, wird neben dem deutschpäpstlichen sehr wohl auch ein französisches Interesse an ihr deutlich. War der Papst wieder Herr von Rom, konnte der Kirchenstaat nötigenfalls als Aufmarschbasis für eine Offensive Ludwigs von Anjou nach Süden dienen, dann nämlich, wenn die Königin Johanna sich seinen Wünschen gegenüber als unnachgiebig erwiesen hätte. Bekanntlich haben Johanna und Ludwig später einen dahingehenden Kompromiß geschlossen, daß sie ihn adoptiert und damit als Nachfolger anerkannt hat; diese Möglichkeit mag bereits bei dem Treffen in Avignon erwogen worden sein.

Aber auch im Arelat stand der Papst französischen Interessen im Wege. Der von Karl V. und Ludwig von Anjou angestrebte Reichsvikariat im Arelat, der - wie erwähnt - ihnen einen Zugriff auf die Provence ermöglicht hätte, hätte bedeutet, daß Avignon und das Venaissin auf allen Seiten von französisch beherrschtem Territorium eingeschlossen worden wären, nicht mehr nur im Westen von Frankreich und im Norden von der Dauphiné, sondern auch im Osten und Süden von der Provence. Die vielbeschworene Abhängigkeit des Avignoneser Papsttums von Frankreich wäre dann Wirklichkeit geworden, jedenfalls solange der Papst in Avignon und im Venaissin residierte. Solange dies der Fall war, konnte der Papst somit die französischen Ambitionen auf das Arelat wie auch Ludwigs italienische Ambitionen keineswegs billigen oder gar unterstützen, mußte ihnen vielmehr in jeder Weise Widerstand leisten. War er dagegen wieder sicher in Rom bzw. in Italien installiert, hätte er sich mit einer solchen Umklammerung des Venaissin abfinden können; dieses wäre - wie schon im 13. und dann wieder im 15. Jahrhundert - eine entlegene und unbedeutende Provinz des Kirchenstaates geworden. Daher dürfte - bei aller Unzufriedenheit - Urban V. doch noch der beste Bundesgenosse der Königin gewesen sein. Als Gegengewicht gegen französische wie gegen kaiserliche Ambitionen im Arelat war sie Urban wenigstens als Rückendeckung unentbehrlich, jedenfalls so lange, bis es ihm gelang, das Papsttum wieder sicher in Rom zu etablieren.

Die wachsende Unzufriedenheit des Papstes mit Johanna wird aber darin deutlich, daß er 1366, also ein Jahr nach Karls IV. Krönung in Arles, bei diesem eine Urkunde erwirkte, durch welche die Appellationsgerichtsbarkeit in den Grafschaften Provence und Forcalquier dem päpstlichen Kämmerer über-

${ }^{125}$ Vgl. ThOMAS, Frankreich (wie Anm. 2), S. 88f., und SpEVÁCEK, Karl IV. (wie Anm. 16), S. 108.

${ }^{126}$ Siehe auch den zweiten Teil dieser Studie; vgl. Anm. 1. 
tragen wurde. Arnald von Auch, der päpstliche Kämmerer ${ }^{127}$, hat diese Urkunde umgehend in Avignon öffentlich bekanntgemacht, was scharfe Proteste von Johannas Amtsträgern in der Provence hervorrief ${ }^{128}$. Aber nicht allein Johannas wegen dürfte Urban diese Urkunde erbeten haben. Indirekt richtete sie sich auch gegen Ludwig von Anjou, insofern zumindest tendenziell Urban mit ihr in die Rolle eines kaiserlichen Vikars für die Provence einrückte ${ }^{129}$ und so Ludwigs Ambitionen blockieren konnte.

$\mathrm{Da}$ schließlich Karl IV. sich durchaus Vorteile von einem französischen Engagement versprechen konnte, ist schon dargelegt worden, jedenfalls solange sich Ludwigs Ambitionen im Arelat auf die Provence und die Dauphiné beschränkten. Um einem weiteren Vordringen schon im Ansatz einen Riegel vorzuschieben, hatte er Amadeus von Savoyen zum Reichsvikar ernannt und Savoyen aus dem Arelat herausgelöst.

Auch dieser war in Avignon und Arles anwesend, auch sein Interesse dürfte Berücksichtigung gefunden haben. Er hatte sich bereits als ehrgeiziger Fürst und fähiger Heerfuihrer erwiesen, der sein Territorium gerne in Italien erweitert hätte. Hier stand ihm Bernabò Visconti, der Herr von Mailand, gegenüber, bekanntlich der Hauptgegner des Papsttums in Italien. Zwar bestand ein Bündnis zwischen Amadeus VI. und den Visconti, das sich gegen den Markgrafen von Montferrat richtete; indes versuchte der Papst gerade in den Jahren von Karls Krönungszug, Amadeus und den Markgrafen zu versöhnen ${ }^{130}$. Der Versuch blieb zwar zu Urbans Lebzeiten erfolglos; das war aber 1365 nicht absehbar. Unter seinem Nachfolger Gregor XI. sollte sich dann erweisen, daß Amadeus durchaus für ein Bündnis gegen die Visconti zu gewinnen war.

Ein ähnliches Verhältnis bestand zwischen Karl IV. und den Visconti. Dem diplomatischen Geschick des Kaisers war es während seines ersten Italienzuges gelungen, sich mit ihnen zu einigen, er hatte sie 1355 gar zu Reichsvikaren in der Lombardei ernannt ${ }^{131}$. Aber auch ihr Verhältnis war nicht ohne Span-

${ }^{127}$ Über ihn vgl. vor allem Daniel Williman, Calendar of the Letters of Arnaud Aubert Camerarius Apostolicus 1361-1371, Toronto 1992 (Subsidia Mediaevalia, 20), S. 17ff., der auf das in der folgenden Anm. genannte Stück jedoch nicht eingeht.

${ }^{128}$ B-H 7216 von 1366 Sept. 7 (freundlicher Hinweis von Thomas Maldener); vgl. auch FoURNIER, Royaume (wie Anm. 30), S. 481.

${ }^{129} \mathrm{Daß}$ die hohe Gerichtsbarkeit den Mittelpunkt der Vikariatskompetenz bildete, zeigt HeCKMANN, Stellvertreter (wie Anm. 47), Bd. 2, S. 550f., die auf diesen Fall jedoch nicht eingeht.

${ }^{130} \mathrm{Vgl}$. Galland, Les papes (wie Anm. 9), S. $278 \mathrm{ff}$.

131 Vgl. die Vikariatsprivilegien: B-H - Const. XI, S. 174, n. 317 von 1354 Dez. 20 (nur Reg.), ed. bei FAVREAU-LILIE, Reichsherrschaft (wie Anm. 66), S. 104, n. 1; B-H 1998 von 1355 März 8 (siehe dazu Const. XI, S. 251, Anm. 3); B-H $2108=$ Const. XI, S. 234, n. 414 von 1355 Mai 8 (nur Reg.) (vgl. zur Überlieferung FAVREAU-LILIE, Reichsherrschaft [wie Anm. 66], S. 63, Anm. 27); B-H - Const. XI, S. 241, n. 427 von 1355 Mai 15 (nur Reg.), aus anderer Überlieferung ed. bei HeCKMANN, Stellvertreter (wie Anm. 47), S. 839, n. 2 von 
nungen ${ }^{132}$, diese gipfelten gar in kriegerischen Auseinandersetzungen zwischen den Visconti und Markwart von Randeck, dem kaiserlichen Vikar in Reichsitalien ${ }^{133}$. Schon 1362 hatte Urban V. bzw. sein Legat Aegidius Albornoz eine Urkunde bei Karl IV. erwirkt, in dem dieser Amadeus VI. verboten hatte, die Visconti zu unterstützen ${ }^{134}$. Eine gemeinsame Offensive Ludwigs von Anjou - als stellvertretendem Reichsvikar der Dauphiné bzw. des Arelats - und Amadeus' VI. - als Reichsvikar für Savoyen -, gerichtet zunächst gegen Mailand, dann gegen Johanna von Neapel, mag insofern eine für alle in Avignon vertretenen Parteien erfreuliche Perspektive gewesen sein.

Wohlgemerkt, ich will keineswegs behaupten, es wäre in diesem Sinne ein förmliches Abkommen geschlossen worden, im Lichte der folgenden Ereignisse ist es aber sehr wahrscheinlich, daß eine unverbindliche Absprache zwischen Papst Urban, Kaiser Karl, Herzog Ludwig und vielleicht auch Graf Amadeus stattgefunden hat. Eine vertragliche Bindung war deshalb unmöglich, weil die antizipierten Pläne eine erfolgreiche Rückkehr des Papsttums nach Rom bzw. nach Mittelitalien voraussetzten; ob diese gelingen würde, war in Avignon noch nicht absehbar. Ebensowenig absehbar war das weitere Schicksal der Königin Johanna. Zwar wurde es immer unwahrscheinlicher, daß sie männliche Nachkommen haben würde, ob überhaupt und in welcher Form Ludwig in Italien seinen Traum vom eigenen Königreich würde verwirklichen können, war bestenfalls in vagen Umrissen absehbar.

Ein förmliches Abkommen ist in Avignon aber doch geschlossen worden; es bietet das gleichsam offizielle Ergebnis des päpstlich-kaiserlichen Zusammentreffens. Unterrichtet sind wir darüber durch weitgehend gleichlautende Briefe Urbans V. und Karls IV. Seit dem Frieden von Brétigny (1360) wurde Frankreich immer wieder von marodierenden Söldnerbanden heimgesucht, die keinen Arbeitgeber mehr fanden ${ }^{135}$. Sie bedrohten auch Avignon und den Westen des Imperiums. In Avignon planten Kaiser und Papst, diese für einen Kreuzzug einzusetzen, der gegen die Türken in Kleinasien hätte geführt werden sollen ${ }^{136}$. Zwei Anmarschwege waren vorgesehen: einer durch das Gebiet des

1355 Mai 15 (Heckmann irrig zu Mai 17); B-H 3042 von 1360 Jan. 22; B-H 3190 von 1360 Jun. 26; vgl. generell FAVREAU-LILIE, Reichsherrschaft (wie Anm. 66), S. 63ff.

${ }_{132}$ Vgl. WIDDER, Itinerar (wie Anm. 124), S. 259ff.; PAULER, Auseinandersetzungen (wie Anm. 124), S. 96.

${ }^{133}$ Vgl. ibid., S. 161f.; WIDDER, Itinerar (Anm. 124), S. 266ff.; FAVREAU-LILIE, Reichsherrschaft (wie Anm. 66), S. 78ff.

${ }^{134}$ B-H 6244 von 1363 Juni 25. Vgl. auch B-H 3963 vom selben Tag.

${ }^{135} \mathrm{Vgl}$. AuTrand, Charles V (wie Anm. 17), S. $491 \mathrm{ff}$.; jetzt auch Fowler, Medieval Mercenaries (wie Anm. 70), bes. S. $123 \mathrm{ff}$.

${ }^{136}$ Im selben Jahr 1365 hat der Kreuzzug Peters von Lusignan, des Königs von Zypern, gegen Alexandria stattgefunden. Vgl. Anthony LUTTRELL, Popes and Crusades: 1362-1394, in: Genèse et débuts du Grand Schisme d'Occident, Paris 1980 (Colloques internationaux du Centre national de la recherche scientifique, 586), S. 575-585, hier S. 577. 
deutschen Reiches über Ungarn - vorausgesetzt, König Ludwig I. von Ungarn wäre einverstanden gewesen -, der andere durch Norditalien nach Venedig; von dort sollten sie mit Schiffen weitertransportiert werden ${ }^{137}$. Die zweite Variante paßt gut zu den skizzierten Plänen. Wie man auf der Landkarte sehen kann, hätte dieses Kreuzheer auf dem Weg von Südfrankreich nach Venedig leicht einen Abstecher über Mailand machen können. Es wäre nicht das erste Mal gewesen, daß ein Kreuzheer sich von seinem ursprünglichen Ziel hätte abbringen lassen. Dieser Plan ist in dieser Form nicht ausgeführt worden, wahrscheinlich deshalb, weil Amadeus VI. damals noch nicht bereit war, sein Bündnis mit den Visconti aufzugeben. Immerhin hat derselbe Fürst 1366 einen Kreuzzug nach Gallipoli geführt ${ }^{138}$, was man als Beginn eines Kurswechsels auf die päpstliche Seite auffassen kann. Wenige Jahre später, unter Gregor XI., hat man diese Pläne in wenig veränderter Form aufgegriffen; das Bündnis, welches der neue Papst gegen die Visconti zustandebringen konnte, hat in großem Maße auf in Frankreich marodierende Söldner zurückgegriffen, die sich gerne für einen erfolgversprechenden und dem Seelenheil förderlichen Feldzug gegen die Feinde der Kirche gewinnen ließen ${ }^{139}$.

Man begreift jetzt, warum das Nichteingehen Karls IV. auf die französischen Arelatpläne keine Verstimmung ausgelöst hat. Der Kaiser hat diese keineswegs abgelehnt, vielmehr ihre Verwirklichung von der Ausführung der skizzierten Pläne abhängig gemacht. Erster Schritt zu ihrer Ausfuhrung mußte - wie gesagt - die erfolgreiche Rückkehr des Papstes nach Rom sein: Urban V. brach am 30. April 1367 dorthin auf. Daß hier ein Zusammenhang mit den Ambitionen Ludwigs von Anjou bestand, wird darin deutlich, daß dieser zusammen mit Bertrand du Guesclin, dem berühmten französischen Kriegshelden, - unmittelbar nach der Abreise des Papstes und damit offenbar erheblich früher als geplant in die Provence einfiel. Die Provenzalen leisteten jedoch - unterstützt durch tatkräftige Hilfe aus Neapel - unerwartet hartnäckigen Widerstand ${ }^{140}$; Urban V.

${ }^{137}$ Vgl. B-H 7164 von 1365 Juni 9, sowie B-H Päpste 100-102 von 1365 Juni 9 = Paul LECACHEUX, Guillaume MOLLAT ( $\mathrm{Hg}$.), Lettres secrètes et curiales du pape Urbain V (13621370) se rapportant à la France, 1 Bd. in 4 Fasz., Paris 1902-1955, n. 1822-1825. Zudem wies Urban V. den Kardinal Androin de la Roche, den päpstlichen Legaten in Italien, an, er möge mit der Königin Johanna und anderen italienischen Magnaten in Gespräche über den geplanten Kreuzzug eintreten. Ed. in: Monumenta Vaticana res gestas Bohemicas illustrantia, Bd. 3 (wie Anm. 98), S. 340, n. 564 von 1365 Juni 10.

${ }^{138}$ Vgl. LutTrell, Popes and Crusades (wie Anm. 136), S. 577; Cox, Green Count (wie Anm. 32), S. 204ff.

${ }^{139}$ Siehe unten mit Anm. 206.

${ }^{140}$ Vgl. Victor L. BourRILLy, Duguesclin et le duc d'Anjou en Provence (1368), in: Revue Historique 152 (1926), S. 161-180; LÉONARD, Les Angevins (wie Anm. 49), S. 425ff.; WEISS, Versorgung (wie Anm. 38), S. 334; zuletzt FowLER, Medieval Mercenaries (wie Anm. 70), S. 242ff. 
protestierte energisch ${ }^{141}$, und das Unternehmen mußte zunächst abgebrochen werden.

Das darf indes nicht darüber hinwegtäuschen, daß Urbans Rückkehr nach Rom durchaus im Rahmen des in Arles hergestellten französisch-deutschen Einvernehmens erfolgt ist. Eine Schlüsselrolle spielte hier Guido von Boulogne, Kardinalbischof von Porto, der wohl erfahrenste päpstliche Diplomat. Er war sowohl mit den Valois als auch mit den Luxemburgern und nicht zuletzt auch mit den Grafen von Genf verwandt; er hatte zuvor diplomatische Missionen nicht nur für diverse Päpste ${ }^{142}$, sondern auch für Karl V. und für Karl IV. durchgeführt. Auch nach Ungarn hatte ihn eine Legation geführt ${ }^{143}$. Bei dem Zusammentreffen Urbans V. mit Karl IV. in Viterbo $1368^{144}$ verabredeten beide, Guido von Boulogne zum neuen Reichsvikar in Tuszien zu ernennen; im Jahre 1369 wurde er Nachfolger Markwards von Randek ${ }^{145}$. Fast gleichzeitig ist er auch zum kaiserlichen Vikar in Lucca ernannt worden ${ }^{146}$. Völlig zu Recht hat Jugie darauf hingewiesen, daß die Übereinstimmung zwischen Kaiser und Papst kaum deutlicher demonstriert werden konnte, als durch die Ernennung eines Kardinals zum kaiserlichen Vikar ${ }^{147}$.

Indes, Urbans Rückkehr ist bekanntlich mißlungen; im September 1370 ist er nach Avignon zurückgekehrt, wo er kurz darauf verstarb, vielleicht weil es ihm nicht gelungen war, einen entscheidenden Erfolg gegen die Visconti zu

${ }^{141} \mathrm{Vgl}$. auch die päpstlichen Proteste bei Karl V. von 1368 Apr. 3, ed. bei ProU, Étude (wie Anm. 116), S. 157, n. 78; LeCACHEUX, MOLLAT (Hg.), Lettres secrètes (wie Anm. 137), n. 2733; zit. bei LÉONARD, Les Angevins (wie Anm. 49), S. 426, Anm. 1, und bei Karl IV., B-H - ed. bei Prou, Étude (wie Anm. 116), S. 157f., n. 78; Monumenta Vaticana res gestas Bohemicas illustrantia, Bd. 3. (wie Anm. 98), S. 602, n. 961; Reg. LECACHEUX, MOLLAT ( $\mathrm{Hg}$.), Lettres secrètes (wie Anm. 137), n. 2735; zit. bei LÉONARD, Les Angevins (wie Anm. 49), S. 426, sowie die Exkommunikation Bertrands du Guesclin, ed. bei Prou, Étude (wie Anm. 116), S. 161, n. 83; LeCACHEUX, MOLlat (Hg.), Lettres secrètes (wie Anm. 137), n. 2839 von 1368 Sept. 1. Sehr bezeichnend ist auch ibid., n. $3059=$ ProU, Étude (wie Anm. 116), S. 165, n. 86 von 1370 Apr. 5.

${ }^{142} \mathrm{Vgl}$. Pierre JUGIE, L'activité diplomatique du cardinal Gui de Boulogne en France au milieu du XIV siècle, in: Bibliothèque de l'École des Chartes 145 (1987), S. 99-147.

${ }^{143} \mathrm{Vgl}$. DERS., La légation en Hongrie et en Italie du cardinal Gui de Boulogne (1348-1350), in: Il Santo. Rivista antoniana di storia, dottrina, arte 29 (1989), S. 29-69.

${ }_{144}$ B-H 4696d-4696f und B-H 4697ff. Vgl. auch die Urkunde Urbans V. von 1368 Dez. 6: Reg. LeCACheuX, Mollat (Hg.), Lettres secrètes (wie Anm. 137), n. 2893 (irrig zu 1368 Dez. 7), ed. bei Pierre Jugie, Le vicariat impérial du cardinal Gui de Bologne à Lucques en 1369-1370, in: Mélanges de l'École française de Rome. Moyen-Âge. Temps modernes 103 (1991), S. 261-357, hier S. 345, n. 19 zu 1368 Dez. 6.

${ }^{145}$ Ich folge hier JUGIE, Vicariat (wie Anm. 144), S. $266 \mathrm{ff}$., und HECKMANN, Stellvertreter (wie Anm. 47), Bd. 2, S. 547f. Die Ernennungsurkunde: B-H $4770=$ HECKMANN, Stellvertreter (wie Anm. 47), Bd. 2, S. 831, n. 40 von 1369 Juli 2, ed. bei ZIMMERMANN (Hg.), Acta (wie Anm. 51), S. 134, n. 66; JugIE, Vicariat (wie Anm. 144), S. 348, n. 21.

${ }_{146}$ B-H $4758=$ HECKMANN, Stellvertreter (wie Anm. 47), Bd. 2, S. 831, n. 39 von 1368 Juni 1, ed. bei JUGIE, Vicariat (wie Anm. 144), S. 346, n. 20.

${ }^{147}$ Ibid., S. 269. 
erzielen. Auch Guido von Boulogne konnte wenig ausrichten. Man könnte meinen, daß sich damit die skizzierten Pläne erledigt hätten. Dem war jedoch nicht so. An der Ausgangslage hatte sich im Grunde nichts geändert, wenn der neue Papst die Politik seines Vorgängers wiederaufnahm und weiterführte, konnten sie nach wie vor zu einem erfolgreichen Abschluß gebracht werden.

\section{Valois, Luxemburg und Ungarn}

Es hat sich herausgestellt, daß die kaiserliche Reise nach Avignon und Arles vor allem eine antineapolitanische Stoßrichtung hatte. Diese war - wie gleich gezeigt wird - noch massiver, als wir bisher gesehen haben. Zudem hingen sowohl die deutsche als auch die französische Ostpolitik in vielfacher Weise mit der Arlesreise zusammen.

Nicht nur mit Ludwig von Anjou und Johann von Berry, sondern auch noch mit dem dritten und jüngsten Bruder König Karls V., nämlich mit Herzog Philipp dem Kühnen von Burgund, ist der Kaiser auf seiner Reise zusammengetroffen. Schon zuvor hatte er dem Herzog, seinem Neffen, geschrieben, er wolle mit ihm zusammentreffen; Philipp der Kühne hatte seinen Bruder Karl V. darüber informiert und dieser hatte dem Treffen zugestimmt ${ }^{148}$. Zwar kam der Herzog - nicht durch eigene Schuld - zu spät, um in Avignon und bei der Krönung in Arles anwesend zu sein ${ }^{149}$, er ist jedoch auf der Rückreise des Kaisers mit diesem, seinem Onkel, am 13. und 14. Juni in der Abtei SaintAntoine-de-Viennois bei Romans zusammengetroffen. Was war der Zweck dieser Zusammenkunft? In Avignon hatte der Kaiser auf Papst Urban V. eingewirkt, daß dieser eine geplante Eheschließung zwischen Albrecht III. von Habsburg, dem Herzog von Österreich, und Elisabeth, der Nichte König Ludwigs I., des Großen, von Ungarn (1326-1382) und voraussichtlichen Erbin seiner Länder ${ }^{150}$, wegen zu naher Verwandtschaft untersage, zumal beide bereits anderweitig versprochen waren, ein Verlangen, dem der Papst auch nachgekommen ist ${ }^{151}$. Karl wollte so verhindern, daß die rivalisierenden Habsbur-

${ }^{148}$ Vgl. den Brief Karls V. an Philipp den Kühnen von 1365 Mai 2, auszugsweise ed. bei Prou, Étude (wie Anm. 116), S. 48, Anm. 3; im Volltext ediert bei Ernest PeTIT, Ducs de Bourgogne de la maison de Valois d'après des documents inédits: Philippe le Hardi, Bd. 1, Paris 1909, S. 7; zit. bei DelaChENAL, Histoire (wie Anm. 8), Bd. 3, S. 214, mit Anm. 4.

${ }^{149}$ Ibid., Bd. 3, S. 227, Anm. 1.

${ }^{150}$ Ludwig hatte damals noch keine Kinder, seine älteste Tochter Katharina wurde erst 1370 geboren, als kaum noch jemand damit rechnete. Vgl. VELDTRUP, Eherecht (wie Anm. 15), S. $396 f$.

${ }_{151}$ B-H Päbste 97, ed. in: Monumenta Vaticana res gestas Bohemicas illustrantia, Bd. 3 (wie Anm. 98), S. 261, n. 436; LeCACHEUX, MolLAT (Hg.), Lettres secrètes (wie Anm. 137), 
ger Erbansprüche auf Ungarn würden geltend machen können. Sein eigenes Verhältnis zu Ludwig von Ungarn war gespannt ${ }^{152}$, vielleicht glaubte er, der Papst werde hier mit größerer Autorität eingreifen können.

Karl IV. hatte für Elisabeth (1354-1380) einen anderen Ehemann ausersehen, keinen anderen als Philipp den Kühnen ${ }^{153}$. Dieser stand dem Plan durchaus aufgeschlossen gegenüber, er hat jedenfalls während des Treffens am 14. Juni 1365 dem Kaiser Vollmacht erteilt, über seine - Philipps - EheschlieBung mit Elisabeth von Ungarn die nötigen Verhandlungen zu führen ${ }^{154}$. Urban V. hatte sich schon zuvor in Avignon mit dieser Lösung einverstanden erklärt und dementsprechende, an Ludwig von Ungarn und seinen Hof adressierte Urkunden ausgestellt ${ }^{155}$. Schließlich war anscheinend auch Karl V. mit dieser Ehe einverstanden ${ }^{156}$, wenn man auch annimmt, daß er schon damals

n. 1603 von 1365 Febr. 24 , n. 1783 , 1784 von 1365 Mai 23 ; Monumenta Vaticana res gestas Bohemicas illustrantia, Bd. 3 (wie Anm. 98) S. 369, n. 605 von 1365 Juli 2. Vgl. DelaCHENAL, Histoire (wie Anm. 8), Bd. 3, S. 219f.; VeldTRUP, Eherecht (wie Anm. 15), S. $381 \mathrm{ff}$;; zur kirchenrechtlichen Problematik vgl. ibid., S. $76 \mathrm{ff}$.

${ }^{152}$ Ibid., S. 377. Immerhin war es Karl IV. im Jahr vor seiner Arlesreise gelungen, einen umfassenden Frieden zwischen Böhmen, Österreich und Ungarn herbeizuführen. Vgl. B-H 4009-4012 von 1364 Febr. 8-10; Samuel SteINHERZ, Die Beziehungen Ludwigs I. von Ungarn zu Karl IV, 2. Theil: Die Jahre 1358-1373, in: Mitteilungen des Instituts für Österreichische Geschichtsforschung 9 (1888), S. 529-637, hier S. 557. Auch waren Karl IV., Ludwig I. von Ungarn und König Kasimir von Polen Ende September 1364 in Krakau zusammengekommen (B-H Reichssachen 414 von 1364 Sept. 22; vgl. STEINHERZ, Beziehungen, S. 558, 609f.). Es ist immerhin möglich, daß sie bei dieser Gelegenheit bereits den noch zu erörternden Eheplan besprochen haben. Der Zusammenhang zwischen kaiserlicher Ost- und Westpolitik wird jedenfalls im Itinerar Karls IV. sehr deutlich: von Krakau nach Arles und von Arles wieder nach Buda.

${ }^{153}$ In der deutschen Forschung wird dieser Plan regelmäßig übersehen, wahrscheinlich weil er - wie Delachenal, Histoire (wie Anm. 8), Bd. 3, S. 219, Anm. 5, mit Recht feststellt seinerzeit Werunsky entgangen war. Das gilt leider auch für die neuen Arbeiten von VELDTRUP, Eherecht (wie Anm. 15), und HECKMANN, Stellvertreter (wie Anm. 47), Bd. 1, S. 172ff. Wenigstens am Rande erwähnt wird er in der einschlägigen Biographie von Richard Vaughan, Philip the Bold, Woodbridge ${ }^{2} 2002$, S. 4.

${ }^{154}$ Diese Vollmacht ist erhalten als Regest in einem alten Inventar dieser Abtei. Erwähnt wird dort une procuration passée par Philippe, filz de Jean roy de France, duc de Bourgogne, à Charles, empereur des Romains et roy de Bohême, son oncle, pour contracter mariage avec dame Elisabeth, fille de feu Estienne [Herzog Stephan von Kroatien, Bruder König Ludwigs I.], duc, et neveu [sic; corr. frère - Ergänzung von Delachenal] du roy de Hongrie. So zit. bei DelaChenal, Histoire (wie Anm. 8), Bd. 3, S. 228, Anm. 1. Anscheinend hat auch Philipp der Kühne selbst einen Gesandten zu Ludwig von Ungarn geschickt. Vgl. FOWLER, Medieval Mercenaries (wie Anm. 70), S. 124, mit Anm. 16. Über die Rolle von Vermittlern bei Eheschließungen von Hochadligen vgl. SPIESS, Familie (wie Anm. 15), S. $82 \mathrm{ff}$.

${ }^{155}$ LECACHEUX, MOLLAT (Hg.), Lettres secrètes (wie Anm. 137), n. 1798-1808 von 1365 Juni 2; vgl. Delachenal, Histoire (wie Anm. 8), Bd. 3, S. 220, Anm. 3. Wahrscheinlich sind diese Urkunden von Karl IV. selbst zu Ludwig von Ungarn gebracht worden.

${ }^{156}$ Das geht aus dem erwähnten Brief Karls V. an Philipp von Burgund hervor (wie Anm. 148), in dem es heißt: Très cher et très amé frère, nous avons reçeu vos lettres conte- 
eine Verbindung seines Bruders mit Margarete, der Erbin Ludwigs von Male, des Grafen von Flandern, betrieben hat ${ }^{157}$.

Was beabsichtigte Karl IV. mit diesem Eheplan? Wir müssen etwas ausholen, da er sich einfügt in ein kompliziertes Geflecht von Eheschließungen, welche - soweit sie vom Kaiser betrieben wurden - offenbar den Zweck hatten, von Böhmen aus Erbansprüche auf die östlichen Länder zu erwerben ${ }^{158}$. Zwei Jahre vor der Arlesreise war der Kaiser seine vierte Ehe eingegangen, und zwar mit Elisabeth von Pommern-Wolgast (1347-1393), der Enkelin König Kasimirs III. von Polen ${ }^{159}$. Da Kasimir keine Söhne hatte und seine Töchter bereits gestorben waren, standen seine Enkel dem Thron am nächsten; mit seiner Eheschließung hatte Karl gleichsam einen Schritt in Richtung auf die polnische Krone getan. Indes hatte Kasimir bereits 1339 eine Nachfolgeregelung getroffen. Diese sah vor, daß sein Neffe, König Ludwig I. von Ungarn, ihm nachfolgen sollte ${ }^{160}$. Insofern war es aus kaiserlicher Sicht sicher ein sinnvoller Gedanke, auch mit Ludwig in verwandtschaftliche Beziehungen zu treten.

Die vorstehenden Ausführungen dürften bei Kennern Befremden hervorrufen, da sie im Widerspruch zur verbreiteten Ansicht stehen, Karl IV. habe ganz im Gegenteil Elisabeth von Ungarn mit seinem eigenen Sohn Wenzel $\left({ }^{*} 1361\right)$ verheiraten wollen ${ }^{161}$. Aus der eben skizzierten Interessenlage ergibt sich in der Tat, daß aus Karls IV. Sicht sein Sohn Wenzel ein geeigneterer Ehemann für Elisabeth als sein Neffe Philipp gewesen wäre. Indes waren

nans comment nostre oncle l'empereur vous a excript que vous alliez à Avignon où il doit estre dedans le mois de Pasques; si sachiez que se vous pouver laisser vostre pays en sureté il nous plaist bien que vous y alliez. Et sachez que nous avons ordonné à y envoyer, tant pour vostre mariage [!] comme pour les autres besoignes que nous y avons à faire, l'arcevesque de Sens, l'evesque de Nevers, et Guillaume de Dormans, chancelier de Viennois, qui sont messages bien solemnels, et qui partiront tantost pour y aller. Si voudrions bien que vous les attendassiez, afin qu'ils s'en allassent aveucque vous, mes que vous fussiez bien certain que nostre oncle demourast tant par delà que vous y peussiez estre avant qu'il s'en partist. Donné à Paris, le secont jour de may.

${ }^{157}$ Vgl. Delachenal, Histoire (wie Anm. 8), Bd. 3, S. 220, $501 \mathrm{ff}$. Dieser Eheplan ist vor dem Hintergrund zu sehen, daß auch Eduard IIl. von England eine Eheschließung seines Sohnes mit besagter Erbin anstrebte, womit er beinahe erfolgreich gewesen wäre. Vgl. AUTRAND, Charles V (wie Anm. 17), S. 521f.

${ }^{158}$ Generell sei verwiesen auf Frantisek KAVKA, Zum Plan der luxemburgischen Thronfolge in Polen (1368-1382). Strittige Forschungsfragen, in: Zeitschrift für Historische Forschung 13 (1986), S. 257-283, und VELDTRUP, Eherecht (wie Anm. 15), passim; ich beschränke mich auf das für mein Thema Wesentliche.

${ }^{159}$ Vgl. ibid., S. $377 \mathrm{ff}$.

${ }^{160}$ Ibid., S. 241.

${ }^{161}$ Ibid., S. 383ff. (mit der älteren Literatur). Bereits 1356 hatte Karl IV. ein erstes Eheprojekt für Elisabeth eingefädelt: Sein Bruder, Markgraf Johann von Böhmen, hatte seinen erstgeborenen Sohn König Ludwig als Gatten für Elisabeth versprochen. Vgl. ibid., S. 347. Philipp der Kühne war also nicht der erste Neffe, den Karl IV. mit Elisabeth von Ungarn hatte verheiraten wollen. 
Karls Beziehungen zu Ludwig gespannt, der Kaiser mag befürchtet haben, mit einem solchen Vorschlag auf brüske Ablehnung zu stoßen. Auch war Wenzel bereits 1361 - noch nicht einmal einjährig - durch ein väterliches Eheversprechen mit der Tochter des Burggrafen von Nürnberg verbunden worden ${ }^{162}$. Da Wenzel noch keine sieben Jahre alt war, ließ sich ein solches Versprechen zwar noch ohne päpstlichen Dispens auflösen, indes wäre diese Argumentation König Ludwig gegenüber doch recht taktlos gewesen. Nachdem der Papst auf kaiserlichen Wunsch hin die nötigen Dispense für eine Ehe zwischen Albrecht und Elisabeth verweigert hatte, mußte der Kaiser damit rechnen, daß Ludwig von Ungarn ihm gegenüber sehr verstimmt war.

Unmittelbar nach seiner Arlesreise ist Karl IV. jedenfalls nach Ungarn gereist und mit König Ludwig I. in Buda zusammengetroffen. Dort sind sie übereingekommen, daß Wenzel - und nicht Philipp der Kühne - mit Elisabeth verlobt werden solite ${ }^{163}$. Auf den ersten Blick scheint dies im Widerspruch zu meinen vorangegangenen Ausführungen zu stehen. Indes wissen wir ja keineswegs, ob die Initiative für ein Ehebündnis zwischen Wenzel und Elisabeth tatsächlich vom Kaiser ausgegangen ist. Dieser mag mit der Hoffnung nach Buda gekommen sein, die aus seiner Sicht zweitbeste Lösung erreichen zu können, um dann freudig überrascht festzustellen, daß Ludwig seinerseits einer ehelichen Verbindung zwischen Elisabeth und Wenzel durchaus aufgeschlossen gegenüberstand.

Wir müssen die weitere Entwicklung dieses Verlöbnisses noch etwas weiter verfolgen. Ludwig von Ungarn selbst hat weder 1365 noch später seine Nachfolge selbst geregelt; er hat aber gegen Ende des Jahres 1365, während er also mit Karl IV. über die Eheschließung verhandelte, Karl von Durazzo, einen entfernten Verwandten aus einer Seitenlinie ${ }^{164}$, nach Ungarn berufen, "ganz offensichtlich in der Absicht, ihn zum Thronfolger zu erheben ${ }^{165}$. Auch wurde Ludwig seit 1370 überraschend doch noch Vater von drei Töchtern, womit nicht nur Karls IV. Interesse an der Ehe Wenzels mit Elisabeth endgültig erlosch, sondern auch die Position Karls von Durazzo in Frage gestellt wurde.

${ }^{162}$ Erst 1363 hatte Karl IV. die Nürnberger Burggrafen (die Zollem) zu Reichsfürsten erhoben, um die geplante Ehe Wenzels mit Elisabeth, der Tochter des Burggrafen, nicht als Mesalliance erscheinen zu lassen. Ibid., S. $383 \mathrm{f}$.

${ }^{163} \mathrm{Vgl}$. B-H Reichssachen 426 von 1365 Dez. 20; das in B-H 4285 inserierte Schreiben Ludwigs an Karl IV. von 1365 Dez. 5, sowie B-H Reichssachen 433 von 1366 Febr. 27; der päpstliche Dispens, ed. in: Monumenta Vaticana res gestas Bohemicas illustrantia, Bd. 3 (wie Anm. 98), S. 415, n. 670 von 1366 Febr. 23; vgl. auch STEINHERZ, Beziehungen (wie Anm. 152), Teil 2, S. 562ff.; VELDTRUP, Eherecht (wie Anm. 15), S. 384ff. Den Ehevertrag hat man dann wohl im Juni 1366 geschlossen. Bekanntlich ist die Ehe dann doch nicht vollzogen worden. Wenzel wurde vielmehr am 29. September 1370 in erster Ehe mit der Wittelsbacherin Johanna von Bayern-Holland verheiratet. Vgl. ibid., S. $418 \mathrm{ff}$.

${ }_{164} \mathrm{Zu}$ den verwandtschaftlichen Beziehungen unter den Anjous vgl. den Stammbaum ibid., S. 392.

${ }^{165}$ Ibid., S. 390; vgl. auch STEINHERZ, Beziehungen (wie Anm. 152), Teil 2, S. 566f. 
Weder jetzt noch in den folgenden Jahren hat Ludwig klargestellt, welche Position Karl nach seinem Tod einnehmen sollte; seine Erbansprüche und seine Position am ungarischen Hof waren aber so geartet, daß er ein ernstzunehmender Kandidat für die Nachfolge in Polen wie in Ungarn war. Damit war er aber zugleich auch - und darin besteht der Zusammenhang zwischen Karls IV. West- und Ostpolitik - ein Kandidat für die Nachfolge im Reich von Neapel und in der Provence. König Ludwig I. von Ungarn war nämlich mit der neapolitanischen Königsdynastie verwandt ${ }^{166}$; beide führten ihre Abstammung auf Karl I. von Anjou, den Bruder König Ludwigs des Heiligen zurück, woraus sich zugleich ein dynastischer Zusammenhang mit dem französischen Königshaus ergibt. Zwar war König Ludwig von Ungarn die Königin Johanna, die Gattin und Mörderin seines Bruders Andreas, zutiefst verhaßt, gleichwohl hätte er bei ihrem Tod Erbansprüche auf das neapolitanische Reich und damit auch die Provence geltend machen können ${ }^{167}$. Diese Ansprüche wären - so er ohne weitere Nachkommen gestorben wäre - auf seine Töchter bzw. Schwiegersöhne und auf Karl von Durazzo übergegangen.

Zunächst bleibt festzuhalten, daß in den Jahren 1365/1366 Vorbereitungen getroffen wurden, um sowohl die Provence als auch das Reich von Neapel gleichsam von zwei Seiten her - von Westen und von Osten - einer französischen Einflußnahme zu öfnen, und zwar - das muß noch einmal betont werden - mit tätiger Unterstützung Kaiser Karls IV., wenn nicht gar auf seine Initiative hin.

Zwar ist die vom Kaiser angeregte Heirat zwischen Philipp und Elisabeth nicht zustandegekommen, der Plan einer französisch-ungarischen Ehe wurde jedoch keineswegs aufgegeben; wir werden noch genauer sehen, daß er in ganz ähnlicher Weise wiederaufgenommen worden ist. Hier mag dieses Projekt zunächst dazu dienen, noch einmal die Fragwürdigkeit des herkömmlichen Paradigmas bei der Deutung der französisch-deutschen Beziehungen unter Karl IV. und Karl V. zu demonstrieren. Diesem Paradigma zufolge müßten wir annehmen, daß während einer antifranzösischen Demonstration der deutsche König und Kaiser eine Ehe des Bruders des französischen Königs mit einer der attraktivsten Erbinnen dieser Zeit einzufädeln gesucht hätte.

Offensichtlich hat sich Karl IV. bei diesem Vorhaben nicht von staatlichen und erst recht nicht von nationalen, sondern vielmehr von dynastischen Interessen leiten lassen. Sein eigener Neffe, der überdies als Graf von Burgund (d.h. der Freigrafschaft) Reichsfürst war, stand ihm offensichtlich näher als ein Angehöriger der konkurrierenden habsburgischen Dynastie.

${ }^{166}$ LÉONARD, Les Angevins (wie Anm. 49), S. 316ff.

${ }^{167}$ Ludwig hatte zwar nach dem Fehlschlag seiner beiden Feldzüge nach Neapel in den Jahren 1347/1348 und 1349/1350 (vgl. ibid., S. 355ff., 361ff.) Papst Clemens VI. gegenüber förmlich auf seine Ansprüche auf Neapel verzichtet, indes ist fraglich, ob seine Nachfolger sich daran gehalten hätten. Vgl. DelACHENAL, Histoire (wie Anm. 8), Bd. 5, S. 89. 
Man stelle sich einmal vor, dieser Plan wäre realisiert worden: Philipp der Kühne als König von Ungarn, Herzog des französischen, Graf des deutschen Burgund und eventuell gar als König von Neapel und Graf der Provence. Das war nicht so utopisch, wie es scheinen mag. Man denke an Karl IV. selbst, dessen Stellung im Reich auf einem ähnlichen Spagat zwischen Luxemburg und Böhmen ruhte. Das burgundische Reich des 15. Jahrhunderts, welches auf Philipp den Kühnen und seine dann doch erfolgte Ehe mit der Erbin von Flandern zurückgeht, war kaum weniger heterogen, es fehlte nicht viel, und es wäre so zwischen Frankreich und Deutschland ein Mittelreich entstanden.

\section{Von Avignon nach Rom}

Nach diesem Umweg nach Osten kehren wir nun wieder in den Mittelmeerraum zurück. In Avignon war 1370 ein neuer Papst erhoben worden, Gregor XI. Er war seinem Vorgänger Urban V. so unähnlich wie nur möglich ${ }^{168}$; in einem Punkt jedoch stimmte er mit ihm überein: Wie Urban ist Gregor nach einigen Jahren aufgebrochen, um den Sitz des Papsttums wieder nach Rom bzw. Italien zu verlegen. Vielleicht nicht ganz freiwillig - ich habe schon an anderer Stelle dargelegt, daß er in weit stärkerem Maße als seine Vorgänger von Frankreich, genauer: von Ludwig von Anjou abhängig gewesen ist ${ }^{169}$, der ein häufiger Gast am Hof in Avignon war ${ }^{170}$.

Zuvor hat Gregor - zur Vorbereitung der Rückkehr - in Italien eine weitgespannte diplomatische Aktivität entfaltet, die durchaus Erfolge erzielte ${ }^{171}$. Dabei finden wir immer wieder Hinweise, die auf ein weitgehendes päpstlichkaiserlich-französisches Zusammenwirken deuten. Bereits anläßlich der Krönung in Arles haben wir die Schlüsselrolle kennengelernt, die Graf Amadeus VI. von Savoyen in diesen Plänen spielte. Auch nach der Krönung blieb Amadeus eine Stütze der kaiserlichen Politik. Zwar wurden ihre Beziehungen mitunter dadurch belastet, daß Amadeus seine Vikariatsrechte auszunutzen

\footnotetext{
${ }^{168} \mathrm{Vgl}$. WEISs, Versorgung (wie Anm. 38), S. 444f.

${ }^{169}$ Ibid., S. 255.

170 Vgl. Delachenal, Histoire (wie Anm. 8), Bd. 4, S. 346ff., 592f. Demnach hat Gregor XI. zeitweise sogar in Ludwigs Haus in Villeneuve gewohnt. Zudem hat Ludwig dem päpstlichen Justizmarschall gestattet, auch in Villeneuve - also in Frankreich - die Jurisdiktion über die dem päpstlichen Hof attachierten Personen auszuüben.

${ }^{171}$ Einen guten Überblick bietet Guillaume MOLLAT, Les papes d'Avignon (1305-1378), Paris ${ }^{9} 1950$, S. $258 \mathrm{ff}$.
} 
versuchte, um die Grafschaft Genf ${ }^{172}$ seiner Herrschaft zu unterwerfen; diesen Bestrebungen hat Karl IV. nach Kräften entgegengewirkt ${ }^{173}$. Bereits 1358 hatte der Kaiser den Grafen von Genf aus der Gerichtsbarkeit der Reichsvikare exemiert ${ }^{174}$ und 1366 hat er den Vikariat des Amadeus insofern eingeschränkt, als er Genf aus diesem herausnahm ${ }^{175}$. Wenige Jahre später - während seines zweiten Italienzuges - hat Karl IV. die Unabhängigkeit Genfs von Savoyen noch einmal bekräftigt: Er erklärte den Grafen Amadeus IV. von Genf (13671369) zu seinem unmittelbaren Vasallen und die Grafschaft Genf zum Reichslehen ${ }^{176}$, erneuerte die seinem Vorgänger am 5. Mai 1358 gewährte Exemption aus der Gerichtsbarkeit der Reichsvikare ${ }^{177}$ und dessen Münzrecht ${ }^{178}$ und ernannte ihn zum Lateranensischen Pfalzgrafen ${ }^{179}$. Dabei ist für das Folgende von Interesse, daß auch ein jüngerer Bruder Amadeus' IV., nämlich Robert von Genf, der spätere Papst Clemens VII., mehrere Wochen lang am kaiserlichen Hof anwesend war. Auch ihm, der damals Bischof von Cambrai (1368-1371) und somit Mitglied der Reichskirche war, hat Karl IV. während des Zuges zwei Urkunden ausgestellt ${ }^{180}$. Zudem hat Robert die genannten Ur-

172 Über diese vgl. Pierre DuPARC, Le comté de Genève, $\mathrm{XI}^{\mathrm{e}}-\mathrm{XV}^{\mathrm{e}}$ siècles, Genf 1955 (Mémoires et documents publiès par la Société d'historie et d'archéologie de Genève, 39) (freundlicher Hinweis von Philippe Genequand).

${ }^{173}$ Zuvor war Karl IV. entsprechenden Bestrebungen König Johanns entgegengetreten. Vgl. B-H - ed. in: Const. XI, S. 287, n. 507; B-H - ed. in: Const. XI, S. 288, n. 508 von 1'355 Aug. 21. Vor allem dem Schutz der Grafschaft Genf galt auch die Emennung des Grafen Heinrich von Montbéliard (Mömpelgard) zum Reichsvikar in der Freigrafschaft Burgund. Vgl. B-H 6844, ed. in: Const. XI, S. 286, n. 506 von 1355 Aug. 21.

${ }^{174}$ B-H 2781 = 6953, ed. in: DUPARC, Comté (wie Anm. 172), S. 297, n. 1 von I358 Mai 5.

${ }^{175}$ B-H 4363, besser bei Ronald NEUMANN, Ekkehart ROTTER (Hg.), Die Zeit Karls IV. 1365-1371, Köln 2003 (Urkundenregesten zur Tätigkeit des deutschen Königs- und Hofgerichts bis 1451,9 ), S. 110, n. 143 von 1366 Sept. 13, und B-H $4501=$ NEUMANN, ROTTER (Hg.), Zeit Karls IV., S. 157, n. 195 von 1367 Febr. 25. Vgl. auch B-H $4462=$ NEUMANN, ROTTER (Hg.), Zeit Karls IV., S. 148, n. 183 von 1366 Dez. 30. Jedoch ist die Behauptung von NeuMANN, ROTTER (Hg.), Zeit Karls IV., S. 158, Amadeus VI. von Savoyen wäre 1367 verstorben, falsch. Offenbar haben sie ihn mit Amadeus III. von Genf verwechselt, der in der Tat in diesem Jahr gestorben ist. Vgl. Jean-Yves MARIOTTE, in: Lexikon des Mittelalters Bd. 1, München 1980, Sp. 499. Über den Konflikt zwischen Genf und Savoyen vgl. auch GaLlAND, Les papes (wie Anm. 9), S. 175f.

${ }^{176}$ B-H 7277 von 1369 Febr. 6, ed. bei Eduard WINKELMANN (Hg.), Acta imperii inedita saeculi XIII et XIV, Bd. 2, Innsbruck 1885 (ND Aalen 1964), S. 591, n. 919.

${ }^{177}$ B-H $4710=7297$ von 1369 Febr. 10, ed. bei WINKELMANN, Acta, Bd. 2 (wie Anm. 176), S. 595, n. 921 .

${ }^{178}$ B-H 7280 von 1369 Febr. 10, ed. bei WinkELManN, Acta, Bd. 2 (wie Anm. 176), S. 593 , n. 920. Erneuert worden ist die ältere Urkunde von 1355 Aug. 21 : B-H $6843=$ Const. XI, S. 289 , n. 509 (nur. Reg.).

${ }^{179}$ BH 7281 von 1369 Febr. 22, ed. bei WinkelmanN, Acta, Bd. 2 (wie Anm. 176), S. 596, n. 922 .

${ }^{180}$ B-H - von 1369 Juli 7; zit. bei Lotte HÜTTEBRÄUKER, Cambrai, Deutschland und Frankreich 1308-1378. Untersuchungen zum Kampf um die deutsche Westgrenze, in: Zeitschrift der Savigny-Stiftung für Rechtsgeschichte. Germanistische Abteilung 59 (1939), S. 88-135, 
kunden für seinen Bruder Amadeus und noch andere Urkunden des Kaisers als Zeuge unterschrieben ${ }^{181}$. Im Gefolge seines Bruders bzw. dem des Kaisers konnte Robert demnach Erfahrungen mit den italienischen Verhältnissen sammeln.

Mit dem Regierungsantritt Peters von Genf (1370-1392), eines jüngeren Bruders Amadeus' IV., verbesserte sich das Verhältnis zwischen Genf und Savoyen wieder; der neue Graf war insbesondere als Vermittler zwischen Amadeus VI. und Papst Gregor XI. tätig ${ }^{182}$, was ihm um so leichter gefallen sein dürfte, als sein noch jüngerer Bruder Robert von Genf (seit 1371) Kardinal dieses Papstes war $^{183}$. Das Vertrauensverhältnis zwischen Amadeus VI. und Karl IV. ist durch den Konflikt zwischen Genf und Savoyen jedenfalls nicht nachhaltig gestört worden, 1372 sollte der Kaiser den Grafen von Savoyen gar zum Reichsvikar in Italien ernennen ${ }^{184}$.

Etwa gleichzeitig, im Jahre 1372, gelang es Gregor XI., die alte Feindschaft zwischen Savoyen und Montferrat zu beenden und beide zu einem Bündnis gegen die Mailänder Visconti zu vereinen ${ }^{185}$. Eine Schlüsselrolle spielte hier eine Person, die uns noch mehrfach begegnen wird, Herzog Otto von Braunschweig-Grubenhagen ${ }^{186}$. Dieser, einer der zahlreichen deutschen Soldritter ${ }^{187}$, der erst in den Diensten König Johanns II. von Frankreich, dann in denen des Markgrafen Johann II. von Montferrat - und damit indirekt in denen Kaiser Karls IV. - gestanden hatte ${ }^{188}$, erwies sich als fähiger Exekutor päpstlicher Pläne. Markgraf Johann hatte ihn testamentarisch zum Vormund seiner unmündigen Söhne eingesetzt, als solcher schloß Otto nach dessen Tod - unter

hier S. 130, Anm. 3. Vom gleichen Tag ist noch eine weitere Kaiserurkunde für einen Empfänger aus Genf belegt (B-H - Reg. WIDDER, Itinerar [wie Anm. 124], S. 468).

${ }^{181}$ Es reicht ein Blick in die "Regesta imperiik. Vgl. auch Wilhelm KLARE, Die Wahl Wenzels von Luxemburg zum Römischen König 1376, Münster 1990 (Geschichte, Bd. 5), S. 191. ${ }^{182} \mathrm{Vgl}$. GallaNd, Les papes (wie Anm. 9), S. 306.

${ }^{183}$ Über die verwandtschaftlichen Beziehungen der Genfer Grafen vgl. die detaillierten Angaben bei Roger Ch. LOGOZ, Clément VII (Robert de Genève): sa chancellerie et le clergé romand au début du grand schisme (1387-1394), Lausanne 1974, S. 3ff.

${ }^{184}$ B-H 5155, ed. bei HECKMANN, Reichsvikariat (wie Anm. 24), S. 83, n. 1 zu (1372 vor Dez. 23; hier liegt wohl ein Druckfehler vor, die Urkunde ist zusammen mit dem folgenden Stück anzusetzen), n. 5156 von 1372 Nov. 23. Zum historischen Kontext vgl. ibid., S. 78f;; eine inhaltliche Analyse bietet Ferdinand SEIBT, Zum Reichsvikariat für den Dauphin 1378, in: Zeitschrift für Historische Forschung 8 (1981), S. 129-158, hier S. 152ff.

${ }_{185} \mathrm{Vgl}$. zuletzt GALlAND, Les papes (wie Anm. 9), S. 282ff.

${ }^{186}$ Vgl. Werner PARAVICINI, Fürstliche Ritterschaft: Otto von Braunschweig-Grubenhagen, in: Braunschweigische Wissenschaftliche Gesellschaft, Jahrbuch 1994, S. 97-138.

${ }^{187}$ Über diese vgl. zuletzt Stephan SELzER, Deutsche Söldner im Italien des Trecento, Tübingen 2001 (Bibliothek des Deutschen Historischen Instituts in Rom, 98); FOWLER, Medieval Mercenaries (wie Anm. 70) (beide mit reicher Bibliographie).

${ }^{188}$ Vgl. B-H 4099 von 1364 Dez. 15. 
päpstlicher Vermittlung ${ }^{189}$ - am 17. Juni 1372 Frieden mit Amadeus VI. und beteiligte sich am 7. Juli 1372 an dem Bündnis gegen Mailand ${ }^{190}$. Auch Karls IV. Verleihung des Vikariats für Italien an Amadeus VI. ${ }^{191}$ sowie dessen Belehnung mit der Markgrafschaft Saluzzo ${ }^{192}$ und die vorangegangene Ächtung und Absetzung Bernarbò und Galeazzo Viscontis als Reichsvikare ${ }^{193}$ ist in diesem Zusammenhang zu sehen. Weiterhin hat Karl IV. die Stadt Bobbio, welche bisher die Visconti als Reichsvikare beherrscht hatten, dem Bruder Gregors XI., dem Markgrafen von Beaufort ${ }^{194}$, verliehen. Außerdem hat der Kaiser auch die (noch minderjährigen) Söhne des Markgrafen Johanns II. von Montferrat zu Reichsvikaren ernannt. Mit der Wahrnehmung dieses Amtes hat er Otto von Braunschweig betraut ${ }^{195}$; dieser hatte also die Position eines stellvertretenden kaiserlichen Reichsvikars inne. Schließlich war auch Frankreich an diesem Bündnis nicht unbeteiligt: Kein Geringerer als Enguerran VII. de Coucy, Abkömmling einer der ältesten französischen Adelsfamilien und Schwiegersohn des englischen Königs, der aber auch verwandtschaftliche Beziehungen nach Deutschland und Savoyen hatte ${ }^{196}$, trat zeitweise in päpstliche Dienste $^{197}$. Diesem Bündnis gelang es, einige Erfolge gegen die Visconti zu

${ }^{189} \mathrm{Vgl}$. Guillaume MoLLAT $(\mathrm{Hg}$.), Lettres secrètes et curiales du pape Grégoire XI (13701378) intéressant les pays autres que la France, 3 Fasz., Paris 1962-1965, n. 775 von 1372 Juni 4; n. 1363, 1363bis von 1373 Jan. 2, n. 2191 von 1373 Sept. 19, n. 2984 von 1374 Nov. 21.

${ }_{190}$ Vgl. Cox, Green Count (wie Anm. 32), S. 264ff.; ParaviCINI, Ritterschaft (wie Anm. 186), S. 111; Galland, Les papes (wie Anm. 9), S. 282ff., bes. S. 284, mit Anm. 322. 191 Wie Anm. 184. Vgl. auch die beiden Briefe Gregors XI. an Karl IV., ed. bei MOLLAT (Hg.), Lettres (wie Anm. 189), n. 918, 919 von 1372 Aug. 1. Amadeus' Vikariatsbezirk ist 1375 und 1376 geringfügig eingeschränkt worden, aber so, daß die Stoßrichtung gegen die Visconti noch deutlicher wurde. Vgl. HECKMANN, Reichsvikariat (wie Anm. 24), S. 79.

${ }^{192}$ B-H 7425 von 1375 Nov. 11.

193 B-H 5115, 5116, ed. bei ZIMMERMANN (Hg.), Acta (wie Anm. 51), S. 141, n. 70 von 1372 Aug. 3.

194 B-H 7505 zu ca. 1372; vgl. auch StEINHERZ, Beziehungen (wie Anm. 152), Teil 2, S. 600, 615ff. Demnach ist die Urkunde zu 1372 Aug. 2 zu datieren und gehört mit der Urkunde zusammen, in welcher der Papst bevollmächtigt wird, zehn Jahre lang über die Länder der Visconti zu verfügen; vgl. Anm. 199.

${ }^{195}$ B-H 5439 = HECKMANN, Stellvertreter (wie Anm. 47), Bd. 2, S. 831, n. 46 von 1374 Dez. 6.

${ }^{196}$ Seine Mutter Katharina war die Tochter Herzog Leopolds I. von Österreich und die Enkelin Amadeus' V., des Grafen von Savoyen. Vgl. Barbara TuCHMANN, Der ferne Spiegel, Das dramatische 14. Jahrhundert, Düsseldorf 1980, S. 54.

${ }^{197} \mathrm{Zu}$ Coucys Biographie ibid., bes. S. 234ff. Vgl. auch GaLLAND, Les papes (wie Anm. 9), S. 285. Die päpstlichen Briefe an Coucy sind ediert von Henri LACAILLE, Enguerrand de Coucy au service de Grégoire XI, 1372-1374, in: Annuaire-bulletin de la Société de l'histoire de France 32 (1895), S. 185-201. Es sei nur am Rande darauf hingewiesen, daß der gleiche Enguerrand de Coucy wenig später, 1375/1376, mit Billigung des kaiserlichen Reichsvikars Wenzel von Luxemburg-Brabant am Oberrhein, also auf Reichsgebiet, einen Feldzug gegen seine Verwandten von mütterlicher Seite, die Herzöge Leopold III. und Albrecht von Österreich, gefiihrt hat, da diese ihm eine von ihm beanspruchte Erbschaft vor- 
erzielen ${ }^{198}$; zudem bestand jetzt in Norditalien ein starker Block, welcher dem Papst als Rückendeckung bei einer Rückkehr nach Rom dienen konnte.

Zu Beginn des Krieges hatte Karl IV. dem Papst die Vollmacht erteilt, zehn Jahre lang die Gebiete, welche die Visconti als Reichsvikare innegehabt hatten, an einen Kandidaten seiner (des Papstes) Wahl zu vergeben ${ }^{199}$. Drei Jahre später, als der endgültige Erfolg bevorzustehen schien, hat Gregor in der Tat einen neuen Herrscher für die Lombardei ins Auge gefaßt, und zwar keinen anderen als Ludwig von Anjou. In einem förmlichen Vertrag zwischen Ludwig und Gregor, geschlossen in der päpstlichen Sommerresidenz in Villeneuve am 29. August 1375, wird Ludwig als künftiger Herrscher der Lombardei vorgesehen, und zwar mit dem Titel eines Königs, den ihm wiederum der Kaiser verleihen sollte, dessen Zustimmung man also sicher $z u$ sein glaubte ${ }^{200}$. Unter den Zeugen des Vertrages findet man den Kardinal Robert von Genf, was man wohl als Anzeichen dafür werten darf, daß dieser Ludwigs Ambitionen aufgeschlossen gegenüberstand. Das wird sich noch als wichtig erweisen.

Auch mit Otto von Braunschweig zeigte sich Gregor XI. hoch zufrieden: Am 28. Dezember 1375 heiratete Otto, der stellvertretende kaiserliche Reichsvikar, in Avignon in Anwesenheit des Papstes die Königin Johanna von Neapel und wurde ihr vierter und letzter Ehemann ${ }^{201}$. Es war dies eine rein politi-

enthielten. Vgl. dazu B-H Reichssachen 613 von (1375) Sept. 24, ed. bei Hans WITTE, Georg WOLFRAM (Hg.), Urkundenbuch der Stadt Straßburg, Bd. 5: Politische Urkunden von 1332 bis 1380, Straßburg 1896, S. 890, n. 1218; vgl. auch Coucys ibid., S. 887, n. 1213, edierten Fehdebrief von (1375) Aug. 31 (in deutscher Sprache!). Weitere Quellen nennt MoLINIER, Sources (wie Anm. 91), Bd. 4, S. 80f., n. 3408-3411. Vgl. TuCHMANN, Spiegel (wie Anm. 196), S. 250ff.; Walter SCHAUFELBERGER, Guglerkrieg, in: Handbuch der Schweizer Geschichte, Bd. 1, Zürich 1972, S. 255f.

${ }^{198} \mathrm{Zu}$ den Hintergründen GaLlaND, Les papes (wie Anm. 9), S. $286 \mathrm{ff}$.

${ }^{199}$ B-H 5114 von 1372 Aug. 2 nach der Quarta vita Gregorii XI, in: BaluZE, Mollat (Hg.), Vitae paparum (wie Anm. 84), Bd. 1, S. 463-465, hier S. 464. Dort heißt es: [Karolus IV] dedit potestatem eidem Gregorio pape per suas litteras suo imperiali sigillo munitas [...] terris, possessionibus [...] in vicariatum suo imperiali nomine aliis concedendi usque ad $X$ annos extunc in antea. Es ist also der Papst selbst, der hier die Länder der Visconti mit der Vollmacht eines Reichsvikars vergibt. Über die Quarta vita vgl. Guillaume MOLLAT, Étude critique sur les Vitae paparum Avenionensium d'Étienne Baluze, Paris 1917, S. 82ff.

${ }^{200}$ C'est le traictié eu entre nostre Sainct Pere le Pape et Monsieur le duc d'Anjou sur le faict de la conqueste de Lombardie. - Premierement plaict à nostre Sainct Pere que l'Empereur donne audit Monsieur d'Anjou, pour luy, ses hoirs et successeurs, tiltre de roy du dit pays, et nostre dit Sainct Pere le procurera à son pouvoir envers le dit Empereur, et en iceluy cas que ledit Monsieur d'Anjou entreprendra ladite conqueste du pays de Lombardie comme sien, nostre Sainct Pere se deschargera pleinement et du tout de la guerre qu'il faict aux tyrans de Melan [...]; DeLACHENAL, Histoire (wie Anm. 8), Bd. 5, S. 43, Anm. 1, Ausführlich zit. ibid., Anm. 2-3, S. 44, Anm. 1-3.

${ }^{201} \mathrm{Vgl}$. Heinrich V. SAuERLAND, Drei Urkunden zur Geschichte der Heirat des Herzogs Otto von Braunschweig und der Königin Johanna von Neapel, in: Quellen und Forschungen aus Italienischen Archiven und Bibliotheken 8 (1905), S. 206-216, dort S. 209, n. 2, der Ehevertrag; dazu die Urkunden Gregors XI. bei Léon MIROT, H. JASSEMIN (Hg.), Lettres 
sche Ehe, die sich vor allem gegen die Ansprüche Karls von Durazzo richtete. Wie aber fügte sich Otto von Braunschweig in die französischen Ambitionen, insbesondere die Ludwigs von Anjou, ein? Hingewiesen sei darauf, daß ein eigenartiges - fast verwandtschaftliches - Verhältnis zwischen beiden bestand. Otto von Braunschweig war nämlich in erster Ehe von 1353 bis 1369 mit Yolande de Vilaragut verheiratet gewesen; sie war die Witwe des am 25. August 1349 gefallenen Königs Jakob III. von Mallorca ${ }^{202}$. Wir erinnern uns, daß Johanna ihrerseits in dritter Ehe mit dem Titularkönig Jakob IV. von Mallorca verheiratet gewesen war und daß Ludwig von Anjou über die Schwester dieses Jakob IV. Ansprüche auf Neapel geltend machen konnte. Auf den ersten Blick mag Otto somit als Rivale Ludwigs und als Gegner der französischen Italienpläne erscheinen, indes ist zu bedenken, daß wegen Ottos und Johannas hohem Alter kein Nachwuchs aus ihrer Ehe mehr zu erwarten war, die Nachfolgefrage in Neapel also weiterhin offen war. Karl V. von Frankreich jedenfalls hielt Otto von Braunschweig für einen Förderer der französischen Italienpläne. In einer königlichen Verhandlungsinstruktion für französische Gesandte aus dem Jahre 1376, die mit Papst Gregor über die an anderer Stelle noch genauer zu erörternden Pläne für eine französische Nachfolge im Reich von Neapel und in der Provence verhandeln sollten ${ }^{203}$, wird ausdrücklich Otto von Braunschweig als ein Mann erwähnt, von dem man sich Unterstützung in dieser Sache erwarten könne ${ }^{204}$.

Aber verfolgen wir zunächst den weiteren Ablauf der Ereignisse. 1375 lebte der Krieg wieder auf; unter der Führung von Florenz rebellierten einige Kommunen des Kirchenstaates ${ }^{205}$. Dadurch ließ sich jedoch Gregor XI. von seinen Plänen nicht abbringen: Im September 1376 brach er von Avignon auf; am 13. Januar 1377 hielt er seinen feierlichen Einzug in Rom. Zuvor hatte er dem Kardinal Robert von Genf die Legation in Italien und die Führung der päpstlichen Truppen anvertraut. Dazu dürften den Kardinal seine italienischen Erfahrungen und auch seine persönliche Bekanntschaft mit Karl IV. qualifiziert haben.

Der seinerzeit in Avignon besprochene Plan wurde nun ausgeführt. Unter der Führung Roberts von Genf und des berüchtigten Söldnerführers John Hawkwood überschritt ein päpstliches Söldnerheer die Alpen und drang nach Italien vor. Galeazzo Visconti ging auf die Seite des Papstes über; mit ihm

secrètes et curiales du pape Grégorie XI (1370-1378) relatives à la France, 5 Fasz., Paris 1935-1957, n. 3872-3875 von 1375 Dez. 26, n. 3876 von 1375 Dez. 27; vgl. LÉONARD, Les Angevins (wie Anm. 49), S. 449f;; PARAVICINI, Ritterschaft (wie Anm. 186), S. $114 \mathrm{ff}$.

${ }^{202} \mathrm{Vgl}$. ibid, S. 107.

${ }^{203}$ Siehe unten mit Anm. 223.

${ }^{204}$ Ed. bei Eugène JARRY, La vie politique de Louis de France, duc d'Orléans, 1372-1407, Paris, Orléans 1889, S. 385, n. 5 von 1376 Mai 30, hier S. 388f.

${ }^{205}$ Vgl. MOLlat, Papes (wie Anm. 171), S. 264ff.; als Kontrast TuChManN, Spiegel (wie Anm. 196), S. 289ff. 
konnte Robert von Genf im Namen des päpstlichen Bündnisses schon im Juli 1376 Frieden schließen ${ }^{206}$. Der Feldzug gipfelte am 3. Februar 1377 in dem bekannten Massaker an der Bevölkerung von Cesena ${ }^{207}$. Insgesamt waren die päpstlichen Truppen erfolgreich; auch Florenz mußte schließlich um Frieden ersuchen.

Im Frühjahr 1378 begann ein großer Friedenskongreß in Sarzana, auf dem fast alle italienischen Mächte vertreten waren. Dort sollte unter päpstlicher Vermittlung ein allgemeiner Friede geschlossen werden ${ }^{208}$. In diesem Zusammenhang ist bemerkenswert, daß auch eine französische Gesandtschaft an dieser Konferenz teilnahm ${ }^{209}$. Den Vorsitz hatte der Kardinal Jean de la Grange, der Kardinal von Amiens; er vertrat im Auftrag Gregors XI. die päpstlichen Interessen ${ }^{210}$. Wegen seiner Abwesenheit von Rom hat er an der Wahl Urbans VI. nicht teilnehmen können; er gehörte dann zu seinen Hauptwidersachern und war einer der Hauptbetreiber des Schismas ${ }^{211}$. Da er vor seinem Kardinalat zum conseil Karls V. gehört hatte, ist man versucht, hier ein französisches Einwirken zu vermuten, zumal - wie erwähnt - sogar eine französische Gesandtschaft in Sarzana anwesend war, hier also eine Absprache hätte stattfinden können. Die Möglichkeit will ich nicht ausschließen, immerhin aber sei darauf hingewiesen, daß auf die Kunde von Gregors Tod die dort versammelten Gesandtschaften beschlossen haben, auf die Römer einzuwirken, daß diese einen italienischen Papst wählten. Man erwog gar, zu diesem Zweck Truppen nach Rom zu entsenden ${ }^{212}$. Nach allem, was wir wissen, haben auch die französischen Gesandten keine Einwände dagegen gehabt.

${ }^{206}$ B-H Reichssachen 626 von 1376 Juli 19.

${ }^{207}$ Welchen Anteil Robert daran hatte, ist nach wie vor umstritten. Vgl. die abgewogene Stellungnahme von Marc DYKMANS, La conscience de Clément VII, in: Genèse et débuts (wie Anm. 136), S. 599-606.

${ }^{208}$ Vgl. Walter BRANDMÜLLER, Zur Frage nach der Gültigkeit der Wahl Urbans VI. - Quellen und Quellenkritik, in: Annuarium Historiae Conciliorum 6 (1974), S. 78-120, hier S. $78 \mathrm{ff}$.

${ }^{209} \mathrm{Vgl}$. den Bericht des florentischen Bevollmächtigten Coluccio Salutati an König Ludwig I. von Ungam, ed. ibid., S. 114, n. 21 von 1378 Mai 6. Vgl. auch ibid., S. 83. Die Bestallungsurkunden der französischen Gesandtschaft bei Léopold DELISLE (Hg.), Mandements et actes divers de Charles V (1364-1380), Paris 1874, S. 806-808, n. 1626-1630 von 1377 Febr. 4.

${ }^{210} \mathrm{Vgl}$. Delachenal, Histoire (wie Anm. 8), Bd. 5, S. 140f.

${ }^{211}$ Vgl. Robert-Henri BAUTIER, Aspects politiques du Grand Schisme, in: Genèse et débuts (wie Anm. 136), S. 457-481, hier S. 464f.

${ }_{212}$ Vgl. BRANDMÜLLER, Frage (wie Anm. 208), S. 83f. Brandmüller vermutet, sie habe für die Rückkehr des Papsttums nach Avignon wirken sollen, einen Beleg dafür gibt er nicht. 


\section{Die Reise nach Paris}

Im Dezember 1377 - nachdem also die Kunde von der Rückkehr und erfolgreichen Installation des neuen Papstes nördlich der Alpen bekanntgeworden war - brach auch Kaiser Karl IV. zu einer Reise auf, und zwar nach Paris, um seinen französischen Kollegen und Neffen zu besuchen ${ }^{213}$. Wichtigstes Ergebnis der Reise war die schon erwähnte Erneuerung des Reichsvikariats in der Dauphiné ' $^{214}$ und die Verleihung des Reichsvikariats im Arelat an den französischen Thronfolger ${ }^{215}$. Zuvor hatte der Kaiser diesen, der erst zehn Jahre alt war, für mündig erklärt ${ }^{216}$. $\mathrm{Da}$ Rom- und Parisreise wie auch die Vikariatsverleihung im Zusammenhang $\mathrm{zu}$ sehen sind, hat man schon lange erkannt: Thomas etwa deutet die Vikariatsverleihung als Gegenleistung des Kaisers für die französische Billigung der Rückkehr Gregors nach Rom ${ }^{217}$. Das setzt aber voraus, daß diese Rückkehr gegen den Willen des französischen Hofes erfolgt ist $^{218}$. Ganz im Gegenteil glaubten jetzt offenbar beide Monarchen, den schon in Avignon gefaßten Plan endlich ausführen zu können. Einer der Gründe dafür, daß die lange angestrebte Vikariatsverleihung zu diesem Zeitpunkt statt-

${ }^{213}$ B-H 5857aff., 7459a; zu Karls IV. Parisreise vgl. DelaCHENAL, Histoire (wie Anm. 8), Bd. 5, S. $61 \mathrm{ff}$; NEUREITHER, Bild (wie Anm. 27), S. 112ff.; SEIBT, Karl IV. (wie Anm. 2), S. 351ff.; THOMAS, Frankreich (wie Anm. 2), S. 85ff.; AuTRAND, Charles V (wie Anm. 17), S. 779ff.; DiEs., Mémoire et cérémonial: la visite de l'Empereur à Paris d'après les Grandes Chroniques de France et Christine Pizan, in: Liliane DulaC, Bernard RIBEMONT (Hg.), Une femme de Lettres au Moyen Âge. Études autour de Christine de Pizan, Orléans 1995 (Médievalia, 16), S. 91-103 (freundlicher Hinweis von Julie Chandler); Heinz THOMAS, Ein zeitgenössisches Memorandum zum Staatsbesuch Kaiser Karls IV. in Paris, in: Wolfgang HAUbRICHS, Wolfgang LAUFER, Reinhard SCHNEIDER (Hg.), Zwischen Saar und Mosel. Festschrift für Hans-Walter Herrmann zum 65. Geburtstag, Saarbrücken 1995 (Veröffentlichungen der Kommission für Saarländische Landesgeschichte und Volksforschung, 24), S. 99-119; zuletzt HECKMANN, Stellvertreter (wie Anm. 47), Bd. 1, S. 225ff. Vgl. auch den Beitrag von Gerald Schwedler in diesem Band.

${ }^{214}$ B-H 5861 von 1378 Jan. 7.

${ }^{215}$ B-H 5862, ed. bei HeCKMANN, Reichsvikariat (wie Anm. 24), S. 86, n. 2 von 1378 Jan. 7; vgl. auch B-H 5863, ed. bei HECKMANN, Reichsvikariat (wie Anm. 24), S. 90, n. 3 von 1378 Jan. 7 (nicht B-H 5861, wie in der Vorbemerkung von Heckmanns Edition angegeben ist). Zum historischen Kontext vgl. DelachenAl, Histoire (wie Anm. 8), Bd. 5, S. 117ff. Eine inhaltliche Analyse dieser und der in Anm. 214 genannten Vikariatsurkunde bietet SEIBT, Reichsvikariat (wie Anm. 184), S. 152ff. Für die Bedeutung, die Karl V. diesen Urkunden beimaß, ist aufschlußreich, $\mathrm{da} \beta$ er sie in eine Aktensammlung kopieren ließ, in der er die wichtigsten Unterlagen für seine Außenpolitik hat zusammenstellen lassen. Vgl. André ARTONNE, Le recueil des traités de la France composé par ordre de Charles V, in: Recueil de travaux offert à M. Clovis Brunel, Bd. 1, Paris 1955 (Mémoires et documents, 12), S. 53-73 (freundlicher Hinweis von Julie Chandler).

${ }^{216}$ B-H 5858 von 1378 Jan. 5. Zur Überlieferung vgl. HECKMANN, Reichsvikariat (wie Anm. 24), S. 65, Anm. 5.

${ }^{217}$ THOMAS, Frankreich (wie Anm. 2), S. $88 \mathrm{ff}$.

${ }^{218}$ Vgl. auch den zweiten Teil dieser Studie; vgl. Anm. 1. 
fand, dürfte darin bestanden haben, daß man auf diese Weise Gregor XI. eine etwaige Rückkehr nach Avignon erschweren wollte. Er wäre in ein Venaissin zurückgekehrt, das auf allen Seiten von französisch beherrschtem Territorium umgeben war. Der Wortlaut des kaiserlichen Vikariatsprivilegs bestätigt dies $^{219}$. In ihm ernennt der Kaiser seinen Großneffen Karl von Vienne (den späteren König Karl VI.) zum Reichsvikar auf Lebenszeit für das gesamte Arelat; ausdrücklich genannt werden die Grafschaften Provence, Forcalquier und Piemont - d.h. die Besitzungen der Königin Johanna -, sowie die Grafschaft Burgund (d.h. die Freigrafschaft), während die Grafschaft Savoyen ebenso ausdrücklich ausgenommen wird. Nicht erwähnt wird das Venaissin. Gleichzeitig hatte Karl IV. den Reichsvikariat des Thronfolgers in der Dauphiné erneuert ${ }^{220}$. Wie ein Blick auf die Landkarte lehrt, war nunmehr die Grafschaft Venaissin auf allen Seiten von französisch beherrschtem Territorium umschlossen; im Westen von Frankreich, im Norden von der Dauphiné, im Osten und Süden von der Provence. Auch die antineapolitanische Stoßrichtung ist offensichtlich: gerade diejenigen Gebiete, welche Johanna von Neapel beherrschte, werden explizit dem Reichsvikariat des Dauphins unterworfen.

$\mathrm{Da} B$ ein Zusammenhang zwischen dem kaiserlichen Parisbesuch, der Vikariatsverleihung und den Ambitionen Ludwigs von Anjou bestand, ist schon von einer gutunterrichteten Quelle bemerkt worden. In der circa 1400 entstandenen Metzer Chronik des Jaique Dex wird ausdrücklich vermerkt, daß nach Karls IV. Besuch in Paris »[...] envoiont le dit roy [Karl V.] et son consceil le duc Lowy d'Angois pour conquester le reaume de Naple pour lui estre en perdiction ¿ $^{221}$.

Als nächster hätte nun Ludwig von Anjou aktiv werden müssen, der mittlerweile dadurch, daß er - wie erwähnt - die Rechte Jakobs IV. erworben hatte, seinen Anspruch auf die neapolitanische Krone untermauert hatte. An einem unmittelbaren Eingreifen ist er offenbar zunächst dadurch gehindert worden, daß er in diesen Jahren mit Feldzügen gegen die Engländer und der Bekämpfung von Aufständen in Südfrankreich beschäftigt war. Zudem waren dort wieder marodierende Söldner aktiv ${ }^{222}$.

Wir sind den Ereignissen jedoch etwas vorausgeeilt. Zunächst muß dargelegt werden, daß - wie schon zuvor bei der Arlesreise des Kaisers - auch bei seiner Parisreise die kaiserliche Westpolitik aufs engste mit der Ostpolitik ver-

${ }^{219}$ Wie Anm. 215.

${ }^{220}$ B-H 5861 von 1378 Jan. 7. Vgl. auch B-H 5859, 5860 von 1378 Jan. 6.

${ }^{221}$ Zit. nach der Metzer Chronik des Jaique Dex (Jacques d'Esch) über die Kaiser und Könige aus dem Luxemburger Hause, hg. von Georg WoLFRAM, Metz 1906 (Quellen zur lothringischen Geschichte, 4), S. 313 (cap. XLII). Über den Autor vgl. Wolframs Einleitung, S. LXXIIff;; NeUREITHER, Bild (wie Anm. 27), S. 74ff. Die Stelle wird angeführt von THOMAS, Memorandum (wie Anm. 213), S. 114, von dessen Deutung ich jedoch abweiche.

${ }^{222}$ Vgl. Delachenal, Histoire (wie Anm. 8), Bd. 5, S. 285ff.; WeISS, Versorgung (wie Anm. 38), S. 334. 
knüpft war. Wie erwähnt, hatte König Ludwig von Ungarn seit dem Jahre 1370 zwar immer noch keine Söhne, wohl aber drei Töchter bekommen; somit war absehbar, daß die von ihm regierten Länder Ungarn und - seit 1370 in Personalunion - auch Polen nach seinem Tod an seine Töchter bzw. Schwiegersöhne übergehen würden. Gleiches galt für Ludwigs Erbansprüche auf das Reich von Neapel, zu dem - wie erwähnt - auch die Provence gehörte.

In den Jahren 1372 bis 1374 ist zwischen König Karl V. von Frankreich und König Ludwig I. von Ungarn ein neues Ehebündnis ausgehandelt worden. Der zweitälteste und damals vierjährige Sohn König Karls V., Ludwig (*1370), der spätere Herzog von Orléans, sollte mit der ältesten Tochter König Ludwigs von Ungarn, Katharina $\left({ }^{*} 1370\right)$, verheiratet werden ${ }^{223}$. Im Unterschied zum ersten Fall blieb es nicht bei unverbindlichen Planungen; es ist vielmehr ein förmlicher Vertrag über die Verlobung beider geschlossen worden ${ }^{224}$. Zwar ist die Ehe dann doch nicht zustandegekommen, aber nicht etwa, weil es den Beteiligten am guten Willen gefehlt hätte, sondern lediglich deshalb, weil Katharina schon 1378 verstarb. Dies war aber nicht absehbar; solange sie lebte, hatte die französische Ostpolitik die Perspektive, daß in näherer Zukunft Prinz Ludwig Ansprüche auf König Ludwigs Erbe würde geltend machen können.

Wir müssen die Verhandlungen noch etwas genauer verfolgen, da sie Aufschluß über die politischen Ziele Karls V. in Osteuropa geben. Dem Ehevertrag kann man entnehmen, daß sein Interesse weniger auf Ungarn und Polen als vielmehr auf König Ludwigs Rechte auf Neapel und die Provence gerichtet war. Im Vertrag war festgelegt worden, daß die künftige Gemahlin Ludwigs von Frankreich - bereits hier ist in Betracht gezogen worden, eventuell eine von Katharinas Schwestern zu ehelichen - als Mitgift das Reich von Neapel und die Provence erhalten sollte (d.h. die Ansprüche darauf) ${ }^{225}$.

In weiteren Verhandlungen haben dann die französischen Unterhändler folgendes verlangt: Gesetzt den Fall, das Königreich Neapel werde durch den Prinzen Karl (gemeint ist offenbar Karl von Durazzo) zurückerobert, die Ehe zwischen Prinz Ludwig und Katharina wäre schon vollzogen und diese würde

${ }^{223}$ Vgl. DELAChENAL, Histoire (wie Anm. 8), Bd. 4, S. 544ff;; Eugène JARRY, La vie (wie Anm. 204), S. 4ff.; Noël VALOIS, Le projet de mariage entre Louis de France et Catherine de Hongrie et le voyage de l'empereur Charles IV à Paris (janvier 1378), in: Annuaire-bulletin de la Société de l'histoire de France 30 (1893), S. 209-223; LÉONARD, Les Angevins (wie Anm. 49), S. 444ff.; THOMAS, Frankreich (wie Anm. 2), S. 86.

${ }^{224}$ Der Vertrag ist ediert bei JARRY, La vie (wie Anm. 204), S. 369, n. 1 von 1374 Aug. 10; zit. bei Delachenal, Histoire (wie Anm. 8), Bd. 4, S. 546, Anm. 3. Darin ist als Insert enthalten die Instruktion König Ludwigs von Ungarn für die ungarische Gesandtschaft von 1374 Apr. 10. Weitere Quellen nennt VELDTRUP, Eherecht (wie Anm. 15), S. 402f., mit Anm. 2492.

${ }_{225}^{22 . . .]}$ regna, terras et dominia Sicilie, Neapolitanum, Pulie, Calabrie, cum omnibus terris, appendentibus et pertinentibus ad ipsa, et principatum Sallerne, comitatumque Provincie, Folcalcherii et Pedemontis et honorem Sancti Angeli [...], so der Ehevertrag (wie vorige Anm.). 
ohne Nachkommen sterben, dann solle Ludwig als König von Neapel abdanken, wenn nicht - hier wird der Text etwas kryptisch - credit prefatus dominus rex Francie quod carissimus predictus frater suus [Ludwig von Anjou] vellet pati tantam indecenciam in personam filii sui evenire: placeat sibi, in illo eventu, si (quod Deus avertat) contingeret, honori prefati filii sui providere ${ }^{226}$. Man darf diese Passage wohl so verstehen, daß Ludwig von Anjou dann als Verteidiger und Sachwalter der Rechte seines Neffen, des Prinzen Ludwig, auftreten sollte, daß Ludwig von Anjou also eine bedeutende Rolle bei der Besitzergreifung und Sicherung des Königreichs Neapel durch die Valois zugedacht war.

Im Verlauf der Verhandlungen hat König Ludwig dann der französischen Forderung zugestimmt, daß, wenn Katharina nach vollzogener Ehe ohne Kinder aus dieser Ehe sterben sollte, Prinz Ludwig gleichwohl die Provence erhalten solle, das Reich von Neapel dagegen (bzw. die Ansprüche auf dieses) würde an Ungarn zurückfallen ${ }^{227}$. In diese Verhandlungen ist auch der päpstliche Hof einbezogen worden ${ }^{228}$; gleichsam im Dreieck reisten die ungarischen und französischen Gesandten zwischen Buda, Paris und Avignon hin und her; selbst zur Königin Johanna ist eine französische Delegation vorgedrungen ${ }^{229}$. Ohne Zustimmung des Papstes, des Lehnsherm des Reiches von Neapel, waren alle Absprachen über die Nachfolge der Königin Johanna wertlos. Zudem hatte Ludwig von Ungarn seinerzeit die Unvorsichtigkeit begangen, dem Papst gegenüber auf seine Rechte auf das Reich von Neapel zu verzichten ${ }^{230}$. Es war Ludwig von Anjou, den sein Bruder Karl V. damit beauftragte, am Hof in Avignon die entsprechenden Nachforschungen anzustellen ${ }^{231}$. Die französische und ungarische Seite waren sich einig, vom Papst zu verlangen, er möge diesen Widerruf annullieren. Von der Königin Johanna verlangten sie, daß sie Ludwig von Ungarn bzw. dessen Tochter Katharina und ihren Verlobten Prinz Ludwig als Nachfolger anerkenne.

Von 1372 bis 1375 , also parallel zu diesen Verhandlungen über ein französisch-ungarisches Verlöbnis, haben ganz ähnliche zwischen Kaiser Karl IV. und König Ludwig von Ungarn stattgefunden. Am 14. April 1375 vereinbarten

${ }^{226}$ Französische Verhandlungsinstruktion von 1375 Dez. 11, ed. bei JARRY, La vie (wie Anm. 204), S. 377, n. 3; zit. bei Delachenal, Histoire (wie Anm. 8), Bd. 4, S. 547, Anm. 1.

${ }^{227}$ Anwort des König von Ungarn an die französische Gesandtschaft, ed. bei JARRY, La vie (wie Anm. 204), S. 382, n. 4 zu 1376 vor Mai 30; zit. bei DELACHENAL, Histoire (wie Anm. 8), Bd. 4, S. 546, Anm. 4 (dort zu 1374 Mai 30; es handelt sich wohl um einen Druckfehler).

${ }^{228} \mathrm{Vgl}$. die betreffenden Papsturkunden: MIROT, JASSEMIN (Hg.), Lettres secrètes (wie Anm. 20I), n. 1480 von 1374 Jan. 8, n. 1690 von 1374 Sept. 22 an Königin Johanna.

${ }^{229}$ Ihre Verhandlungsinstruktionen sind, ed. bei JARRY, La vie (wie Anm. 204), S. 385, n. 5 von 1376 Mai 30.

${ }^{230} \mathrm{Vgl}$. ibid., S. $10 \mathrm{f}$

${ }^{231}$ So in der zitierten Instruktion für die französischen Gesandten, ed. ibid., S. 377, n. 3, hier S. 378 . 
sie in Brünn, daß Karls IV. zweitältester Sohn Sigmund (1368-1437), der spätere Kaiser, die zweitälteste Tochter Ludwigs, Maria (1372-1395), heiraten solle $^{232}$. Diese Ehe ist bekanntlich im Jahre 1385 tatsächlich zustandegekommen; sie war letztlich die Ursache dafür, daß Sigmund König von Ungarn wurde. Auch hier war die Kurie einbezogen. Nicht nur mußte der Papst die nötigen Dispense wegen zu naher Verwandtschaft erteilen. Er entsandte selbst einen Legaten, der sich an den Verhandlungen zwischen Karl IV. und Ludwig beteiligt hat und versuchte, ein Bündnis zwischen beiden gegen die Visconti zustandezubringen ${ }^{233}$. An der Kurie müssen sich die ungarischen, französischen und deutschen Unterhändler in den beiden Eheangelegenheiten gleichsam die Klinke in die Hand gegeben haben.

$\mathrm{Zu}$ einem vorläufigen Abschluß scheinen die Verhandlungen 1376 gekommen zu sein. Am 23. August dieses Jahres erneuerte Gregor XI. die Urkunde, mit der seinerzeit König Ludwig von Ungarn am 11. Oktober 1351 gegenüber Papst Clemens VI. auf seine Rechte auf das Reich von Neapel verzichtet hat$\mathrm{te}^{234}$. Das muß man wohl als eine Ablehnung des französisch-ungarischen Ansinnens auffassen - interessanterweise zu dem Zeitpunkt, als Gregor kurz vor der Romreise stand, er also - so darf man hinzufügen - auf neapolitanische Hilfe besonders angewiesen war.

In der Literatur wird oft argumentiert, in diesem doppelten Verlöbnis habe sich die Konkurrenz zwischen Deutschland und Frankreich bzw. zwischen Luxemburg und Valois um die Erbschaft Ludwigs I. ausgedrückt ${ }^{235}$. Diese Interpretation ist jedoch fragwürdig. Sie setzt im Grunde immer das selbstverständliche Bestehen eines französisch-deutschen Gegensatzes voraus. Wenn wir uns vor Augen halten, daß die Verbindung zwischen Frankreich und Ungarn ursprünglich von Karl IV. selbst angeregt worden ist, so wird man zumindest die Möglichkeit, daß die gleichzeitig erfolgten Verhandlungen über die beiden Verlöbnisse von entsprechenden deutsch-französische Absprachen begleitet worden sind, nicht ausschließen. Es ist immerhin auffällig, daß sich im April 1372, also zu Beginn der deutsch-ungarischen Eheverhandlungen, eine französische Gesandtschaft am kaiserlichen Hof in Prag aufgehalten hat; ihr gehörte Raoul de Louppy an, der seinerzeit bei den Verhandlungen in Avi-

${ }^{232}$ Vgl. B-H 5023a von 1372 März, 5024 von 1372 März 14; B-H Reichssachen 754 von 1373 Juni 21; die päpstlichen Ehedispense: B-H Päbste 141, ed. in: Monumenta Vaticana res gestas Bohemicas illustrantia, Bd. 4: Acta Gregorii XI., hg. von Carol STlouKAL, Prag 1949-1953, S. 509f., n. 899 von 1374 Dez. 6, und B-H - ed. in: Monumenta Vaticana res gestas Bohemicas illustrantia, Bd. 4, S. 513f., n. 903 von 1374 Dez. 15; der Ehevertrag: B-H Reichssachen 609 von 1375 Apr. 15. Vgl. generell STEINHERZ, Beziehungen (wie Anm. 152), 2. Teil, S. 590ff.; VELDTRUP, Eherecht (wie Anm. 15), S. 399ff.

${ }^{233}$ Vgl. B-H Päpste 131-135 von 1372; B-H Reichssachen 549 von 1372 Mai 9.

${ }^{234}$ Zit. bei JARRY, La vie (wie Anm. 204), S. 14, Anm. 1; Regest in Mollat (Hg.), Lettres (wie Anm. 189), n. 3850.

${ }^{235}$ Zuletzt VELDTRUP, Eherecht (wie Anm. 15), S. 402f. 
gnon ebenfalls anwesend gewesen war $^{236}$. Diese These wird noch wahrscheinlicher, wenn man bedenkt, daß Karl V., der in langwierigen Kriegen gegen den englischen König bemüht war, die Folgen des Vertrages von Brétigny zu beseitigen, auch seinerseits auf die Rückendeckung Karls IV. angewiesen war. Beispiele für eine Zusammenarbeit zwischen Kaiser und König oder zwischen Onkel und Neffe habe ich eine ganze Reihe sowohl aus dem Arelat als auch aus Italien angeführt, weitere aus dem deutsch-französischen Grenzraum sind bei Raymond Cazelles zusammengestellt ${ }^{237}$. Aus den angeführten Quellen ergibt sich, daß Karl V. die Interessen seines Onkels respektiert hat, insofern er seine Ansprüche auf Ungarn, Neapel und die Provence beschränkt hat, von irgendwelchen Absichten auf Polen ist in den Instruktionen Karls V. für seine Gesandten nicht die Rede. Das ist um so bemerkenswerter, als Ludwig I. seinerseits am 17. September 1374 in Kaschau (Kosice) seiner Tochter Katharina von den polnischen Ständen hatte huldigen lassen, er sie somit offenbar als seine Nachfolgerin hatte aufbauen wollen ${ }^{238}$. Die französischen Gesandten hatten dagegen den Auftrag, darauf hinzuwirken, daß Katharina von Ungarn auf keinen Fall mit einem deutschen Prinzen verheiratet werden solle, um zu verhindern, daß dieser Ansprüche auf das Reich von Neapel würde geltend machen können ${ }^{239}$. An Neapel wiederum hat Karl IV. - soweit bekannt - keinerlei Interesse gehabt. Zudem hatten Karl IV. und Karl V. einen gemeinsamen Gegner, nämlich Karl von Durazzo, der seinerseits Erbansprüche geltend machen konnte. Karl von Durazzo war, dies dürfte Karl V. klar gewesen sein, dem ungarischen Hof sehr viel näher als er. Wäre Ludwig von Ungarn gestorben - wohlgemerkt ohne Nachfolgeregelung - hätte Karl von Durazzo in Ungarn vollzogene Tatsachen schaffen können, bevor Karl V. oder Ludwig von Orléans überhaupt die Todesnachricht erhalten hätten. Ohne die Unterstützung Karls IV., des nächsten Nachbarn Ludwigs von Ungarn, wäre Karl V. somit kaum in der Lage gewesen, seine Ansprüche auf Ungarn durchzusetzen.

${ }^{236}$ Vgl. B-H 5034a von 1372 Apr. 1, ed. bei WinkElmaNN (Hg.), Acta, Bd. 2 (wie Anm. 176), S. 875-878, n. 1222; Delachenal (Hg.), Chronique (wie Anm. 23), Bd. 3, Anhang, S. 147-153, n. 21. Beglaubigungsschreiben Karls V. für seine Gesandten: B-H Reichssachen 544, ed. bei WinkelmanN (Hg.), Acta, Bd. 2 (wie Anm. 176), S. 874, n. 1221 von 1372 Febr. 24. Über die Gesandtschaft vgl. DelaChENAL, Histoire (wie Anm. 8), Bd. 4, S. 403; Thomas, Regnum (wie Anm. 78), S. 223ff., und Autrand, Charles V (wie Anm. 17), S. 581, die auf den hier genannten Aspekt jedoch nicht eingehen.

${ }^{237}$ CAZELlES, Société (wie Anm. 18), S. $493 \mathrm{ff}$.

${ }^{238}$ Vgl. VELDTRUP, Eherecht (wie Anm. 15), S. 402f.; Jörg K. HOENSCH, Verlobungen und Ehen Kaiser Sigismunds von Luxemburg, in: Georg JENAL, Stephanie HAARLÄNDER (Hg.), Herrschaft, Kirche, Kultur. Beiträge zur Geschichte des Mittelalters. Festschrift für Friedrich Prinz zu seinem 65. Geburtstag, Stuttgart 1993 (Monographien zur Geschichte des Mittelalters, 37), S. 265-277, hier S. 269.

${ }^{239}$ So in der Verhandlungsinstruktion von $1375 \mathrm{Dez}$. 11, ed. bei JARRY, La vie (wie Anm. 204), S. 377ff., n. 3, hier S. 380. 
Spätestens seit dem Abschluß des zweiten der beiden Verlöbnisse war jedenfalls absehbar, daß eine Abgrenzung der Interessensphären zwischen Karl IV. und Karl V. nötig sein werde, um Streit um die ungarische Erbschaft $\mathrm{zu}$ vermeiden; diese Abgrenzung herbeizuführen war das politische Ziel ${ }^{240}$, welches Karl IV. auf seiner Parisreise verfolgte ${ }^{241}$. Auch hoffte der Kaiser, Karl V., der gute Beziehungen zu Ludwig I. hatte, zu einer Intervention zu seinen Gunsten zu bewegen. Nur wenige Monate vor Karls IV. Parisreise war eine Abordnung König Ludwigs I. in Paris erschienen und hatte dessen $\mathrm{Zu}$ stimmung zu der französischen Forderung überbracht, Ludwig I. möge sich sowohl damit einverstanden erklären, daß Karls Sohn, Prinz Ludwig, im Falle er seine Frau überlebe, sein Leben lang den Titel König von Neapel führen dürfe, als auch damit, daß die Provence erblich an die Nachkommen aus dieser Verbindung übergehe ${ }^{242}$. Aber damit nicht genug. Karl V. hatte seinerseits zugestimmt, die Versuche Ludwigs von Ungarn und seines Sohnes (also wohl des Prinzen Ludwig), das Reich von Neapel wiederzuerlangen, zu unterstüt$z^{2}{ }^{243}$. Man darf dies wohl als französisch-ungarisches Bündnis zur Erlangung Neapels auffassen. Ob diese auf friedlichem Wege - durch diplomatischen Druck auf die Königin Johanna - oder gewaltsam hätte erfolgen sollen, hat man wahrscheinlich von der weiteren Entwicklung abhängig gemacht. Was wir aber daraus mit aller Deutlichkeit ersehen können, ist, daß auf deutscher, französischer und auf ungarischer Seite die neapolitanische Frage gerade auf der Tagesordnung stand. Die ungarische Gesandtschaft scheint sich, als Karl IV. in Paris weilte, ebenfalls noch dort aufgehalten zu haben ${ }^{244}$. Sie dürfte dann auch einen Brief Karls V. an Ludwig von Ungarn überbracht haben, der uns sowohl über die weiteren Pläne Karls V. wie auch über die Intentionen seines kaiserlichen Onkels informiert. In ihm bittet Karl V. den ungarischen König, er möge die ungarischen Großen darauf vereidigen, Katharina als seine rechtmäßige Nachfolgerin anzuerkennen. Ohne die Nachfolge in Ungarn waren eben die Ansprüche auf Neapel und die Provence nicht zu haben.

\footnotetext{
${ }^{240}$ Auch hier gilt, daß ich die Parisreise keineswegs erschöpfend behandeln will, sondern nur, soweit es für mein Thema nötig ist.

${ }^{241} \mathrm{Vgl}$. DELACHENAL, Histoire (wie Anm. 8), Bd. 5, S. $89 \mathrm{ff}$.

${ }^{242}$ Vgl. VALOIS, Projet (wie Anm. 223), S. 214f., sowohl nach der ungarischen Antwort auf die französischen Forderungen bei JARRY, La vie (wie Anm. 204), S. 382, n. 4 zu vor 1376 Mai 30, als auch nach einer verlorenen Urkunde, deren Wortlaut in einem alten Inventar erhalten ist. Vgl. auch SEIBT, Karl IV. (wie Anm. 2), S. 355, der sehr zu Recht die Gleichzeitigkeit beider Aktionen betont.

${ }^{243}$ Die entsprechende Urkunde ist nur als Regest in einem alten Inventar erhalten. Vgl. VALoIS, Projet (wie Anm. 223), S. 215, Anm. 2.

${ }^{244}$ Vgl. Delachenal, Histoire (wie Anm. 8), Bd. 5, S. 91.
} 
Im gleichen Brief unterrichtet Karl V. auch Ludwig über seine Gespräche mit dem Kaiser ${ }^{245}$. Demnach habe der Kaiser während des Treffens in Paris ihn (also Karl V.) gebeten, er möge zustimmen, daß Polen an ihn (Karl IV.) falle, soweit die Ansprüche von Karls V. Sohn (also Ludwigs von Orléans) betroffen seien. Er (Karl V.) habe indes darauf bestanden, keine bestimmten Zusicherungen $\mathrm{zu}$ geben, solange König Ludwig nicht zugestimmt habe $\mathrm{e}^{246}$. Auf den ersten Blick sieht das nach einer Ablehnung der kaiserlichen Bitte aus, indes hat Thomas sehr zu Recht hervorgehoben, daß Karl V. eine derartige Abmachung mit Karl IV. nicht in Vertragsform hätte schließen können, ohne seine Glaubwürdigkeit bei Ludwig I. einzubüßen. Entscheidend mußte hier in der Tat die Zustimmung Ludwigs I. sein. Welche Tochter bzw. welcher Schwiegersohn welchen Reichsteil erben würde, hing weitgehend von ihm ab; ein entsprechendes Testament hatte er noch nicht gemacht und auch später hat er keine Nachfolgeregelung getroffen. Das spricht aber nicht dagegen, daß Karl IV. und Karl V. eine Absprache über ihre Interessenssphären hätten treffen und sich gegenseitiger Unterstützung versichern können, und zwar wahrscheinlich in dem Sinne, daß Prinz Ludwig Ungarn - einschließlich der Erbansprüche auf Neapel und die Provence - und Prinz Sigmund Polen erhalten sollten $^{247}$. Zwar ist bekannt, daß letztlich ganz im Gegenteil Sigmund König von Ungarn geworden ist, zum damaligen Zeitpunkt aber waren Karls IV. Interessen sehr viel stärker auf Polen gerichtet ${ }^{248}$. Umgekehrt war Karl V. an Ungarn nicht nur um seiner selbst willen, sondern vor allem wegen der Erbaussichten auf Neapel interessiert. Ein Ereignis ist hier signifikant: Am 19. März 1375 hatte sich Ludwig von Anjou eidlich seinem Bruder Karl gegenüber verpflichtet, all seine Macht einzusetzen, um Königin Johanna dahin zu bringen, als Erbin Katharina von Ungarn einzusetzen, die Verlobte des Prinzen Ludwig $^{249}$. Das gibt nicht nur Aufschluß über die Intentionen Karls V., son-

${ }^{245}$ Dieses undatierte Schreiben ist zuerst ediert von Kervyn de Lettenhove in: Jean FrolsSART, Euvres, hg. von Joseph Baron KERVYN DE LETTENHOVE, Bd. 9: Chroniques 13771382, Brüssel 1869 (Anhang), S. 574f,; danach zit. bei Theodor LINDNER, Geschichte des deutschen Reiches unter König Wenzel, Bd. 1, Braunschweig 1875, S. 391 (dort als Stilübung interpretiert); zit. bei JARRY, La vie (wie Anm. 204), S. 7, Anm. 2 zu 1374 Febr.Apr.; abermals ed. bei VAloIs, Projet (wie Anm. 223), S. 221-223 zu 1378 Ende Jan.-Febr. (siehe dort auch zur Überlieferung); zit. bei DelaChEnAL, Histoire (wie Anm. 8), Bd. 5, S. 92, Anm. 1.

${ }^{246}$ [Karl IV.] requisivit ut, in quantum pro dicto filio nostro nos concernit, consentiremus quod haberet [Karl IV.] regnum Polonie. Sed omnibus nobis verbum exinde promoventibus istud semper nostrum fuit responsum quod, quia specialiter ista vos tangit materia, nullum omnino tractatum teneremus quin ex consensu et propria vestri ordinatione primo et principaliter processisset. (wie Anm. 245).

${ }^{247} \mathrm{Vgl}$. THOMAS, Frankreich (wie Anm. 2), S. $87 \mathrm{f}$.

${ }^{248}$ Vgl. VELDTRUP, Eherecht (wie Anm. 15), S. 403f. (mit der älteren Literatur).

${ }^{249}$ Vgl. DelaChenal, Histoire (wie Anm. 8), Bd. 4, S. 543, Anm. 2. 
dern zeigt auch, daß er den Ehrgeiz seines Bruders für die eigenen Ziele nutzen wollte ${ }^{250}$.

Gleichwohl muß betont werden, daß Karl IV. in bezug auf König Ludwig von Ungarn in hohem Maße von dem Wohlwollen Karls V. abhängig war. Wie wir gesehen haben, war die älteste Tochter Ludwigs mit einem Sohn Karls V. und nur die zweitälteste mit einem Sohn Karls IV. verheiratet. Während sich der ungarische König die Eheanbahnungsversuche des Kaisers immer nur zögernd und mißtrauisch hatte gefallen lassen, hatte er zur Vermählung seiner ältesten Tochter mit Prinz Ludwig selbst die Initiative ergriffen. Es war also zu erwarten bzw. - aus Karls IV. Sicht - zu befürchten, daß König Ludwig sich seiner ältesten Tochter weit generöser als gegenüber seiner zweitältesten zeigen werde ${ }^{251}$.

Dafür, daß in der Tat eine solche informelle Absprache zwischen Onkel und Neffen stattgefunden hat ${ }^{252}$, spricht, daß sie gut zu der ja zweifellos erfolgten Verleihung des Reichsvikariats im Arelat an den französischen Thronfolger paßt. Gesetzt den Fall, die französisch-ungarische Ehe wäre zustandegekommen, so wären die Erbansprüche König Ludwigs auf das Reich von Neapel ${ }^{253}$ und damit auf die Provence auf seine Tochter bzw. seinen Schwiegersohn übergegangen. Der Rechtstitel des Reichsvikars hätte den Valois ermöglicht, in der Provence mit gleichsam doppelter Autorität aufzutreten: sowohl als Graf der Provence als auch als Stellvertreter des römischen Königs bzw. Kaisers. Man sieht hier recht gut, daß Karl IV. mit der Verleihung des Vikarstitels an Karl VI. keineswegs auf das Arelat verzichtet hat, wie man in der Literatur immer wieder lesen kann, sondern daß er lediglich eine antizipierte und von ihm gebilligte Entwicklung - die dann freilich nicht wie erwartet eingetreten ist - auch seinerseits unterstützt hat. Ebensowenig wäre bei einem Gelingen von Karls V. Plänen die Provence an Frankreich übergegangen. Vielmehr hätte Ludwig von Orléans, der ja lediglich der zweitgeborene Sohn Karls V. war, sie seinen Kindern weitervererbt. Wohl aber hätte Karl VI., der künftige französische König, in seiner Eigenschaft als Reichsvikar des Arelats eine Art Oberhoheit über seinen Bruder auch in dessen Eigenschaft als Graf der Provence ausüben können. Da die Verleihung des Vikariats aber nur auf Lebenszeit erfolgt war, hätte der Nachfolger Karls VI. beim Nachfolger Karls IV. um eine Erneuerung ersuchen müssen. Für unser Thema bleibt festzuhalten, daß Karl IV. zweimal - 1365 und 1377/1378 - durchaus willens war, die Provence, Ungarn und das Reich von Neapel dem Einfluß der verwandten französischen Königsdynastie zu öffnen.

${ }^{250}$ So CONTAMINE, L'ombre (wie Anm. 117), S. 127.

${ }^{25 !}$ Vgl. im einzelnen VELDTRUP, Eherecht (wie Anm. 15), S. 402f.

${ }^{252}$ So auch THOMAS, Frankreich (wie Anm. 2), S. 87f.

${ }^{253} \mathrm{Zu}$ den verwandtschaftlichen Beziehungen zwischen den Herrscherhäusern in Ungarn und Neapel vgl. den Stammbaum bei VELDTRUP, Eherecht (wie Anm. 15), S. 104. 
König Ludwigs I. Initiative, eine eheliche Verbindung seiner Tochter mit dem französischen Königshaus herbeizuführen, hatte sicher auch den Hintergrund, wenigstens auf die Nachfolge der ihm verhaßten Königin Johanna, der Mörderin seines Bruders Andreas, die er selbst vergeblich zu stürzen versucht hatte, Einfluß zu nehmen ${ }^{254}$.

Nachdem wir nun versucht haben, die in Paris vertraulich getroffenen Absprachen zu rekonstruieren, sei noch auf die öffentliche, für alle sichtbare Seite dieses Besuches eingegangen. Karls IV. Parisreise hat gerade unter dem Aspekt des Zeremoniells seit langem die Aufmerksamkeit der Forschung auf sich gezogen, da wir in diesem Fall außerordentlich detailliert unterrichtet sind, nämlich durch eine Schilderung in den »Grandes Chroniques ${ }^{255}$, welche im Auftrag Karls V. aller Wahrscheinlichkeit nach sein Kanzler, Pierre d'Orgemont, verfaßt hat ${ }^{256}$. Wir haben hier gleichsam das Bild der Zusammenkunft vor uns, welches der französische König der Mit- und Nachwelt von diesem Besuch vermitteln wollte ${ }^{257}$. Ohne auf die Details eingehen zu wollen ${ }^{258}$, seien die zwei Haupttendenzen hervorgehoben, von denen der Bericht durchzogen ist: die Gleichberechtigung und die Übereinstimmung von regnum und imperium $^{259}$. Diese gipfelte in zwei Ansprachen vor hochstehenden französischen und deutschen Klerikern und Fürsten: In der ersten rechtfertigte Karl V. seine Politik gegenüber England, in der zweiten antwortete ihm Karl IV. und billigte die Ausführungen seines Neffen ${ }^{260}$. Selbst den Anschein, der französische König stehe protokollarisch niedriger als der Kaiser, hat Karl V. vermieden, und zwar offensichtlich mit Billigung Karls IV. Dies war nicht ganz einfach, denn dadurch, daß Karl IV. zugleich den Wunsch seines Neffen erfüllte, den französischen Thronfolger zum Dauphin und Reichsvikar im Arelat zu ernennen womit üblicherweise die Leistung des Handgangs und des Treueids verknüpft war -, bestand die Gefahr, daß zwar nicht der König selbst, wohl aber der Thronfolger eine seinen Status mindernde Abhängigkeit vom Kaiser hätte auf sich nehmen müssen. Hier ist Karl IV. seinem Neffen weit entgegengekom-

\footnotetext{
${ }^{254}$ So Delachenal, Histoire (wie Anm. 8), Bd. 4, S. 544f.

${ }^{255}$ Delachenal (Hg.), Chronique (wie Anm. 23), Bd. 2, S. 193-277.

${ }^{256} \mathrm{Vgl}$. NeUreither, Bild (wie Anm. 27), S. 65ff., 114f. Vgl. auch A. VERNET, in: Lexikon des Mittelalters, Bd. 2, München 1983, Sp. 2034f.

${ }^{257}$ Wir haben es hier selbstverständlich nicht mit einem unparteiischen Bericht zu tun. Vgl. dazu THOMAS, Memorandum (wie Anm. 213), S. 103ff.

${ }^{258}$ Am eingehendsten ist DeLACHENAL, Histoire (wie Anm. 8), Bd. 5, S. 61ff.; vgl. auch die in Anm. 213 genannte Literatur.

${ }^{259}$ Es fallt auf, daß in der reichen Literatur zu diesem Thema (vgl. Anm. 213) immer nur der erste Aspekt, nie der zweite betont wird. Dabei hat nach allem, was wir wissen, Karl IV. nie den Anspruch auf einen wie auch immer gearteten Vorrang vor Karl V. erhoben. Auch hier dürfte sich wieder das am Anfang besprochene Paradigma bemerkbar machen.

${ }^{260}$ Delachenal (Hg.), Chronique (wie Anm. 23), Bd. 2, S. 248ff.; vgl. DERS, Histoire (wie Anm. 8), Bd. 5, S. 103ff.; AuTRAND, Charles V (wie Anm. 17), S. 785f.; DIES., La visite (wie Anm. 213), S. 100f.
} 
men: Schon während seiner Anreise hat er betont, Karl V. könne König Wenzel ebenfalls als einen seiner Söhne ansehen ${ }^{261}$. Auch hat Wenzel während seines Besuchs Karl V. seine Freundschaft und Dienstbereitschaft versprochen $^{262}$. Beide Kronprinzen, der deutsche und der französische, waren somit eine reziproke Verpflichtung eingegangen. Offenbar wollten beide Monarchen erreichen, daß sich ihr gutes Verhältnis auch auf ihre Nachfolger übertrug.

Ähnlich wie schon in Arles haben wir auch in Paris eine Demonstration französisch-deutscher Übereinstimmung vor uns; eine Demonstration, die wohl dazu dienen sollte, die zweifellos anwesenden englischen Berichterstatter ${ }^{263}$, aber auch den ebenfalls in Paris anwesenden ungarischen Gesandten zu beeindrucken ${ }^{264}$.

\section{$\mathrm{X}$. An der Grenze zwischen regnum und imperium}

Nachdem wir die Geschichte des Arelats im Rahmen der französischdeutschen Beziehungen bis zum Vorabend des Großen Schismas verfolgt haben, sei noch ein Blick auf die anderen deutsch-französischen Grenzräume geworfen. Dabei strebe ich keine erschöpfende Darstellung an, es soll lediglich eine Skizze des augenblicklichen Forschungsstandes gegeben werden.

$\mathrm{Zu}$ den strukturellen Problemen, die Karl IV. von seinem Vater übernommen hatte, gehörte die Aufspaltung seiner ererbten Territorien in zwei Schwerpunkte, einen westlichen, die Grafschaft Luxemburg, und einen östlichen, das Königreich Böhmen. Karl IV. hat sich früh entschlossen, den Schwerpunkt seiner eigenen Aktivitäten in den Osten zu verlegen, ohne jedoch die westlichen Besitzungen vernachlässigen $z u$ wollen ${ }^{265}$ : Er war demnach auf geeignete Stellvertreter angewiesen. Schon zwei Wochen nach seiner Krönung zum römischen König ernannte er am 9. Dezember 1346 Erzbischof Balduin von Trier, seinen Großonkel und Förderer seiner Königskandidatur, zum Reichsvi-

${ }^{261}$ Delachenal (Hg.), Chronique (wie Anm. 23), Bd. 2, S. 199; vgl. NeUreither, Bild (wie Anm. 27), S. 116.

${ }^{262}$ [...] le roy des Rommans vint, et si tost que l'Empereur le vit, il l'apela et le prist par la main, et luy fist promectre, par sa foy en la main du Roy [Karls V.], que il l'ameroit et serviroit, tant comme il vivroit, devant tous le princes du monde, et les enfans du Roy aussi [...]; Delachenal (Hg.), Chronique (wie Anm. 23), Bd. 2, S. 264; vgl. Neureither, Bild (wie Anm. 27), S. 142.

${ }^{263}$ Über englische Spionage in Frankreich vgl. Christopher ALLMAND, Spionage und Geheimdienst im Hundertjährigen Krieg, in: Wolfgang KRIEGER (Hg.), Geheimdienste in der Weltgeschichte. Spionage und verdeckte Aktionen von der Antike bis zur Gegenwart, München 2003, S. 97-110, 354-356.

264 Über diesen vgl. Delachenal, Histoire (wie Anm. 8), Bd. 5, S. 91.

${ }^{265} \mathrm{Vgl}$. SeIBT, Karl IV. (wie Anm. 2), passim, bes. S. $164 \mathrm{ff}$. 
kar in Galliam et Germaniam, insbesondere in der Grafschaft Luxemburg ${ }^{266}$. Der sehr erfahrene, allerdings auch schon hochbetagte Balduin, der lange Zeit die Politik der luxemburgischen Dynastie geprägt hatte, war für dieses Amt zweifellos sehr geeignet; er wußte freilich sein neues Amt auch dazu zu nutzen, die Interessen seines Erzbistums zu wahren.

Im Jahre 1353 übertrug dann Karl IV. seinem Halbbruder Wenzel die Grafschaft Luxemburg. Nach dem Tode Balduins von Trier im Jahre 1354 wuchs Wenzel allmählich in die Rolle des königlichen Statthalters im Westen hin$e^{267} .1354$ erhob der Kaiser Luxemburg zum Herzogtum. Wenzel konnte durch seine Ehe mit Johanna, der ältesten Tochter Herzog Johanns III. von Brabant, im Jahre 1351 auch Ansprüche auf Brabant geltend machen. Nach dem Tode Johanns III. konnte sich Wenzel - unterstützt von seinem Bruder in Brabant gegen Ludwig von Male, den Grafen von Flandern, durchsetzen. Vor allem aber wurde er vom Kaiser im Jahre 1366, also kurz nach der Arlesreise, zum Reichsvikar im Westen ernannt ${ }^{268} ; 1367$ wurde er auch kaiserlicher Landvogt im Elsaß. Wenzel herrschte nun über ein Territorium, daß von der Nordsee bis zum Oberrhein reichte ${ }^{269}$. Von Luxemburg und Brabant aus sollte er offenbar als Vertreter des Kaisers die Reichsrechte im Westen des Imperiums wahren und ausüben. Die Parallele zur Position Ludwigs von Anjou in Frankreich ist auffällig.

Die Förderung Wenzels durch Karl IV. ist um so bemerkenswerter, als das persönliche Verhältnis zwischen beiden oft sehr gespannt war. Offenbar war aber der Kaiser bereit, darüber hinwegzusehen, um die Interessen des Hauses Luxemburg zu fördern. Das dürfte ihm um so leichter gefallen sein, als Wenzels Ehe mit Johanna kinderlos blieb, er mit einem Heimfall beider Herzogtümer rechnen konnte, was auch in einem entsprechenden Erbschaftsvertrag festgehalten worden ist ${ }^{270}$. Gleichwohl erlitt diese Politik einen schweren Rückschlag, als Herzog Wenzel 1371 in der Schlacht von Bäsweiler vom Herzog von Jülich gefangengenommen wurde. Erst ein Jahr später konnte der

${ }^{266}$ Vgl. Winfried REICHERT, Landesherrschaft zwischen Reich und Frankreich. Verfassung, Wirtschaft und Territorialpolitik in der Grafschaft Luxemburg von der Mitte des 13, bis zur Mitte des 14, Jahrhunderts, 2 Bde., Trier 1993 (Trierer Historische Forschungen, 24, 1-2), Bd. 1, S. $476 \mathrm{ff}$, bes. S. $504 \mathrm{ff}$.

${ }^{267}$ Vgl. THOMAS, Regnum (wie Anm. 78), S. $15 \mathrm{ff}$. und passim; REICHERT, Landesherrschaft (wie Anm. 266), Bd. 1, S. 523ff.; Michael Pauly, Luxemburg auf dem Schachbrett Karls IV., in: Hémecht 48 (1996), S. 379-390.

${ }^{268}$ Vgl. Heinz ThOMAS, Die Ernennung Herzog Wenzels von Luxemburg-Brabant zum Reichsvikar, in: Winfried EBERHARD u.a (Hg.), Westmitteleuropa - Ostmitteleuropa. Festschrift für Ferdinand Seibt, München 1992 (Veröffentlichungen des Collegium Carolinum, 70), S. 143-152 (dort auf S. 149-152, B-H 4410a, die Emennungsurkunde von 1366 Okt. 26); DERS., Regnum (wie Anm. 78), S. $328 f f$.

${ }^{269}$ Das betont DERS., Die Luxemburger und der Westen des Reichs zur Zeit Kaiser Karls IV., in: Jahrbuch fur westdeutsche Landesgeschichte 1 (1975), S. 59-96, bes. S. 86ff.

${ }^{270}$ Vgl. ibid., S. 84; PAULY, Luxemburg (wie Anm. 267), S. 385. 
Kaiser ihn durch hohe Lösegeldzahlungen befreien. Die Forschung ist sich einig, da $B$ dadurch die kaiserliche Position im Westen erheblich geschwächt worden ist: Erzbischof Friedrich von Köln, den Karl IV. 1372 zum neuen Reichsvikar im Westen ernannte, hatte in erster Linie seine eigenen Interessen im Auge. Für unsere Fragestellung ist wesentlich, daß Karl V. und Frankreich für diese Entwicklung in keiner Weise verantwortlich waren. Gerade Wenzel unterhielt auch seinerseits gute Beziehungen zum französischen $\mathrm{Hof}^{271}$. In den "Grandes Chroniques« ist seine Niederlage bei Bäsweiler mit Bedauern verzeichnet worden; zugleich wird bemerkt, daß der Graf von Saint-Pol, der an seiner Seite gekämpft hatte, in der Schlacht gefallen sei $^{272}$. Generell gilt hier das Fazit von Heinz Thomas, daß Frankreich wtrotz seiner offenkundigen Überlegenheit [...] den Bestand des Reiches am Oberlauf der Maas bis zum Ende des 14. Jahrhunderts nie grundsätzlich in Frage gestellt « hat ${ }^{273}$.

Ein anderer Fall sei noch herausgegriffen, der gerne als Paradebeispiel der französischen Ausdehnungspolitik angeführt wurde: der Fall Cambrai. In einer (auch von mir) immer noch oft zitierten Studie, die sorgfältig dokumentiert ist, sich aber auch explizit in dieses Paradigma einfügt, legt Lotte Hüttebräuker dar, daß es zuerst König Philipp dem Schönen gelungen ist, im Jahre 1298 "Cambrai seinem Willen zu unterwerfen«. Es folgt ein langes Hin und Her, das dann rund 45 Seiten oder 350 Jahre später mit dem Fazit endet, werst Ludwig XIV. hat es [Cambrai] schließlich für Frankreich gewonnen ${ }^{274}$. Mit anderen Worten: Mehr als drei Jahrhunderte hat es gedauert, bis die französische Monarchie Cambrai dem eigenen Staat einverleibt hat. Hier wird besonders gut die Absurdität deutlich, die darin liegt, eine über Jahrhunderte durchgehaltene "Ausdehnungspolitik" anzunehmen, die dann noch - gemessen an ihren Möglichkeiten - derart geringe Resultate gehabt hat.

${ }^{271}$ Siehe oben mit Anm. 23; PAULY, Luxemburg (wie Anm. 267), S. 383.

${ }^{272}$ Delachenal (Hg.), Chronique (wie Anm. 23), Bd. 2, S. 158f. Gui de Luxembourg, der Graf von Saint-Pol, war Vasall Karls V., hatte aber auch verwandtschaftliche Beziehungen zu den Luxemburgern. Insofern ist er typisch für jene Grenzsituation.

${ }^{273}$ THOMAS, Regnum (wie Anm. 78), S. 343.

${ }^{274}$ HÜTTEBRÄUKER, Cambrai (wie Anm. 180), S. 90, 135. Für die Regierungszeit Karls V. kommt die Autorin immerhin zu dem Ergebnis: "Von einem Konflikt der beiden Mächte hören wir nichts, ja 1365 haben sich Karl IV. und Karl V. sogar gemeinsam für einen Cambraier Kleriker verwandt«. Ibid., S. 128. 
XI. Die Stellung des französischen Hofes zur Rückkehr Urbans V. und Gregors XI. nach Rom

Mit meinen Ausführungen stehe ich im Widerspruch zu der überkommenen und - soweit ich sehe - einmütigen Lehrmeinung, daß der französische Hof und insbesondere König Karl V. ein Gegner der Rückkehr des Papsttums nach Rom gewesen seien. Häufig findet man diese These im Zusammenhang mit einer zweiten, daß das Avignoneser Papsttum von Frankreich abhängig gewesen $\operatorname{sei}^{275}$. Dabei scheint es niemanden zu stören, daß die beiden Behauptungen einander offensichtlich widersprechen. Wenn das Papsttum von Frankreich abhängig war, wie konnten dann Urban V. und Gregor XI. gegen den Willen Frankreichs gleichwohl nach Rom zurückkehren? Mustern wir aiso die Argumente, die für diese Ansicht angeführt werden ${ }^{276}$. Im Hinblick auf Urban V. ist unbestritten, daß Karl V. eine Gesandtschaft nach Avignon geschickt hat, die im April 1367 dort ankam, also kurz vor Urbans Abreise nach Rom am 30. April. Daß sie den Auftrag gehabt hat, Urban von seiner Reise zurückzuhalten, wird als selbstverständlich vorausgesetzt ${ }^{277}$. Um die quellenmäßige Evidenz dieser Ansicht ist es jedoch nicht sonderlich gut bestellt. Erhalten ist das umfangreiche Fragment einer Rede, welche der französische Gesandte wohl auf einer öffentlichen Konsistorialsitzung an der Kurie gehalten hat und die - weitschweifig, aber eindeutig - in der Tat Urban V. abrät, nach Rom zu reisen ${ }^{278}$. Diese Rede, die seinerzeit anscheinend für eine Perle der Rhetorik gehalten wurde, hat unter den Zeitgenossen eine Kontroverse ausgelöst, an der sich kein Geringerer als Francesco Petrarca beteiligt hat ${ }^{279}$; in ihr wurden die Vor- und Nachteile der beiden Papstsitze Avignon und Rom lebhaft erörtert. Für unser Problem ist wesentlich, daß diese Rede eben gerade für die Öffentlichkeit gedacht war, sie die gleichsam offizielle Stellungnahme Karls V. zu Urbans Vorhaben darstellte ${ }^{280}$. Daß es gute Gründe gab, die von mir skizzierten Pläne, insbesondere soweit die Königin Johanna betroffen war, gerade nicht an die Öffentlichkeit dringen zu lassen, ist wohl klargeworden. Über das,

${ }^{275}$ Siehe dazu die Fortsetzung dieser Studie; vgl. Anm. 1.

${ }^{276} \mathrm{Vgl}$. vor allem DELACHENAL, Histoire (wie Anm. 8), Bd. 3, S. $515 \mathrm{ff}$., von dessen Deutung ich abweiche, der aber die Quellen mit gewohnter Sorgfalt zusammengestellt hat.

${ }^{277}$ Typisch ist hier Prou, Étude (wie Anm. 116), S. 64: "Bien que les documents qui mentionnent cette ambassade ne nous en révèlent en aucune façon le but, il y a lieu de croire que les envoyés royaux venaient persuader le pape de demeurer à Avignon«.

${ }^{278}$ Ausfuhrlich referiert und zitiert bei DeLACHENAL, Histoire (wie Anm. 8), Bd. 3, S. $517 \mathrm{ff}$.

${ }^{279}$ Für die Einzelheiten ibid., S. 524ff. Vgl. auch Karlheinz STIERLE, Francesco Petrarca. Ein Intellektueller im Europa des 14. Jahrhunderts, Darmstadt 2003, S. 75ff. (freundlicher Hinweis von Wemer Paravicini).

${ }^{280}$ Das betont auch Autrand, Charles V (wie Anm. 17), S. $541 \mathrm{ff}$. 
was die französische Gesandtschaft hinter verschlossenen Türen mit Urban V. besprochen hat, wissen wir - wie so oft - nichts.

Etwas besser ist es um die Quellenlage bei Gregors Rückkehr bestellt ${ }^{281}$, wo es zwei einschlägige Quellen gibt. In einem Brief des Grafen von Saarbrükken, der das Amt des bouteiller am französischen Hof innehatte, an die Gräfin von Bar, Yolande von Flandern ${ }^{282}$, wird berichtet, der französische König habe die Absicht gehabt, in Lyon mit Gregor XI., Kaiser Karl IV. und dem Grafen von Lancaster zusammenzutreffen. Zweck dieser Zusammenkunft sei es gewesen, den Papst von der Reise nach Rom abzuhalten. Da Karl V. jedoch befurchtet habe, seine Bitte werde von Gregor abgelehnt werden, habe er auf eine persönliche Zusammenkunft verzichtet. Der Graf gibt offenbar am französischen Hof kursierenden Klatsch wieder, er erweist sich jedoch als nicht sonderlich gut informiert. Im Frühjahr 1376 hatte Gregor XI. den Kaiser gedrängt, dieser möge ihn zusammen mit seinem Sohn Wenzel in Avignon besuchen, um über Wenzels Wahl zum römischen König zu verhandeln. In der überlieferten Korrespondenz, in der sich Karl IV. entschuldigt, daß er wegen seiner Krankheit nicht kommen könne, ist jedoch von einer Beteiligung Karls V. oder des Herzogs von Lancester nicht die Rede ${ }^{283}$. Auch hätten, um ein solches Treffen zu arrangieren, doch entsprechende Vorbereitungen getroffen werden müssen, hätten insbesondere Boten an Papst, Kaiser, König und Herzog geschickt werden müssen. Irgendeinen Beleg dafür haben wir jedoch nicht, was insbesondere im Falle des Papstes signifikant ist, dessen diplomatische Korrespondenz insgesamt gut erhalten ist ${ }^{284}$. Zumindest die Absage auf die erfolgte Einladung müßte sich hier finden lassen. Man wird daher verstehen, daß ich dieses Zeugnis für nicht sehr bedeutsam halte.

${ }^{281} \mathrm{Vgl}$. vor allem DelaChENAL, Histoire (wie Anm. 8), Bd. 4, S. 590ff., sowie Léon MiRoT, La politique pontificale et le retour du Saint-Siege à Rome en 1376, in: Le Moyen Âge 11 $(=2$. Serie, 2) (1898), S. 85-101, 193-213, 354-375, 413-457, hier S. 416ff. (erschienen selbständig unter demselben Titel, Paris 1899); LEHOUX, Jean de France (wie Anm. 100), Bd. 1, S. 384f,; sehr viel abwägender Mollat, Papes (wie Anm. 171), S. 268f. Gerade Mirot hätte es besser wissen sollen. Er hat nämlich als erster die Zahlungen Ludwigs von Anjou an Gregor XI. nachgewiesen. Vgl. DERS., Les rapports financiers de Grégoire XI et du duc d'Anjou, in: Mélanges d'Archéologie et d'Histoire 17 (1897), S. 113-144.

${ }^{282}$ La cause pourquoy le Roy n'est alez devers le Pape est telle: le Roy monseigneur aloit devers le Pape especialment sus toutes autres choses pour li faire demorer de non aller à Rome; si a santi par aucun de ses bons amis que pour chose du monde li Pape ne demouroit; se li semble qu'il ne seroit mie son honeur se il aloit là pour li faire demorer et il ne demoroit à sa priere [...]; 1376 Aug. 20, ed. bei Jules FINOT, Inventaire sommaire des Archives départementales du Nord anterieures à 1790, Bd. 7, Lille 1892, S. 92f.; zit. bei DELACHENAL, Histoire (wie Anm. 8), Bd. 4, S. 591, Anm. 1.

${ }^{283}$ Die Quellen sind ediert von Julius WEIZSÄCKER, Deutsche Reichstagsakten unter König Wenzel, Bd. 1, Göttingen ${ }^{2} 1956$, S. 90ff. Vgl. KLARE, Wahl (wie Anm. 181), S. 152ff.

${ }^{284}$ Karsten Plöger danke ich für die Mitteilung, daß sich auch in der englischen Überlieferung keine Spur für die Vorbereitung eines solchen Zusammentreffens findet. 
Weiterhin wird behauptet, ausgerechnet Ludwig von Anjou, der sich häufig in Avignon aufhielt, sei von seinem königlichen Bruder beauftragt worden, Gregor XI. von seiner Abreise abzuhalten. Die Rede, welche Ludwig am 7. Februar 1375, also über ein Jahr vor Gregors Abreise, vor dem Konsistorium gehalten hat, ist die zweite einschlägige Quelle, die explizit aussagt, daß Karl V. und Ludwig von Anjou Gegner dieser Reise gewesen seien. Sie liegt in zwei Fassungen vor: einer langen bei Froissart ${ }^{285}$, deren Historizität schon Delachenal nicht ernstgenommen hat, und in einer kurzen Zusammenfassung, welche ein Gesandter am avignonesischen Hof seiner Heimatstadt geschickt hat $^{286}$. Daß dieser Bericht für die übermittelten Fakten glaubwürdig ist, bestreite ich nicht, aber abgesehen davon, daß auch für diese Rede die gleiche Kritik wie für die vorangegangene gültig ist, wird gerade bei ihr sehr deutlich, $\mathrm{da} B$ sie im Rahmen einer förmlichen Inszenierung gehalten worden ist. Offenbar um das Pro und Contra der bevorstehenden Romreise augenfällig und die Kurialen wie auch die auswärtigen Gesandten und Berichterstatter mit seiner Entscheidung bekanntzumachen, hat Gregor erst Ludwig in einer Konsistorialsitzung die Gründe vorbringen lassen ${ }^{287}$, welche gegen die Reise sprachen. $\mathrm{Ihm}$ antwortete Kardinal Jakob Orsini, der die für die Reise sprechenden Gründe vortrug. Abschließend ergriff dann der Papst selbst das Wort und verkündete seinen Entschluß, nach Rom zu ziehen. Es haben somit beide Seiten der französische König wie der Papst - hier ihre offizielle Position deutlich gemacht. Immerhin dürten auch die Zeitgenossen bemerkt haben, daß dieser gemeinsame Auftritt Ludwigs und des Kardinals, ungeachtet des vordergründigen Gegensatzes, der in ihren Reden zum Ausdruck kam, gerade die grundsätzliche Übereinstimmung von Papsttum und französischer Monarchie in dieser Frage demonstrierte, daß hier die Form wichtiger als der Inhalt war.

Schließlich ist kurz vor der Abreise Gregors nach Rom der jüngste Bruder des Königs, Herzog Philipp der Kühne, in Avignon eingetroffen; dies erweckte bei den in Avignon anwesenden Berichterstattern offenbar den Eindruck, er solle Gregor von seiner Reise zurückhalten ${ }^{288}$. Das ist jedoch extrem unwahr-

${ }^{285}$ Froissart, Euvres (wie Anm. 245), S. 47f;; zit. bei DELACHENAL, Histoire (wie Anm. 8), Bd. 4, S. 593, Anm. 1.

${ }^{286}$ Zit. ibid., Anm. 2, nach MiRot, Politique (wie Anm. 281), S. 68, Anm. 1 (= S. 418, Anm. 1 der Zeitschriftenfassung). Ed. bei A. SEgre, I dispacci di Cristoforo da Piacenza procuratore mantovano alla corte ponteficia (1371-1383), in: Archivio storico italiano, 5. Serie, 43 (1909), S. 27-95, und 44 (1909), S. 253-326, hier 43 (1909), S. 71 f. Über Christopherus von Piacenza vgl. LÉONARD, Les Angevins (wie Anm. 49), S. 454, der ihn gut informiert, aber »point très intelligent« nennt.

${ }^{287}$ Es handelte sich um ein consistorium privatum. Indes beweist der Bericht des Christopherus (wie Anm. 286), daß der Inhalt keineswegs vertraulich geblieben ist.

${ }^{288}$ Vgl. Delachenal, Histoire (wie Anm. 8), Bd. 4, S. 594. Demnach ist Philipp der Kühne vom 25. August bis zum 4. September 1376 in Avignon nachgewiesen. Christopherus von Piacenza berichtet (ed. bei SEGRE, Archivio [wie Anm. 286], Bd. 4, S. 93, n. 22 von 1376 
scheinlich. Fast gleichzeitig mit Philipps Eintreffen in Avignon traf nämlich ein Gesandter Karls V. in Avignon ein. Dieser überbrachte Papst Gregor die erste Rate eines größeren Kredits, welcher die Reise nach Rom überhaupt erst möglich gemacht hat. Der Gegensatz zwischen dem, was nach außen verlautbart wird, und dem, was hinter den Kulissen stattfindet, läßt sich kaum besser verdeutlichen: Insgesamt 160000 Goldfranken haben nämlich Karl V. und Ludwig von Anjou an Gregor XI. kurz vor seiner Abreise überbringen las$\operatorname{sen}^{289}$. Die erste Rate, 60000 Franken des französischen Königs, überbrachte der königliche Spezialgesandte Johannes Marcerii; sie ist am 19. August 1376 in der Apostolischen Kammer in Avignon verbucht, also fast gleichzeitig mit der Ankunft Philipps des Kühnen ${ }^{290}$. Einen Monat später, am 16. September 1376, folgten weitere 60000 Franken Ludwigs von Anjou; diesmal überbrachte sie Petrus Scatisse, der Schatzmeister des Königs von Frankreich. Ohne diese Gelder hätte Gregor XI., der sich in großen finanziellen Schwierigkeiten befand, die Kosten für die Reise nach Rom nicht bezahlen können. Somit ist die Rückkehr des Papsttums nach Rom nur durch französische Unterstützung möglich geworden.

Immerhin existiert eine glaubwürdige Quelle, die uns darüber informiert, welche Ansichten Karl V. über die Rückkehr des Papsttums nach Rom gehabt hat; leider ist sie keineswegs eindeutig. Es handelt sich um den "Songe du Vergier«, ein Werk, welches das Verhältnis von weltlicher und geistlicher Gewalt zum Thema hat. Dieser Text ist zunächst in einer lateinischen Version verfaßt worden, dem "Somnium Viridarii ${ }^{291}$; ihn hat man dann mit vielfachen Änderungen im Detail ins Französische übersetzt. Anscheinend ist er von dem königlichen Rat und Hofrichter Évrart de Trémaugon verfaßt worden; sicher ist, daß Karl V. großen Anteil an dem Werk genommen und persönlich daran mitgewirkt hat ${ }^{292}$. Gestaltet ist das Buch als Dialog zwischen einem Kleriker

Sept. 7, hier S. 94), die fratres regis Francie hätten versucht, Gregor von der Reise zurückzuhalten.

${ }^{289}$ Vgl. Stefan WEISS, Kredite europäischer Fürsten für Gregor XI. Zur Finanzienung der Rückkehr des Papsttums von Avignon nach Rom, in: Quellen und Forschungen aus Italienischen Archiven und Bibliotheken 77 (1997), S. 176-205, hier S. 198ff.; jetzt auch DERS., Rechnungswesen und Buchhaltung des Avignoneser Papsttums (1316-1378). Eine Quellenkunde, Hannover 2003 (MGH Hilfsmittel, 20), S. 174. Daß hier beide Brüder gemeinsam handelten, widerlegt den sonst naheliegenden Verdacht, Ludwig von Anjou hätte Politik auf eigene Faust und gegen die Intentionen seines Bruders getrieben.

${ }^{290}$ Etwa gleichzeitig muß auch eine französische Gesandtschaft, welche den päpstlichen Konsens zur Eheschließung zwischen Prinz Ludwig und Katharina von Ungarn einholen sollte, an der Kurie eingetroffen sein (dazu siehe oben mit Anm. 228). Thre Verhandlungsinstruktionen sind ediert bei JARRY, La vie (wie Anm. 204), S. 385, n. 5 von 1376 Mai 30.

${ }^{291}$ Somnium Viridarii, hg. von Marion SCHNERB-LIÈVRE, 2 Bde., Paris 1993-1995.

${ }^{292}$ Le Songe du Vergier, édité d'après le manuscrit royal $19 \mathrm{C}$ IV de la British Library, hg. von Marion SCHNERB-LIĖVRE, 2 Bde., Paris 1982. Vgl. vor allem die Introduction der Herausgeberin in Bd. 1, S. XIXff., dort auf S. LXIXff. zur Mitwirkung Karls V.; vgl. auch AU- 
und einem Ritter; jedes einzelne Problem wird zunächst von dem einen, dann von dem anderen erörtert. Man ist sich darüber einig, daß in der Regel der Ritter die königliche Position vertritt, denn er ist es, der zumeist die überzeugenderen Argumente vorbringt. In diesem Buch wird auch auf die Frage der Rückkehr des Papsttums nach Rom eingegangen. Während aber in der lateinischen Erstfassung, welche in den Jahren 1374 bis 1376 entstanden ist, die Argumente des Ritters für den Verbleib in Avignon weitaus überzeugender geraten sind, ist es in der französischen Fassung, welche unmittelbar nach der Fertigstellung der lateinischen Version in Angriff genommen und die $1378-$ noch vor Ausbruch des Schismas - fertiggestellt worden ist, gerade umgekehrt ${ }^{293}$. Nun argumentiert der Kleriker weit überzeugender, mag der Ritter auch noch so drastisch bemüht sein, seinem Widerpart die Vorzüge Frankreichs und den schlechten Charakter der Römer vor Augen zu führen. Hier scheint sich eine Meinungsänderung König Karls V. niedergeschlagen zu haben; er mag sich von einem anfänglichen Gegner der Rückkehr zu einem Befürworter entwickelt haben. Dies könnte seinen Hintergrund darin haben, daß Karl V. seit mehreren Jahren einen Erfolg nach dem anderen erzielt hatte; die endgültige Vertreibung der Engländer aus Frankreich schien unmittelbar bevorzustehen. Soeben war unter päpstlicher Vermittlung am 12. März 1376 in Brügge ein Waffenstillstand zwischen England und Frankreich ausgehandelt worden, von dem man hoffte, er werde in einen generellen Friedensschluß einmünden ${ }^{294}$. Insofern mochte Karl nun den Zeitpunkt gekommen sehen, an dem er die Kräfte Frankreichs nicht mehr in erster Linie dem Kampf gegen England zu widmen brauchte. Dem Argument des Klerikers jedenfalls, Frankreich befinde sich - ganz anders als Rom - in einem Zustand des Glücks und des Wohlstands, konnte der Ritter schwer widersprechen, noch weniger dem Argument, daß die lasterhaften Römer den päpstlichen Beistand sehr viel nötiger als die frommen Franzosen hätten: Dei, enim, Filius non venit propter justos, sed propter peccatores ${ }^{295}$.

TRAND, Charles V (wie Anm. 17), S. 736ff.; zuletzt HECKMANN, Stellvertreter (wie Anm. 47), Bd. 1, S. 222ff.

${ }^{293}$ So SCHNERB-LiÈvre (Hg.), Songe (wie Anm. 292), S. LXXVIII. DelaChenal, Histoire (wie Anm. 8), Bd 4, S. 600, der dies ebenfalls beobachtet hat, ist der Ansicht, der sonst völlig loyale Verfasser habe sich hier ausnahmsweise gegen die Ansicht des Königs ausgesprochen. Man wird verstehen, da $B$ ich diese Ansicht nicht teile. Man vergleiche Somnium Viridarii (wie Anm. 291), II c. CCCLXII und CCCLXIII (SCHNERB-LièVRe [Hg.], Somnium [wie Anm. 291], Bd. 2, S. 249ff.) mit Songe de Vergier, I c. CLV und CLVI (SCHNERBLIĖVRE [Hg.], Songe [wie Anm. 292], Bd. 1, S. $315 \mathrm{ff}$.).

${ }^{294}$ DELACHENAL, Histoire (wie Anm. 8), Bd. 4, S. 587. Einen Zusammenhang zwischen den Verhandlungen in Brügge und Gregors Entschluß zur Rückkehr nach Rom hat bereits Yves RENOUARD, La papauté à Avignon, Paris 1954 (ND 2004), S. 54, gesehen.

${ }^{295}$ Songe de Vergier, I c. CLV 11/12 (SCHNERB-LiĖVRE [Hg.], Songe [wie Anm. 292], Bd. I, S. 319). 
$\mathrm{Da} ß$ die These, der französische König sei ein Gegner der päpstlichen Rückkehr nach Rom gewesen, so wenig in Frage gestellt worden ist, hat seine Ursache abermals in dem in der Einleitung charakterisierten Paradigma. Wenn man das Avignoneser Papsttum mit Frankreich identifiziert, es als abhängig vom französischen Interesse darstellt - beides höchst fragwürdige Thesen ${ }^{296}$-, dann ist in der Tat nicht zu begreifen, warum Urban V. und Gregor XI. nach Rom zurückgekehrt sind. Dies konnte nur dadurch erklärt werden, daß es eben gegen den Willen Frankreichs und gegen den Willen der - französischen Kardinäle und hohen Kurialen geschah. Auch die Deutung des Schismas hängt mit diesem Paradigma zusammen. Aufgrund vager Indizien unterstellt man Karl V., er habe die Wahl Clemens VII. betrieben, um die Päpste nach Avignon zurückzuführen. Die Frage, was Karl V. eigentlich von einer solchen Rückkehr nach Avignon gehabt hätte, wird dagegen nie gestellt.

${ }^{296}$ Siehe dazu die Fortsetzung dieser Studie; vgl. Anm. 1. 